Bitte zitieren Sie dieses Papier als:

OCDE (2018), "Analyse von Megatrends im Interesse der besseren Gestaltung der Zukunft des Tourismus ", OECD-Studien Tourismus, 2018/02, OECD Publishing, Paris, https://doi.org/10.1787/95ef8c1d-de

\title{
OECD-Studien Tourismus
} 2018/02

\section{Analyse von Megatrends im Interesse der besseren Gestaltung der Zukunft des Tourismus}

OECD
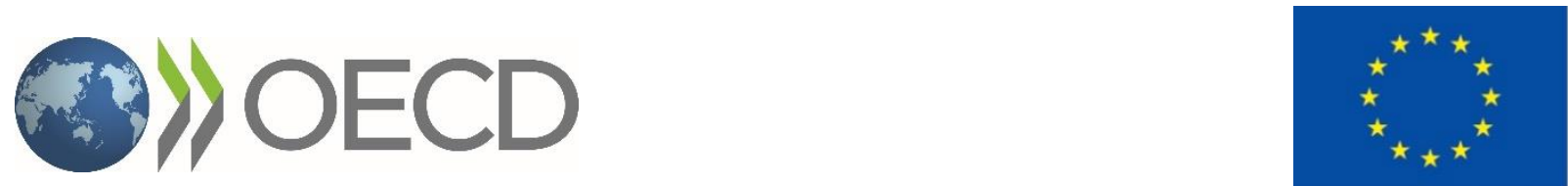


\section{Analyse von Megatrends im Interesse der besseren Gestaltung der Zukunft des Tourismus}

Die Zukunft des Tourismus wird durch grosse gesellschaftliche, wirtschaftliche, politische und technologische Änderungen sowie wachsende Ansprüche an den Umweltschutz geprägt sein, die neue und oftmals unvorhersehbare Herausforderungen, Bedrohungen und Chancen mit sich bringen. Diese Megatrends bilden sich langsam aus. Sobald sie aber an Fahrt gewonnen haben, üben sie einen tiefgreifenden und anhaltenden Einfluss auf menschliche Handlungen, Prozesse und Wahrnehmungen aus. Auch der Tourismus ist entsprechend betroffen. Es gibt vier Megatrends, die sich wahrscheinlich erheblich auf den Tourismus auswirken werden und entsprechend relevant sind: i) die sich wandelnde Besuchernachfrage; ii) nachhaltiges Wachstum des Tourismus; iii) Basistechnologien ( enabling technologies») sowie iv) Reisemobilität. Um informierte politische Entscheidungen treffen und die Zukunft des Tourismus gestalten zu können, ist es wichtig, die vielschichtigen Auswirkungen dieser Megatrends bis 2040 zu untersuchen. Die vorliegende Tourismusstudie entwickelt eine Reihe plausibler Szenarien und potenzieller politischer Antworten auf die oben erwähnten Megatrends. Sodann untersucht sie, wie sich politische Entscheidungsträger besser auf Megatrends vorbereiten können, und stellt eine Reihe von Leitlinien für wirksame strategische Frühaufklärung im Bereich des Tourismus auf.

Stichwörter: Tourismus, Megatrends, strategische Frühaufklärung, Szenarioplanung, Besuchernachfrage, nachhaltiger Tourismus, Basistechnologien, Reisemobilität 
Das vorliegende Dokument wurde durch den Tourismusausschuss an seiner 102. Sitzung vom 30. Oktober 2018 genehmigt und freigegeben [CFE/TOU(2017)7/FINAL] und durch das OECD-Sekretariat für die Veröffentlichung vorbereitet. Die Veröffentlichung dieses Dokuments wurde durch Lamia Kamal-Chaoui, Direktorin des Centre for Entrepreneurship, SMEs, Regions and Cities, genehmigt.

Das vorliegende Dokument sowie jegliche darin enthaltenen [statistischen] Daten und Karten werden unbeschadet des Status oder der Souveränität jeglicher Länder, des Verlaufs von Landesgrenzen sowie der Bezeichnungen von Ländern, Orten oder Regionen zur Verfügung gestellt.

OECD-Strategiepapiere geben nicht unbedingt die offiziellen Ansichten der OECD oder ihrer Mitgliedsländer wieder. Die enthaltenen Ansichten und Argumente sind diejenigen der jeweiligen Verfasser. Kommentare zu Strategiepapieren sind willkommen und können an folgende Adresse gesendet werden: The Centre for Entrepreneurship, SMEs, Regions and Cities, OECD, 2 rue André-Pascal, 75775 Paris Cedex 16, Frankreich.

Das vorliegende Dokument wurde mit finanzieller Unterstützung der Europäischen Union erstellt. Die hierin vertretenen Ansichten müssen in keinerlei Hinsicht den offiziellen Ansichten der Europäischen Union entsprechen.

Die Übersetzung in die deutsche Sprache wurde durch das Staatssekretariat für Wirtschaft SECO (Schweiz) ausgeführt.

Die vorliegende Übersetzung wird in Vereinbarung mit der OECD veröffentlicht. Es handelt sich dabei nicht um eine offizielle Übersetzung der OECD. Für die Qualität der Übersetzung und deren Übereinstimmung mit dem ursprünglichen Text der Publikation in der Ausgangssprache sind ausschliesslich die Urheber der Übersetzung verantwortlich. Bei Abweichungen zwischen dem Inhalt der ursprünglichen Publikation und der Übersetzung ist ausschliesslich der Text der ursprünglichen Publikation massgebend.

(C) OECD 2018 OECD-Inhalte dürfen zur eigenen Verwendung vervielfältigt, heruntergeladen oder ausgedruckt werden. Es ist gestattet, Auszüge aus Publikationen, Datenbanken und Multimediaprodukten der OECD in eigenen Dokumenten, Präsentationen, Blogs, Websites und Unterrichtsmaterialien zu verwenden, sofern die OECD in geeigneter Weise als Quelle und Inhaberin der Urheberrechte genannt ist. Alle Anfragen hinsichtlich einer kommerziellen Verwendung und hinsichtlich Übersetzungsrechten sind an rights@oecd.org zu richten. 


\section{Über die OECD}

Die OECD ist eine multidisziplinäre, zwischenstaatliche Organisation mit 36 Mitgliedsländern, die sich bei ihrer Arbeit auf eine wachsende Zahl Nichtmitglieder aus allen Teilen der Welt stützt. Die Kernaufgabe der Organisation ist es heute, Staaten bei ihrer Zusammenarbeit im Interesse einer stärkeren, saubereren und gerechteren weltweiten Wirtschaft zu unterstützen. Im Rahmen ihres Netzwerks aus 250 Fachausschüssen und Arbeitsgruppen bietet die OECD ein Umfeld, in dem Regierungen politische Erfahrungen austauschen, Antworten auf aktuelle Probleme finden, gute Praktiken erkennen und ihre Innen- und Aussenpolitik koordinieren können.

Folgende Länder sind Mitglieder der OECD: Australien, Belgien, Chile, Dänemark, Deutschland, Estland, Finnland, Frankreich, Griechenland, Irland, Island, Israel, Italien, Japan, Kanada, Korea, Lettland, Litauen, Luxemburg, Mexiko, Neuseeland, Niederlande, Norwegen, Österreich, Polen, Portugal, Schweden, Schweiz, Slowakei, Slowenien, Spanien, Tschechische Republik, Türkei, Ungarn, Vereinigtes Königreich und Vereinigte Staaten. Die Europäische Kommission beteiligt sich ebenfalls an der Arbeit der OECD.

\section{ÜBER DEN TOURISMUSAUSSCHUSS}

Das vorliegende Strategiepapier wurde vom OECD Centre for Entrepreneurship, SMEs, Regions and Cities (CFE) im Rahmen des Arbeitsprogramms des Tourismusausschusses erstellt. Der im Jahr 1948 gegründete Tourismusausschuss ist das Forum der OECD für den Austausch über politische Weichenstellungen und strukturelle Veränderungen, die die Entwicklung des inländischen und internationalen Tourismus beeinflussen, sowie für deren Beobachtung.

Um den grossen Herausforderungen gerecht zu werden, vor denen die Tourismusbranche steht, und um das volle wirtschaftliche Potenzial des Tourismus zu maximieren, ist ein integrierter und vielfältiger Ansatz für die Entwicklung der Tourismuspolitik erforderlich, in den viele verschiedene Regierungsebenen und -behörden eingebunden sind. Ein derartiges Umfeld bietet nach Ansicht der OECD-Mitglieder erhebliche Vorteile für eine Zusammenarbeit, um Wirtschafts-, Nachhaltigkeits- und Beschäftigungsfragen gemeinsam anzugehen und für Leistungsfähigkeit, Bewertungsmöglichkeiten, Innovationen und Liberalisierung im Bereich der Tourismuspolitik zu sorgen. Auch eine engere Zusammenarbeit mit wichtigen Schwellenländern wird als kritisch für spürbare Erfolge dieser Bemühungen angesehen.

Die Website des Tourismusausschusses (www.oecd.org/cfe/tourism/) enthält detaillierte Informationen zur Arbeit der OECD im Bereich des Tourismus. 


\section{Danksagungen}

Der vorliegende Bericht wurde durch das OECD Centre for Entrepreneurship, SMEs, Regions and Cities (CFE) unter Leitung seiner Direktorin Lamia Kamal-Chaoui erstellt. Der Bericht ist Teil des Arbeitsprogramms des OECD-Tourismusausschusses. Er wurde mit Mitteln der Europäischen Union gefördert*.

Der vorliegende Bericht baut auf Kapitel 2 von «OECD Tourism Trends and Policies 2018, Megatrends Shaping the Future of Tourism» auf (OECD-Studie zu Trends und politischen Konzepten im Tourismus 2018 - Megatrends, die die Zukunft des Tourismus bestimmen). Er wurde durch die Politikanalysten Peter Haxton und Taekyeong Jung unter Leitung von Alain Dupeyras, Leiter der Abteilung Regionalentwicklung und Tourismus, sowie Jane Stacey, Leiterin der Einheit Tourismus, koordiniert und redigiert. Der Bericht wurde von Sunil Johal, Jordann Thirgood und Kiran Alwani (Mowat Centre) unter Zuhilfenahme wichtiger Beiträge und Entwürfe des Sekretariats verfasst. Weitere Beiträge und Unterstützung kamen von Anna Bolengo, Junior Policy Analyst, sowie Alexandra Campbell und Monserrat Fonbonnat, die administrative Hilfestellung leisteten.

Aus 19 Mitglieds- und Partnerländern der OECD kamen spezifische Beiträge, Rückmeldungen und Hinweise: Australien, Belgien, Bulgarien, Dänemark, Deutschland, Estland, Finnland, Griechenland, Japan, Kroatien, Litauen, Luxemburg, Österreich, Portugal, Rumänien, Schweiz, Slowakei, Spanien und Türkei. In den Bericht flossen Erkenntnisse aus zwei Workshops ein (einer durch Portugal mitveranstaltet), in denen politische Entscheidungsträger und Branchenführer zu interaktiven, eingehenden Diskussionen über Megatrends zusammen kamen.

Ausserdem leistete eine Reihe internationaler Organisationen und Branchenführer Beiträge zu diesem Bericht: UN Environment, UNESCO, UNWTO, Alliance for Excellency in Tourism, Alliance 46.2, Ecole hôtelière de Lausanne, European Tourism Association, European Tourism Commission, International Air Transport Association, International Federation on Ageing, Internationale Eisenbahnverband (UIC), Promoting Entrepreneurship for Sustainable Development sowie World Travel and Tourism Council.

Darüber hinaus kamen dem Bericht Gespräche mit Kolleginnen und Kollegen bei der OECD in der Strategic Foresight Unit, dem Development Centre, dem International Transport Forum sowie dem Centre for Entrepreneurship, SMEs, Regions and Cities zugute.

\footnotetext{
* Das vorliegende Dokument wurde mit finanzieller Unterstützung der Europäischen Union erstellt. Die hierin vertretenen Ansichten müssen in keinerlei Hinsicht den offiziellen Ansichten der Europäischen Union entsprechen.
} 


\section{Inhaltsverzeichnis}

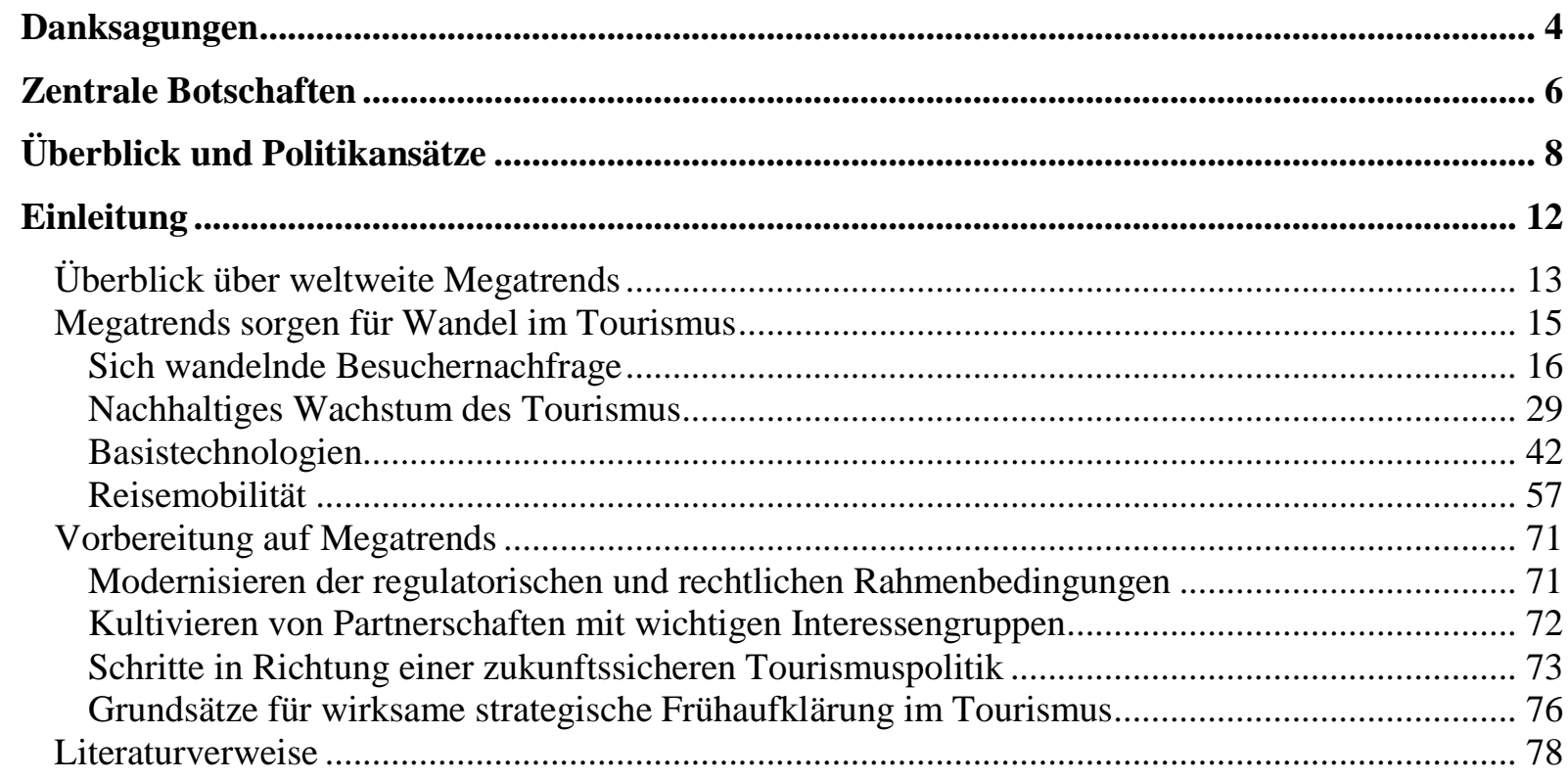

\section{Tabellen}

Tabelle 1. OECD-Bezugssystem für Megatrends.

\section{Abbildungen}

Abbildung 1. Wichtige Trends in Bezug auf die sich wandelnde Besuchernachfrage 16

Abbildung 2. Wichtige Entwicklungen in Zusammenhang mit einem nachhaltigen Wachstum des

Tourismus

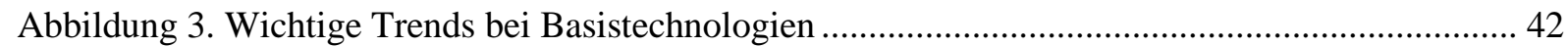

Abbildung 4. Wichtige Trends bei der Reisemobilität ....................................................................... 57

Abbildung 5. Überblick über die wichtigen Elemente der Schweizer Tourismuspolitik ...................... 75

Abbildung 6. Leitprinzipien für wirksame strategische Frühaufklärung.............................................. 76

\section{Kästen}

Kasten 1. Marketing für chinesische Reisende in Neuseeland ....................................................... 22

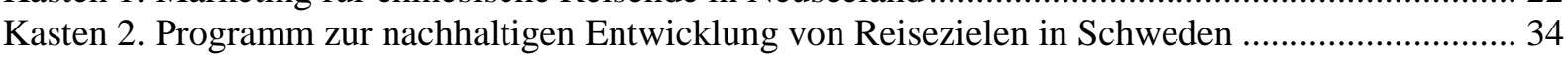

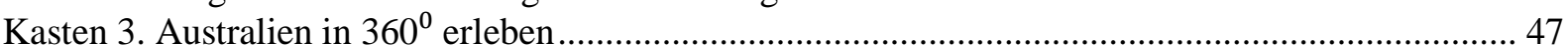

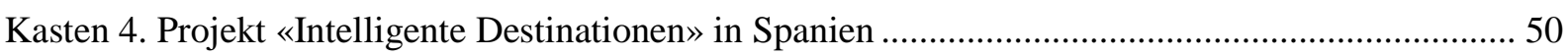

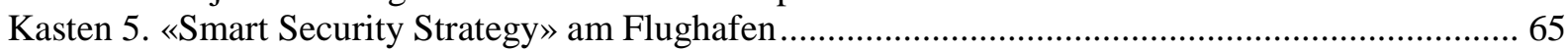

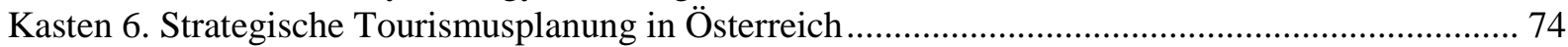

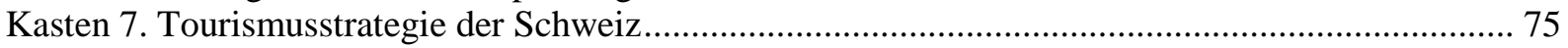




\section{Zentrale Botschaften}

Um auf Megatrends vorbereitet zu sein, muss man sie zunächst verstehen. Der vorliegende Bericht trägt hierzu bei, indem er Megatrends benennt und analysiert, die bis zum Jahr 2040 und darüber hinaus voraussichtlich Änderungen im Tourismussektor vorantreiben werden. Dies sind im Einzelnen: i) die sich wandelnde Besuchernachfrage; ii) nachhaltiges Wachstum des Tourismus; iii) Basistechnologien sowie iv) Reisemobilität. Der Bericht nennt eine Reihe spezifischer Politikansätze zur Vorbereitung auf die einzelnen Megatrends, streicht jedoch allgemeiner heraus, dass die politischen Entscheidungsträger systemische und strategische Ansätze entwickeln müssen, um die Anpassung an ein sich immer schneller wandelndes, in sich verflochtenes und dynamisches Umfeld zu gewährleisten.

Die politischen Entscheidungsträger müssen proaktiv Massnahmen ergreifen, um Unsicherheiten abzubauen und sich wirksam auf Megatrends vorzubereiten, die sich erheblich auf den Tourismus auswirken werden. Neben einem integrierten staatlichen Ansatz sollten die Regierungen ihre Massnahmen auf drei Schlüsselbereiche konzentrieren:

- Regulatorische und rechtliche Rahmenbedingungen modernisieren. Regelmässige Überprüfung der regulatorischen und rechtlichen Rahmenbedingungen, um veraltete Anforderungen abzuschaffen und das Entstehen innovativer Ansätze für die Bereitstellung von Gütern und Dienstleistungen zu fördern. Breit angelegte Einbindung wichtiger Interessengruppen, um sicherzustellen, dass die Perspektiven neuer und entstehender Marktteilnehmer berücksichtigt werden; Bereitstellung von Mechanismen für regelmässiges Feedback, um nötigenfalls Anpassungsmöglichkeiten zu erkennen.

- Partnerschaften mit wichtigen Interessengruppen kultivieren. Förderung eines fortlaufenden Dialogs, in den Regierung, Tourismusbranche und die Gemeinschaft eingebunden sind. Die Koordination über verschiedene Ebenen hinweg und zwischen den einzelnen Regierungsstellen ist entscheidend für den Umgang mit den komplexen ressortübergreifenden Sachverhalten, die in diesem Sektor zu erwarten sind. Um globale Probleme zu lösen, werden internationale Vereinbarungen als Grundlage nationaler politischer Massnahmen erforderlich sein.

- Möglichkeiten erkunden, politische Entscheidungen «zukunftssicher» zu machen. Förderung einer Kultur der Innovationen und des Veränderungsmanagements innerhalb der Regierungen, um sicherzustellen, dass langfristige Megatrends innerhalb des Entscheidungsprozesses angemessen berücksichtigt werden. Es ist sicherzustellen, dass politische Entscheidungsträger die Möglichkeit besitzen, datenbasierte Entscheidungen zu treffen, die wichtige Trends und Probleme im Tourismusbereich berücksichtigen. Ein Prozess der langfristigen Zukunftsbeobachtung muss etabliert werden, um schwache Signale für Veränderungen zu erkennen, die sich wahrscheinlich auf den Tourismus auswirken werden. 
Verfahren der strategischen Frühaufklärung können Entscheidungsträgern in der Tourismuspolitik helfen, alternative Zukunftsszenarien vorherzusehen und die Entwicklung zukunftsweisender politischer Konzepte inspirieren. Der vorliegende Bericht befasst sich mit den folgenden Leitprinzipien, die den Wert dieser Verfahren maximieren:

1. Agilität - Verwenden der bestehenden Erkenntnisse und Projektionen bei gleichzeitig ausreichender Agilität, um sich an die sich entwickelnden Realitäten anzupassen.

2. Multiplizität - Berücksichtigen alternativer Zukunftsszenarien beim Entwickeln politischer Konzepte und Programme und entsprechende Vorbereitung.

3. Proaktivität - Ergreifen proaktiver Schritte, um auf die gewünschte Zukunft hinzuarbeiten.

4. Langfristige Nachhaltigkeit - Berücksichtigen der Auswirkungen politischer Massnahmen auf künftige Generationen und Ergreifen verantwortungsvoller Massnahmen in der Gegenwart.

5. Engagement und Inklusion - Zusammenarbeit mit vielfältigen Interessengruppen, die verschiedene Sichtweisen und Interessen vertreten.

6. Internationale Zusammenarbeit - Zwischenstaatliche Zusammenarbeit, um sicherzustellen, dass politische Konzepte und Entscheidungen weltweit nachhaltig sind. 


\section{Überblick und Politikansätze}

Es haben sich eine Reihe von Trends entwickelt, die die Gesellschaft in den kommenden Jahrzehnten transformieren könnten. Die bedeutendsten dieser Trends werden als Megatrends bezeichnet. Megatrends umfassen weltweit bedeutsame gesellschaftliche, wirtschaftliche, politische, umweltbezogene und technologische Veränderungen, die langfristig ablaufen. Obwohl sich Megatrends oft langsam entfalten und relativ stabilen Pfaden folgen, haben sie potenziell sehr starke Auswirkungen und können die Weltwirtschaft und Gesellschaft in bestimmte Richtungen treiben. Die genauen Ergebnisse dieser Trends sind typischerweise ungewiss. Dennoch ist es wichtig, dass Regierungen proaktiv die potenziellen langfristigen Auswirkungen dieser Trends berücksichtigen und Zukunftsplanungen auf fundierte Vorhersagen stützen.

Für politische Entscheidungsträger im Tourismusbereich ist es entscheidend, zu erkennen, was diese breit angelegten und langfristigen Veränderungen für den Tourismus bedeuten und welche potenziellen Herausforderungen und Chancen sie mit sich bringen könnten. Die Tourismusbranche ist in den vergangenen Jahrzehnten erheblich gewachsen. Während dieses Wachstum voraussichtlich anhalten wird, werden Megatrends das Gesicht des Tourismus bis zum Jahr 2040 wahrscheinlich erheblich verändert haben.

Um auf Megatrends vorbereitet zu sein, muss man sie zunächst verstehen. Der vorliegende Bericht trägt hierzu bei, indem er Megatrends benennt und analysiert, die in den kommenden Jahren voraussichtlich Änderungen im Tourismussektor vorantreiben werden. Dies sind im Einzelnen: i) die sich wandelnde Besuchernachfrage; ii) nachhaltiges Wachstum des Tourismus; iii) Basistechnologien sowie iv) Reisemobilität.

- Die sich wandelnde Besuchernachfrage infolge des demografischen Wandels, wird die Art und Weise verändern, in der Menschen weltweit reisen. Eine weltweit immer grössere Mittelschicht - hauptsächlich getrieben durch das Wachstum in den Schwellenländern - wird die Kaufkraft des Einzelnen weltweit erheblich erhöhen und neue Tourismusmärkte entstehen lassen. Durch die weltweiten Bevölkerungsstrukturen wird die Zahl der älteren Reisenden, die spezielle Bedürfnisse und Reisevorlieben haben, stetig steigen. Künftige technikversierte Generationen werden die Gästestruktur auf dem Tourismusmarkt immer stärker dominieren.

- Nachhaltiges Wachstum des Tourismus ist entscheidend, um potenziell schädlichen Auswirkungen eines ungezügelten touristischen Wachstums sowohl auf die Umwelt als auch auf die gastgebenden Gemeinden zu begegnen. Dies betrifft Treibhausgasemissionen, den Land- und Wasserverbrauch sowie den nicht nachhaltigen Verbrauch von Nahrungsmitteln ebenso wie die Verdrängung traditioneller Gesellschaften und die Nachteile eines «überbordenden» Tourismus für die gastgebenden Gemeinden. Der Tourismus ist ausserdem in hohem Masse von den Auswirkungen des Klimawandels betroffen. Aufbauend auf breit angelegtem Engagement aller Interessengruppen und nachhaltigen Entwicklungsgrundsätzen kann er eine wichtige Rolle dabei spielen, den Übergang zu einer kohlenstoffarmen und ressourceneffizienten Wirtschaft voranzutreiben.

- Basistechnologien ändern auch weiterhin die Art und Weise, in der Menschen arbeiten, reisen und Geschäfte abwickeln. Die digitale Wirtschaft, Automatisierung und künstliche Intelligenz, Blockchain und virtuelle/erweiterte Realität besitzen das 
Potenzial, Reisen erschwinglicher, effizienter und für viele Menschen zugänglicher zu machen. Gleichzeitig können in einer Zeit, in der die Menschen immer stärker digital leben, Möglichkeiten, sich auszuklinken und analoge oder natürliche Erfahrungen zu machen, zu einer bevorzugten Alternative werden.

- Reisemobilität, einschliesslich der Möglichkeit, sicher und frei grenzüberschreitend zu reisen, wird ein Schlüsselfaktor für Erfolg und Wachstum im Tourismussektor sein. Der Verkehr war immer ein wichtiger Wegbereiter für den internationalen Tourismus, der die Verbraucher zu kommerziellen Dienstleistern und die Anbieter an die weltweiten Märkte bringt. Allerdings ist Mobilität ein kompliziertes Thema, das übergreifend mit Verkehr, Grenzkontrollen, persönlicher und Betriebssicherheit sowie dem breiteren geopolitischen Umfeld zu tun hat. Diese Faktoren können stark durch externe Einwirkungen wie politische Unruhen, Pandemien und Naturkatastrophen beeinflusst sein. Pläne und politische Konzepte für das Tourismusmanagement müssen all diese Dinge berücksichtigen, um ein nachhaltiges Wachstum des Sektors zu gewährleisten.

\section{Politikansåtze}

Megatrends, wie die oben umrissenen, werden den Tourismussektor bis zum Jahr 2040 vor viele Chancen und Herausforderungen stellen. Um besser $\mathrm{zu}$ verstehen, wie sich die einzelnen Megatrends entwickeln könnten, untersucht der Bericht jeweils plausible alternative Zukunftsszenarien. Basierend auf einer detaillierten Analyse der jeweiligen Szenarien wird eine Reihe Politikansätze vorgetragen, anhand derer sich Regierungen auf diese Megatrends vorbereiten und auf sie reagieren können. Im Folgenden einige wichtige Beispiele:

- Politische Entscheidungsträger und die Branche sollten sich wegen der alternden Bevölkerung auf eine wachsende Nachfrage durch ältere Touristen einstellen. Aus Regierungssicht sollte sich diese Vorbereitung weitgehend auf die Verbesserung der Anforderungen an die Barrierefreiheit und auf Infrastrukturinvestitionen konzentrieren, um Personen mit eingeschränkter Beweglichkeit und kognitiven Einschränkungen zu unterstützen. Ausserdem sollten Bemühungen unternommen werden, um auch im Digitalzeitalter im digitalen Bereich unterschiedlich versierten Besuchern entgegen zu kommen.

- Die Destinationen sollten überdenken, wie Reiseerlebnisse verpackt und vermarktet werden, da sich der demografische Wandel wahrscheinlich dramatisch auf die Wahl von Reiseziel und Reiseerlebnis auswirken wird. Innovative digitale Kampagnen unter Einbezug sozialer Medien, um den Austausch von Reiseerfahrungen zu fördern, werden immer wichtigere Bestandteile von Marketingstrategien in der Tourismusbranche werden.

- Die stärkere horizontale und vertikale politische Koordination und die bessere Integration multipler politischer Konzepte sollten gefördert werden, um einen strategischeren und koordinierteren Ansatz für nachhaltiges Wachstum des Tourismus zu unterstuitzen. Langfristige Strategien und politische Konzepte, die sich um hochwertige Arbeitsplätze, die Entwicklung von Kompetenzen, Unternehmertum, Innovation, effektive Investitionen und integrierte Regionalentwicklung bemühen, sind für ein nachhaltiges und integratives Wachstum des Tourismus ausserordentlich wichtig. 
- Eine enge Zusammenarbeit mit Tourismusbranche und lokalen Gemeinden ist notwendig, um an Destinationen, deren Umwelt und gesellschaftliche Situation gefährdet ist, zur besseren Steuerung der Touristenströme beizutragen und die touristische Entwicklung in alternativen Gegenden zu fördern, sodass potenzielle Vor- und Nachteile gestreut werden. Mögliche Ansätze wären die Einführung dynamischer Preismechanismen, die die Nachfrage verteilen und/oder die tatsächlichen Kosten tourismusbezogener Aktivitäten besser wiedergeben können, die Verminderung der Saisonalität, um Gefahren durch überbordenden Tourismus zu begrenzen, und der Einsatz von Technologien zur besseren Steuerung der Besucherzahlen ${ }^{1}$.

- Die politischen Entscheidungsträger sollten Massnahmen ergreifen, um kleinen und mittleren Unternehmen (KMU) den Übergang in die digitale Wirtschaft zu erleichtern. Der digitale Wandel kann KMU neue Möglichkeiten bieten, auf einfache Weise internationale Märkte zu erschliessen und direkt mit Kunden auf der ganzen Welt in Kontakt zu treten. Ein wichtiges Element dieses Prozesses ist die Vereinfachung des Zugriffs von KMU auf technisches Wissen und spezialisierte Informationen (z. B. Verbindungen mit Dienstleistern und Technologieanbietern einschliesslich Forschungszentren und Universitäten, um die Einführung von IKT, Lernmöglichkeiten und Innovationen zu fördern).

- In einer Zeit, in der Technologie eine immer grössere Rolle für touristische Erlebnisse spielt, wird die internationale Zusammenarbeit zu einem unverzichtbaren Bestandteil aller Bemühungen im Hinblick auf Datensicherheit und Schutz der Privatsphäre. Dies erfordert als weltweites und grenzüberschreitendes Phänomen kontinuierliche Gespräche über verschiedene Regierungsebenen innerhalb der einzelnen Länder hinweg wie auch länderübergreifende Zusammenarbeit ${ }^{2}$.

- Es sollte sichergestellt werden, dass die mittel- bis langfristigen Bedürfnisse der Tourismusbranche als Teil des Planungsprozesses für den Zugang zu Verkehr und Infrastruktur verstanden werden. Entscheidend ist, dass politische Entscheidungsträger in den Bereichen Tourismus und Verkehr eng zusammenarbeiten und gemeinsam mit der Branche Verkehrsdienstleistungen und Infrastrukturen entwickeln, die den Bedürfnissen sowohl der Einheimischen als auch der Touristen entsprechen.

- Politische Entscheidungsträger müssen Möglichkeiten finden, die derzeitigen und neu entstehenden Technologien zu nutzen, um die Visaerteilung und den grenzüberschreitenden Verkehr für Reisende ohne erhöhtes Risiko zu vereinfachen (im Rahmen von Vorerfassungs- und Vorabgenehmigungs-

\footnotetext{
${ }^{1}$ So führt beispielsweise die Parkleitung in Cinque Terre in Norditalien derzeit einen Versuch mit einer App durch, mit der interessierte Besucher in Echtzeit sehen können, wie viele Menschen auf bestimmten Wegen unterwegs sind. So sollen während Spitzenzeiten zusätzliche Besucher abgeschreckt werden (BBC, 2018).

2 Die Datenschutz-Grundverordnung (DSGVO) der EU - ein modernisierter Rahmen für die Datenschutzgesetzgebung, der im Mai 2018 in Kraft getreten ist - ist in dieser Hinsicht ein vielversprechender Schritt in die richtige Richtung. Die DSGVO führt eine Reihe von Reformen ein, die die Chancengleichheit der Unternehmen verbessern und Einzelpersonen grössere Kontrolle über ihre personenbezogenen Daten geben (Europäische Kommission, 2018).
} 
Programmen $)^{3}$. Neben der höheren Effizienz und den geringeren Kosten werden derartige Programme auch für ein deutlich angenehmeres Reiseerlebnis sorgen, wenn sie erfolgreich in grösserem Umfang eingesetzt werden und regional und/oder länderübergreifend die Mobilität verbessern.

Nach wie vor ist unsicher, wie sich die Megatrends bis zum Jahr 2040 auf den Tourismus auswirken werden. Um jedoch nach vorne blicken zu können, müssen sich die Regierungen zunächst ein klares Bild über die Vorteile verschaffen, die der Tourismus für ihre Wirtschaft bedeutet, und entsprechend investieren. Sie benötigen eine klare strategische Vision mit gut formulierten Zielen und müssen wichtige Interessengruppen mittels eines integrierenden Ansatzes zusammenbringen. Die Entwicklung umfassender langfristiger Pläne, die sich auch über Legislaturperioden hinaus erstrecken - bei gleichzeitiger Flexibilität, um neu aufkommende Trends und sich entwickelnde Prioritäten schnell erkennen und darauf reagieren zu können - bietet eine stabile Plattform für nachhaltiges und integratives Wachstum: Wachstum, das nicht nur den aktuellen und künftigen wirtschaftlichen, gesellschaftlichen und umweltbezogenen Auswirkungen Rechnung trägt, sondern auch die Bedürfnisse der Besucher, der Branche, der Umwelt und der gastgebenden Gemeinden berücksichtigt.

\footnotetext{
${ }^{3}$ Das Programm «Nexus Card», an dem derzeit berechtigte Reisende zwischen Kanada und den
} Vereinigten Staaten teilnehmen, ist ein gutes Beispiel für ein derartiges Arrangement. 


\section{Einleitung}

Der Schwerpunkt der Weltwirtschaft wird sich in den kommenden 50 Jahren nach Osten und nach Süden verschieben. Es wird erwartet, dass die Entwicklungsländer bis zum Jahr 2030 für zwei Drittel des weltweiten Wachstums und die Hälfte des weltweiten Produktionsvolumens verantwortlich und die wichtigsten Destinationen des Welthandels sein werden. Schwellenländer wie China und Indien entwickeln sich zu immer wichtigeren Märkten für Unternehmen der verschiedensten Branchen. Eine schnell entstehende neue Mittelschicht wird zu einer höheren Nachfrage nach Basiskonsumgütern und Produkten anderer Kategorien führen. Diese nachfrageorientierten Faktoren bedeuten, dass die Schwellenländer vermutlich weiterhin bevorzugte Produktionsstandorte bleiben. Gleichzeitig werden erhebliche Verschiebungen hin zu Dienstleistungen dazu führen, dass China und andere Schwellenländer auf lange Sicht und zulasten der OECD-Länder grosse Anteile des Dienstleistungsmarktes an sich ziehen werden (OECD, 2016a).

Der weltweite Tourismus ist in den vergangenen Jahrzehnten erheblich gewachsen. Er profitierte von der zunehmenden Globalisierung und technischen Fortschritten, die zu günstigeren Flugpreisen geführt und es den Menschen erleichtert haben, ihre Reisen selbst zu planen und zu buchen und ihre Erfahrungen in Echtzeit an ihre Freunde weiterzugeben. Obwohl dieses Wachstum wohl anhalten wird, dürfte sich das Erscheinungsbild des Tourismus bis zum Jahr 2040 aufgrund geänderter Umweltbedingungen, technologischer Innovationen und des demografischen Wandels wohl dramatisch verändern.

Wie wird der Tourismussektor im Jahr 2040 aussehen und wie können sich politische Entscheidungsträger auf die potenziell weitreichenden Veränderungen vorbereiten? Der vorliegende Bericht versucht, die Zukunft des Tourismus einzuschätzen, indem er die Megatrends analysiert, die sich wahrscheinlich auf diesen Sektor auswirken werden. Dazu werden plausible potenzielle Zukunftsszenarien betrachtet, die sich entwickeln könnten, und Empfehlungen für Regierungen und die Tourismusbranche abgegeben, wie sich negative Auswirkungen begrenzen lassen und potenzielle Vorteile genutzt werden könnten.

Megatrends umfassen weltweit bedeutsame gesellschaftliche, wirtschaftliche, politische, umweltbezogene und technologische Veränderungen, die langfristig ablaufen. Diese wirken sich typischerweise über Jahrzehnte hinweg aus und besitzen daher das Potenzial, Wirtschaftszweige, einschliesslich des Tourismussektors, auf der ganzen Welt fundamental zu verändern und «auf den Kopf zu stellen. Der vorliegende Bericht identifiziert und analysiert vier wichtige Megatrends, die in den kommenden Jahrzehnten voraussichtlich zu grossen Veränderungen führen und sich erheblich auf den Tourismus auswirken dürften.

Die Analysen der einzelnen Megatrends werden durch eine Aufstellung der wichtigsten Fakten und Vorhersagen sowie deren potenzielle Implikationen für den Tourismussektor ergänzt. Wir weisen auf eine Reihe kritischer Unsicherheiten hin - Wendepunkte, an denen sich der zu erwartende Verlauf der betreffenden Trends ändern kann - und nutzen diese als Ausgangspunkte für die Entwicklung dreier plausibler Zukunftsszenarien. Diese Szenarien werden vorgestellt und besprochen und bilden die Grundlage für umsetzbare Empfehlungen an politische Entscheidungsträger im Tourismusbereich. Aufbauend auf diesen Erkenntnissen endet das Kapitel mit Vorschlägen für übergeordnete Strategien, mit denen politische Entscheidungsträger die Zukunft des Tourismus besser gestalten können, ergänzt durch einen Reihe von Leitlinien für wirksame Verfahren der strategischen Frühaufklärung im Tourismusbereich. 
Der vorliegende Bericht stützt sich auf eine umfangreiche Literaturrecherche und einen Prozess zur Einbeziehung von Interessengruppen. Dieser umfasste eine im Sommer 2017 in den OECD-Ländern durchgeführte Umfrage, Rückmeldungen aus einem OECDWorkshop betreffend die Analyse von Megatrends zur besseren Gestaltung der Zukunft des Tourismus sowie aus einem zweiten Workshop zur Ausarbeitung von Szenarien, der im Jahr 2018 mit Unterstützung von Turismo de Portugal in Lissabon, Portugal, durchgeführt wurde. In beiden Workshops waren Regierungen, internationale Organisationen und die Tourismusbranche sehr gut vertreten. Die Analyse nutzt die Ergebnisse des «OECD High Level Meeting on Tourism Policies for Sustainable and Inclusive Growth» (OECDSpitzentreffen zur Tourismuspolitik im Interesse eines nachhaltigen und integrativen Wachstums) aus dem Jahr 2017 sowie Kapitel 2 der OECD-Publikation «Tourism Trends and Policies 2018» (Trends und politische Konzepte im Tourismus 2018), Megatrends shaping the future of tourism (Megatrends, die die Zukunft des Tourismus bestimmen).

\section{Überblick über weltweite Megatrends}

Rund um die Welt haben sich Trends entwickelt, die das Potenzial haben, die Gesellschaft zu verändern. Die bedeutendsten dieser Trends werden als Megatrends bezeichnet, da sie sowohl grosse Bereiche betreffen als auch langfristig wirken - in der Regel wenigstens zwei Jahrzehnte lang. Megatrends basieren folglich auf Umständen, die sich weltweit in vielen Ländern gleichzeitig entwickeln und oftmals Weltwirtschaft und Gesellschaft in bestimmte Richtungen leiten können.

Megatrends führen mit grosser Wahrscheinlichkeit $\mathrm{zu}$ bedeutsamen, langfristigen Veränderungen, die gesellschaftliche, wirtschaftliche, politische, umweltbezogene und technologische Aspekte betreffen. Trotz ihrer potenziell grossen Auswirkungen entfalten sie sich oft langsam und folgen relativ stabilen Pfaden. $\mathrm{Zu}$ den weltweiten Megatrends, denen Länder auf der ganzen Welt im Verlauf des nächsten Jahrzehnts wahrscheinlich unterliegen werden, zählen unter anderem der demografische Wandel, gegenseitige wirtschaftliche Abhängigkeiten, Staatsverschuldung, Klimawandel und Verstädterung. Megatrends wie beispielsweise die Verstädterung eröffnen mit grosser Wahrscheinlichkeit gesellschaftliche und wirtschaftliche Chancen, belasten aber auch Infrastruktur und Ressourcen, da immer mehr Menschen in Städten wohnen. Obwohl die genauen Ergebnisse dieser Trends nicht sicher sind, lassen sich informierte Vorhersagen treffen, anhand derer Regierungen mit ersten Schritten der Vorausplanung beginnen können.

Um auf Megatrends vorbereitet zu sein, muss man sie zunächst umfassend verstehen. Regierungen auf der ganzen Welt müssen proaktiv tätig werden und vorausschauende Entscheidungen treffen, die sich langfristig auswirken. Nur so ist es möglich, potenziellen Herausforderungen zu begegnen und Chancen, die sich vielleicht ergeben, zu nutzen. Politische Entscheidungsträger müssen also die Auswirkungen von Megatrends in den durch sie verantworteten Bereichen berücksichtigen, auch um wirtschaftlichen Wohlstand, Sicherheit, gesellschaftlichen Zusammenhalt und Umweltverträglichkeit zu gewährleisten (KPMG und Mowat Centre, 2013).

Um beim Umgang mit Megatrends zu unterstützen, hat die OECD einen Ansatz entwickelt, der sich auf vier Schlüsselkategorien stützt: Menschen, Planet, Produktivität und Gemeinwesen (Tabelle 1). 
Tabelle 1. OECD-Bezugssystem für Megatrends

\begin{tabular}{ll}
\hline Menschen & Dieser Megatrend bezieht sich allgemein auf den demografischen Wandel sowie auf Trends \\
hinsichtlich Gesundheit, Arbeit und gesellschaftlichem Zusammenhalt. In Zusammenhang mit \\
Tourismus ist dieser Trend am engsten mit der sich wandelnden Besuchernachfrage verknüpft, die \\
auf Trends wie der alternden Bevölkerung und der weltweit wachsenden Mittelschicht basiert. \\
Dieser Megatrend bezieht sich allgemein auf den Zustand der Umwelt und die Auswirkungen des \\
Klimawandels sowie auf den Zugang zu Ressourcen wie Nahrungsmitteln, Energie und Wasser. In \\
Zusammenhang mit Tourismus ist dieser Trend am engsten mit nachhaltigem Wachstum des \\
Tourismus verknüpft, durch das Umweltbeeinträchtigungen durch Reisende angesichts der \\
Auswirkungen des Klimawandels reduziert werden sollen. \\
Dieser Megatrend bezieht sich allgemein auf Wachstumsgrundlagen wie Technologie, Innovationen \\
und Unternehmertum. In Zusammenhang mit Tourismus hat die wachsende Bedeutung von \\
Basistechnologien, beispielsweise in Form von Plattformen der «Sharing Economy», die Art und \\
Weise verändert, in der Menschen auf der ganzen Welt reisen können. In den kommenden \\
Jahrzehnten werden Fortschritte, beispielsweise durch Automatisierung, den Sektor wohl weiter \\
verändern. \\
Dieser Megatrend bezieht sich allgemein auf den Zustand von Governance, Vertrauen und \\
Verantwortlichkeit im öffentlichen Raum. In Zusammenhang mit Tourismus spielen öffentliche \\
Entscheidungen in vielen Bereichen eine Rolle, insbesondere im Bereich der Reisemobilität. So \\
wirken sich beispielsweise das Ausmass staatlicher Unterstützung für den internationalen Verkehr \\
und die Akzeptanz ausländischer Besucher erheblich auf die Mobilität aus.
\end{tabular}

Quelle: OECD (2014)

Der Tourismussektor und die damit verbundenen Branchen sind Teil eines weltweiten Wirtschaftssystems, das einer ganzen Reihe von Megatrends unterliegen kann. Beispielsweise sagt die International Air Transport Association (IATA) voraus, dass sich die Passagiernachfrage in den kommenden 20 Jahren infolge der aufstrebenden Mittelschicht in den Entwicklungsländern, divergierender demografischer Entwicklungen, der zunehmenden Liberalisierung des Luftverkehrs und des Klimawandels verändern wird (IATA, 2016). Das vorliegende Kapitel untersucht basierend auf Rückmeldungen von Mitglieds- und Partnerländern, der Branche und internationaler Organisationen ähnliche Trends in Zusammenhang mit:

- der sich wandelnden Besuchernachfrage,

- nachhaltigem Wachstum des Tourismus,

- Basistechnologien,

- Reisemobilität.

Der weltweite Tourismus ist über sechs Jahrzehnte lang stetig gewachsen. Den Höhepunkt bildeten 1,2 Milliarden ankommende Besucher im Jahr 2016. Diese Zahl wird bis 2030 auf voraussichtlich 1,8 Milliarden ansteigen, wobei die internationalen Touristenzahlen an Destinationen in Schwellenländern voraussichtlich doppelt so schnell ansteigen werden wie in entwickelten Tourismuszielen. Die weltweiten Ausgaben für Reisen haben sich im Einklang dazu zwischen den Jahren 2000 und 2016 von USD 495 Milliarden auf USD 1,2 Billionen mehr als verdoppelt und machen 7\% der weltweiten Exporte von Waren und Dienstleistungen aus (UNWTO, 2017a). In den OECD-Ländern ist der Tourismus für durchschnittlich 4,2\% des BIP, 6,9\% der Arbeitsplätze und 21,7\% der Dienstleistungsausfuhren verantwortlich.

Insgesamt können sich die genannten wichtigsten Megatrends sowohl positiv als auch negativ auf das vorhergesagte Wachstum des Tourismus auswirken. Um auf die genannten Megatrends wirksam reagieren und sich entsprechend anpassen zu können, müssen politische Entscheidungsträger und die Tourismusbranche besser verstehen, worum es sich 
handelt und welche Auswirkungen auf den Tourismus in den kommenden Jahrzehnten zu erwarten sind.

\section{Megatrends sorgen für Wandel im Tourismus}

Wird die wahrscheinliche Entwicklung in den kommenden Jahrzehnten betrachtet, ist klar, dass der Tourismus sich aufgrund grossflächiger gesellschaftlicher, wirtschaftlicher, politischer, umweltbezogener und technologischer Veränderungen wandeln wird. Diese «Megatrends» bilden sich langsam aus. Sobald sie aber an Fahrt gewonnen haben, üben sie einen tiefgreifenden und anhaltenden Einfluss auf menschliche Handlungen, Prozesse und Wahrnehmungen aus.

Megatrends bringen neue und oftmals unvorhergesehene Herausforderungen, Bedrohungen und Chancen mit sich, deren Auswirkungen in der Wirtschaft als Ganzes und in individuellen Sektoren unterschiedlich sein können. Obwohl wir nicht sicher sein können, wie diese Einflüsse den Tourismus verändern, können wir davon ausgehen, dass sich die Struktur dieses Wirtschaftszweigs bis zum Jahr 2040 deutlich weiterentwickeln wird, da i) sich Einkommen und Bildungsstand in den Schwellenländern verbessern, die Weltbevölkerung weiter altert und neue Verbrauchergruppen auf den Plan treten; ii) sich die Weltwirtschaft weiter in Richtung kohlenstoffärmerer Zukunft und Ressourceneffizienz entwickelt; iii) Basistechnologien und Peer-to-Peer/Shared-UsagePlattformen weiterhin neue Märkte und Geschäftsmodelle für den Tourismus erschliessen sowie iv) sich der zu erwartende Anstieg der Besucherzahlen, Sicherheitsfragen, geänderte politische Massnahmen im Hinblick auf einfacheres Reisen, verkehrstechnische Innovationen, Zugangs-Infrastrukturen und flugrechtliche Bestimmungen ausnahmslos auf die Reisemobilität auswirken.

Die Untersuchung und das Verstehen der multidimensionalen Auswirkungen der genannten Megatrends ist für Regierungen und die Tourismusbranche gleichermassen kritisch, wenn es darum geht, fundierte politische Entscheidungen zu treffen und die Zukunft des Tourismus zu gestalten. Nach eingehender Diskussion derartiger Trends wird es politischen Entscheidungsträgern leichter fallen, aktuell unvorhergesehene und aufkommende Themen auf die strategische Agenda der Politik zu setzen, mögliche politische Massnahmen zu entwickeln und den öffentlichen und privaten Akteuren besser beim Umgang mit den sich abzeichnenden Chancen und Herausforderungen zu helfen. 


\section{Sich wandelnde Besuchernachfrage}

\section{Abbildung 1. Wichtige Trends in Bezug auf die sich wandelnde Besuchernachfrage}

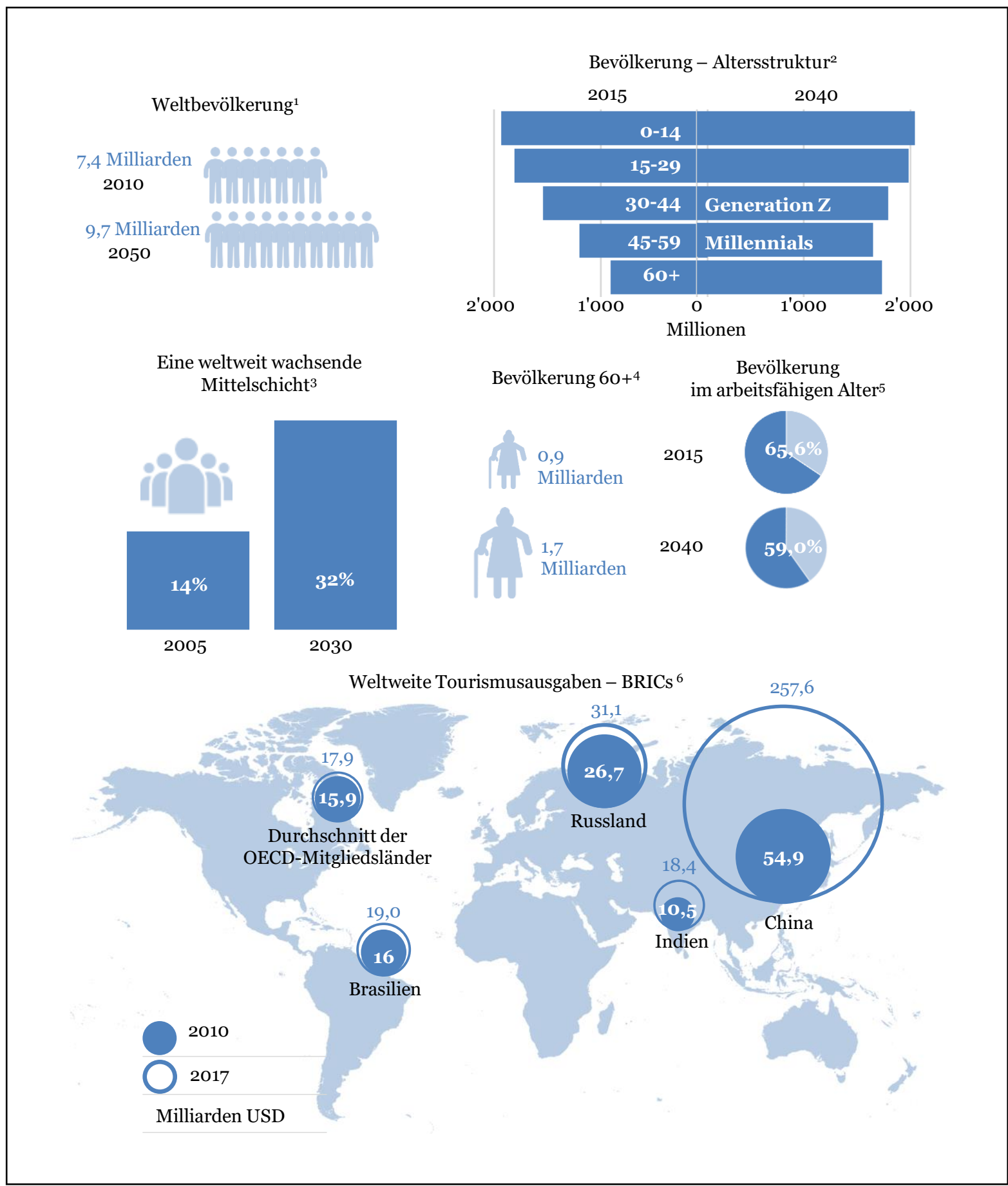

OECD-Infografik, basierend auf verschiedenen Quellen: 1. UN (2017). World Population Prospects; 2. UN (2017); 3. Bussolo et al. (2014); 4. UN (2017); 5. UN (2017); 6. UNWTO (2017a); OECD (2018), Durchschnitt der OECDMitgliedsländer bezieht sich auf die internationalen Tourismusausgaben im Jahr 2016. Einige der Symbole wurden durch Freepik von www.flaticon.com entworfen. 
Die Struktur der Reisewirtschaft wird sich in den nächsten Jahrzehnten mit dem steigenden Einkommens- und Bildungsniveau in den Schwellenländern, dem Abbau von Geschlechterungleichgewichten, der anhaltenden Alterung der Weltbevölkerung und dem Aufkommen neuer Verbrauchergruppen weiterentwickeln. Alle genannten Faktoren wirken sich in Kombination auf die Neigung zu reisen ebenso aus wie auf die Erwartungen der Reisenden. Obwohl sich das Wachstum abschwächt, wird mit einem Anstieg der Weltbevölkerung von 7,4 Milliarden im Jahr 2015 auf 9,7 Milliarden im Jahr 2050 gerechnet, getrieben insbesondere durch die Entwicklungsländer.

Der demografische Wandel wird sich in den kommenden Jahren entscheidend auf die Besuchernachfrage auswirken. Insbesondere führen Trends wie das anhaltende Wachstum der weltweiten Mittelschicht sowie alternde Bevölkerungen dazu, dass die Menschen in den kommenden Jahrzehnten weltweit im Allgemeinen wohlhabender und älter werden. Die immer stärkere Bedeutung heranwachsender Generationen wird zusätzlich dazu beitragen, aktuelle Überlegungen, die den Tourismusmarkt beeinflussen, umzustossen. Tatsächlich werden Millennials und die Generation $\mathrm{Z}$ die Mobilität massgeblich bestimmen. Ihr Reiseverhalten könnte zu signifikanten Verschiebungen auf dem Tourismusmarkt führen.

Infolge dieser Trends wird sich nicht nur die Art und Weise des Reisens ändern, auch die Bedürfnisse und Anforderungen werden sich sehr von denen im heutigen Tourismus unterscheiden. Dies eröffnet künftig neue Chancen und führt zu neuen Herausforderungen sowie einer wahrscheinlichen Abkehr von der heutigen im Wesentlichen westlich geprägten Einstellung zu Reisen, Urlaub und den dazugehörigen Verhaltensweisen (Kyyrä und Rantala, 2016).

Die Welt erlebt derzeit insbesondere wegen des zunehmenden Wohlstands in den Schwellenländern ein signifikantes und schnelles Wachstum der weltweiten Mittelschicht. Die grosse Zunahme der Kaufkraft und des Konsums der Mittelschicht wird in den kommenden Jahren wahrscheinlich eine massgebliche Rolle für die Weltwirtschaft spielen. Tatsächlich besagen Schätzungen, dass in nur wenigen Jahren die Mehrheit der Weltbevölkerung zur Mittelschicht zu zählen sein wird (Kharas, 2017). Die Mittelschicht wächst aber nicht nur, sie wächst auch schnell.

Dieser Trend wird weitreichende Auswirkungen haben, insbesondere aufgrund der zunehmenden Kaufkraft dieser wachsenden Bevölkerungsgruppe. Die Kombination dieses Wachstums mit technologischen Fortschritten führt dazu, dass die Angehörigen der Mittelschicht weltweit grösseren Zugang zu Waren und Dienstleistungen haben werden.

Trotz des schnellen Wachstums der weltweiten Mittelschicht werden in den kommenden Jahrzehnten aber reichlich Herausforderungen zu Tage treten. So könnte sich zum Beispiel der Wegfall von Arbeitsplätzen aufgrund von Technologie und Automatisierung erheblich auf die Anzahl der zur Mittelschicht zu zählenden Menschen auswirken (Bremmer, 2016). Tatsächlich könnte die Ungleichheit innerhalb dieser grossen Bevölkerungsgruppe wachsen.

Ausserdem sind die Wachstumstrends in verschiedenen Teilen der Welt unterschiedlich. Für die schnell wachsende Mittelschicht sind insbesondere die Schwellenländer verantwortlich. In den Industrieländern wird das Wachstum weitaus geringer ausfallen. In manchen westlichen Ländern ist es sogar zum Erliegen gekommen oder ist negativ. Da die Mittelschicht in den Entwicklungsländern wächst, werden diese Teile der Welt eine immer wichtigere Rolle als Herkunftsmärkte für den weltweiten Tourismus spielen. 
Eine weitere wachsende Bevölkerungsgruppe sind ältere Menschen. Die Gründe liegen sowohl in einer höheren Lebenserwartung als auch im Rückgang der Geburtenraten (ESPAS, 2015). Aufgrund der alternden Bevölkerungen wird sich der Anteil der Menschen über 60 Jahren an der Weltbevölkerung in den kommenden 35 Jahren wahrscheinlich nahezu verdoppeln, wobei die Zunahme in manchen Regionen höher ist als in anderen. In den nächsten 50 Jahren wird die Bevölkerung in den meisten OECD-Ländern altern. Gleichzeitig wird die Bevölkerung in den Entwicklungsländern, insbesondere in Afrika und Südasien, erheblich wachsen. Die Geburtenraten liegen in vielen Industrieländern, aber auch in manchen grossen Schwellenländern wie China und Brasilien unterhalb des Ersatzniveaus. Zwischen 2010 und 2060 wird die Bevölkerung der OECDLänder voraussichtlich um $17 \%$ wachsen. Gleichzeitig sinkt aber der Anteil der erwerbsfähigen Bevölkerung (Alter 15 bis 64 Jahre) um vielleicht 7\%. Dies könnte zu einem Mangel an Arbeitskräften führen, durch den die steigende Nachfrage im Tourismus nicht gedeckt werden kann (Abbildung 1). Die Alterung der erwerbsfähigen Bevölkerung kann sich negativ auf das langfristige Wachstum auswirken, die Sozialsysteme unter Druck setzen und massgebliche Veränderungen im Konsumverhalten und bei den Investitionsströmen bedingen.

In diesem Rahmen dürften das Angebot und die Menge von Waren und Dienstleistungen, die eher durch ältere Menschen in Anspruch genommen werden, auch im Tourismus substanziell wachsen. Infrastrukturen und unterstuitzende Dienstleistungen werden sowohl an die wachsende Nachfrage als auch an die sich ändernden Bedürfnisse und Vorlieben der Besucher angepasst werden müssen. So ist beispielsweise die Barrierefreiheit (sowohl was den physischen Zugang als auch den Zugang zu Informationen angeht) wahrscheinlich ein Bereich, der für ältere Touristen besonders wichtig ist.

Mit heranwachsenden Generationen sind Bevölkerungsgruppen gemeint, die sich bereits heute abzeichnen. Die Generation Z (geboren in den späten 1990er Jahren bis zu den frühen 2010ern) sowie die Millennials (geboren in den frühen 1980ern bis zu den mittleren 1990ern) werden 2040 wichtige Marktchancen im Tourismussektor bieten.

Beide genannten Bevölkerungsgruppen sind mit Technologie und dem Internet aufgewachsen. Dies wirkt sich stark darauf aus, wie diese Menschen auf verschiedene Tourismusprodukte und -dienstleistungen zugreifen, zwischen ihnen navigieren und mit ihnen interagieren. Tatsächlich ist dies eine im Vergleich zu früheren Generationen wahrscheinlich besonders anspruchsvolle Gruppe, da sie an schnellen und direkten Informationszugriff mittels digitaler Technologie gewöhnt ist. Die Mitglieder dieser Gruppe bevorzugen ausserdem mit grosser Wahrscheinlichkeit eher Individualreisen als frühere Generationen und sind eher offen dafür, Produkte oder Dienstleistungen wie Transportmittel oder Unterkünfte nur vorübergehend zu nutzen oder zu mieten, anstatt sie selbst zu erwerben.

Aus den Veränderungen in diesen Bevölkerungsgruppen mit ihren jeweils sehr spezifischen Reisepräferenzen werden sich unterschiedliche Sachzwänge für Politik und Tourismusbranche ergeben.

Wichtige Fakten und Vorhersagen

Ende des Jahres 2016 gehörten weltweit rund 3,2 Milliarden Menschen zur Mittelschicht. Jährlich kommen rund 150 Millionen Menschen zu dieser Gruppe hinzu, die Mehrheit davon (schätzungsweise 88\%) in Asien (Kharas, 2017). 
Im Jahr 2015 gab die Mittelschicht weltweit USD 35 Billionen aus - rund ein Drittel der gesamten weltweiten Wirtschaftsleistung. Diese Zahl wird sich bis zum Jahr 2030 voraussichtlich nahezu verdoppeln (USD 29 Billionen), wobei jedoch nur USD 1 Billion des Wachstums aus den Industrieländern kommen wird (Kharas, 2017). Andere Vorhersagen deuten darauf hin, dass die schnell wachsende Mittelschicht bis zum Jahr 2030 insbesondere in Asien zu verstärktem Wachstum der grossen Städte führen wird (ESPAS, 2015).

Die Vereinten Nationen (UN) prognostizieren, dass 2050 in fast allen Regionen der Welt ein Viertel der Bevölkerung mindestens 60 Jahre alt sein wird. Derzeit wächst diese Bevölkerungsgruppe um rund 3\% jährlich. 2030 dürfte sie 1,4 Milliarden Menschen umfassen und bis 2050 auf 2,1 Milliarden anwachsen (UN, 2017).

Die Gesellschaften altern weltweit unterschiedlich schnell. So sind beispielsweise in Europa schon heute 25\% der Bevölkerung mindestens 60 Jahre alt. Im Jahr 2050 werden voraussichtlich 35\% dieser Gruppe angehören (UN, 2017). In anderen Teilen der Welt sind weniger dramatische Anstiege zu erwarten.

Forschungen zeigen, dass der Tourismus einer der Hauptprofiteure einer alternden Bevölkerung sein wird, deren Mitglieder im Vergleich zu früheren Generationen eher geneigt sind, freizeitorientierte Erfahrungen zu machen. Tatsächlich wurden touristische Angebote, die sich gezielt an ältere Menschen richten, in der Branche als besonders lukrativ und wachstumsstark erkannt. Im Vereinigten Königreich gaben Personen ab 65 Jahren zwischen 1999 und 2011 beispielsweise GBP 1,3 Milliarden mehr für Auslandsreisen aus, während Menschen zwischen 16 und 34 Jahren ihre Ausgaben im gleichen Zeitraum um GBP 922 Millionen kürzten (Kingman, 2012).

Eine neuere von der Europäischen Kommission in Auftrag gegebene Studie zeigt in ähnlicher Weise das Wachstumspotenzial des barrierefreien Tourismus in Europa. Laut dieser Studie erzeugt die Nachfrage nach barrierefreiem Tourismus durch aus der Europäischen Union kommende Menschen mit speziellen Anforderungen an die Barrierefreiheit derzeit einen wirtschaftlichen Beitrag von insgesamt EUR 394 Milliarden zum BIP der Europäischen Union (3\% des gesamten BIP der EU27 im Jahr 2012). Die Studie geht ausserdem davon aus, dass die Nachfrage bis zum Jahr 2020 um nahezu 44\% steigen und somit zu einem potenziellen Anstieg des Beitrags zur Wirtschaftsleistung von 39\% führen könnte, wenn die Tourismusdestinationen innerhalb der Europäischen Union so verbessert würden, dass ein nahezu barrierefreier Zugang zu Gebäuden, Hotels, Restaurants, Museen und verschiedenen Dienstleistungen möglich wäre (Miller, 2014).

Ein Beispiel hierfür ist das Wachstum bei Mehrgenerationenreisen, an denen oft ganze Familien teilnehmen und die durch ältere Touristen mit hoher Kaufkraft und viel Freizeit angetrieben werden. Rund ein Drittel aller Rentner und Pensionäre haben schon Reisen mit Menschen anderer Generationen unternommen (Age Wave und Merrill Lynch, 2016). Für Destinationen, die für diesen wachsenden Markt in Frage kommen, ist es eine einzigartige Herausforderung, Aktivitäten zu entwickeln und aufeinander abzustimmen, die alle Mitglieder einer solchen Reisegruppe interessieren.

Ein weiteres Nischensegment, das in den kommenden Jahren wahrscheinlich signifikant wachsen wird, ist der Gesundheitstourismus. Da die Kosten für Krankenversicherung und Behandlungen - sei es aus gesundheitlichen oder aus kosmetischen Gründen - in den Industrieländern immer weiter steigen, werden sich in den Schwellenländern attraktive Optionen ergeben. Die Qualität der Ärzte und der Infrastruktur in den Schwellenländern verbessert sich bei gleichzeitig gering bleibenden Kosten im Vergleich zu den 
Herkunftsmärkten. Daher werden Touristen wohl verstärkt in Erwägung ziehen, zu Wellnesszwecken ins Ausland zu reisen und/oder eine medizinische Behandlung mit einer kurzen Auszeit zu verknüpfen (Alén et al., 2015).

Zurzeit entfallen rund 20\% des weltweiten Reiseaufkommens auf Millennials. Sie geben weltweit schätzungsweise USD 203 Milliarden aus. 2040 werden die betreffenden Personen 45 bis 60 Jahre alt sein. Die ältesten Mitglieder dieser Gruppe werden sich dem Ruhestandsalter nähern und in den kommenden 25 Jahren zusätzlichen Wohlstand angesammelt haben. Der Anteil dieser Gruppe an den Gesamtausgaben dürfte daher erheblich steigen.

Bis zu diesem Zeitpunkt wird auch die den Millennials nachfolgende Gruppe, die Generation Z, eine wichtige Kraft auf dem Tourismusmarkt ebenso wie auf dem Arbeitsmarkt sein. Diese Personen sind dann zwischen 30 und 45 Jahre alt. Bereits 2020 wird diese Bevölkerungsgruppe mit 2,6 Milliarden Mitgliedern den grössten Teil der Weltbevölkerung stellen und voraussichtlich die Millennials mit dann schätzungsweise 2,3 Milliarden Mitgliedern ablösen (Weinswig, 2016). Angesichts des zu erwartenden Anstiegs der Tourismusnachfrage aus den asiatischen Schwellenländern werden junge Reisende aus diesem Teil der Welt eine wichtige Zielgruppe bilden.

Die Daten deuten darauf hin, dass Millennials jährlich öfter verreisen als andere Generationen - mit vier oder mehr Reisen jährlich. Allerdings sind ihre Reisen im Vergleich zu denen anderer Bevölkerungsgruppen tendenziell kürzer (Globetrender, 2017). Darüber hinaus wählen die Betreffenden eher Reiseerlebnisse, die sie als «authentisch» ansehen. Sie bevorzugen Reisen fernab der ausgetretenen Pfade und möchten «leben wie die Einheimischen» (Future Foundation, 2016).

Eine durch Airbnb durchgeführte Studie ergab, dass Reisen für viele Millennials wichtiger sind als andere Prioritäten, einschliesslich des Wohnungs- oder Autokaufs. Für Millennials, die in den Vereinigten Staaten, dem Vereinigten Königreich und China befragt wurden, waren neue Erfahrungen ausserdem wichtiger als Eigentum (Airbnb, 2016). Kombiniert man dies mit der selbstverständlichen Nutzung digitaler Technologien durch diese Gruppe, ist davon auszugehen, dass die Betreffenden eher eigene Reisen zusammenstellen, anstatt sich auf die Beratung von Reisebüros zu verlassen oder Pauschalreisen zu buchen.

\section{Implikationen für den Tourismussektor}

Alle genannten demografischen Faktoren weisen auf erhebliche Wachstumschancen für den Tourismussektor hin. Mit der Bevölkerungsalterung treten mehr Menschen in den Ruhestand und sind eher bereit, Einkommen und Ersparnisse für Freizeitaktivitäten wie Reisen auszugeben. Das Wachstum der Mittelschicht insgesamt wird in ähnlicher Weise dazu führen, dass mehr Menschen bereit sind, Geld für Luxusgüter wie den Tourismus auszugeben.

Obwohl das weltweite Wachstum der Mittelschicht erhebliches Potenzial für ein Wachstum des Tourismus birgt, kann die Zukunft auch Herausforderungen bereithalten. Da die Mittelschicht in asiatischen Ländern am deutlichsten wächst, wird die Nachfrage nach Reisen und Tourismusangeboten wohl auch dort am stärksten steigen. Die Tourismusbranche könnte jedoch gezwungen sein, potenziell kollidierende Interessen zu berücksichtigen, da das schnelle Wachstum in den Schwellenländern im Kontrast zu einem langsamen Wachstum in den Industrieländern steht (Kharas, 2017).

Darüber hinaus ist das Wachstum der Mittelschicht möglicherweise nicht stabil, da der aktuelle Wachstumspfad durch geopolitische oder makroökonomische Instabilitäten 
beeinflusst werden könnte. Gleichzeitig könnten die Automatisierung und neu entstehende Technologien die Wachstumsmuster und Erwartungen verändern. Regierungen und Tourismusbranche müssen die betreffenden Signale weiterhin beobachten, deren wahrscheinliche Auswirkungen bewerten und ihre langfristigen Strategien und Zielmärkte gegebenenfalls anpassen.

Angesichts der alternden Weltbevölkerung ist der nahtlose Transport zum Zielort ebenso wie am Zielort selbst (einschliesslich der Herausforderung der «ersten» und der «letzten» Meile - der Beförderung des Reisenden von seinem Zuhause bis zum Flughafen, Seehafen oder Bahnhof und dann vom Ankunftsort bis zum endgültigen Reiseziel) ein strategischer Aspekt, dessen Berücksichtigung immer wichtiger wird. Die tourismusrelevante Infrastruktur, die Beförderungsmittel sowie die Bereitstellung von Informationen müssen sorgfältig gestaltet und betrieben werden, um einer immer grösseren Zahl von Kunden mit eingeschränkter Mobilität und begrenzten Kommunikationsmöglichkeiten Rechnung zu tragen und es diesen Personen zu gestatten, sich zuversichtlich am Zielort zurecht zu finden. Der Begriff «universelles Design» steht in Zusammenhang mit Mobilität für Verkehrssysteme, die für Menschen mit verschiedenen Fähigkeiten/Einschränkungen und Bedürfnissen gleichermassen ausgelegt sind. Mit Übernahme eines entsprechenden Ansatzes können potenzielle Tourismusmärkte auf Personen mit speziellen Bedürfnissen erweitert werden, während Reisende ohne Mobilitätseinschränkung gleichermassen zufrieden gestellt werden. So kommen Rampen für Touristen mit eingeschränkter Beweglichkeit und Rollstuhlfahrer beispielsweise ebenso Reisenden mit Rollkoffern oder Eltern mit Kinderwagen zugute.

Obwohl die Kaufkraft der älteren Bevölkerungsgruppen in den kommenden Jahrzehnten voraussichtlich hoch bleiben wird (Dobbs et al., 2016), könnte sich die derzeitige Entwicklung ändern, falls sich die Lage am Arbeitsmarkt destabilisieren und das Ruhestandsalter in bestimmten Ländern weiter angehoben werden sollte. Dies könnte zu einer stärkeren Spreizung der Kaufkraft innerhalb jener Personengruppe führen, die sich im Jahr 2040 dem Ruhestand nähert. Um den sich entwickelnden Bedürfnissen und ändernden Erwartungen dieser Gruppe wirkungsvoll gerecht werden zu können, wird es entscheidend auf Flexibilität ankommen.

Für die Reiseentscheidungen älterer Touristen können viele Faktoren eine Rolle spielen. Beispielsweise werden Personen, die noch berufstätig sind, ihre Urlaubsreisen eher abhängig von den finanziellen Mitteln und der Zeit planen, die ihnen zur Verfügung stehen. Personen, die bereits im Ruhestand sind, machen ihre Planung dagegen eher von ihrem Gesundheitszustand abhängig (Alén et al., 2015). Daraus ergibt sich auch, dass Menschen, die über das traditionelle Ruhestandsalter hinaus arbeiten müssen, kaum allein auf Grundlage ihrer Gesundheit über eine Reise entscheiden werden. 


\section{Kasten 1. Marketing für chinesische Reisende in Neuseeland}

Neuseeland ist bereits von einigen Auswirkungen der sich wandelnden Besuchernachfrage betroffen. Für Neuseeland ist China mittlerweile der am schnellsten wachsende und insgesamt zweitgrösste Herkunftsmarkt. Das neuseeländische Ministry of Business, Innovation and Employment (Wirtschafts-, Innovations- und Arbeitsministerium) geht davon aus, dass sich die Anzahl chinesischer Reisender zwischen 2017 und 2023 auf voraussichtlich 913'000 Besucher verdoppeln wird, die schätzungsweise NZD 4,3 Milliarden jährlich ausgeben werden. Im Zuge dieses Trends entwickelte Neuseeland Massnahmen, die der Tourismusbranche helfen sollen, den Zustrom chinesischer Reisender zu steuern.

So veranlasste die Regierung im Jahr 2012 eine Untersuchung des chinesischen Marktes. Eines der Ergebnisse dieser Untersuchung war die Forderung nach Entwicklung eines landesweiten Toolkits, um es den «neuseeländischen Unternehmen und Destinationen zu ermöglichen, ihre Servicelevel schneller an die chinesischen Besucher anzupassen». Tourism New Zealand übernahm die Führungsrolle bei der Anwendung dieses Toolkits, das durch die Regierung, Tourismus-Branchenverbände und den privaten Sektor getragen wird. Tourism New Zealand entwickelt im Rahmen seiner Arbeit Schulungen und Networking-Veranstaltungen mit verschiedenen Branchensegmenten.

Die Bemühungen der Regierung erstrecken sich auch auf eine Verschiebung des Schwerpunkts weg von Reisegruppen und hin zu Individualreisenden. Angesichts dieser Verschiebung gab das Wirtschafts-, Innovations- und Arbeitsministerium im Jahr 2015 das China Visitor Insight Program in Auftrag, das innerhalb der Tourismusbranche zu einem besseren Verständnis der Bedürfnisse und Vorlieben von Individualreisenden aus China beitragen soll. Das Programm beinhaltet Webinare und Online-Dienste zu Themen wie der Entwicklung von für diesen Markt spezifischen Produkten sowie entsprechender Präsenz in den sozialen Medien. Es konzentriert sich auf Marketing für Individualreisende, die mutmasslich länger bleiben und grössere Reisestrecken zurücklegen. An den Workshops im Rahmen dieser Bemühungen haben bereits über 1000 Tourismusanbieter teilgenommen. Darüber hinaus ergreift die Regierung Massnahmen, um chinesische Reisende ausserhalb der Spitzenzeiten ins Land zu locken und ihnen gezielt neue und aufstrebende Reiseziele innerhalb von Neuseeland anzubieten.

Als weitere Unterstützung für Reisende aus China hat die neuseeländische Regierung die Einreise aus diesem Land erleichtert, indem beispielsweise der Zeitrahmen für mehrfach verwendbare Einreisevisa für chinesische Besucher verlängert wurde und diese Reisenden an der Grenze beschleunigt abgefertigt werden.

Quelle: Ministry of Business, Innovation \& Employment, Neuseeland

Trotz des zu erwartenden Anstiegs des Marktes für über 60-Jährige in den kommenden Jahren werden die Millennials, die Generation Z und weitere heranwachsende Generationen 2040 die Mehrzahl der inländischen und internationalen Touristen stellen. Ein immer grösserer Anteil dieser Reisenden wird zur Mittelschicht gehören und aus Schwellenländern kommen. Neuere Studien haben beispielsweise ergeben, dass Millennials aus China - wo die Mittelschicht ganz erheblich gewachsen ist - mehr Wert auf Reisen legen als Millennials aus anderen Ländern (Airbnb, 2016). Der Tourismussektor wird sich an diese Trends anpassen und innovative Ansätze entwickeln müssen, um neuen Anforderungen und spezifischen Vorlieben innerhalb dieser individuellen Gruppen gerecht 
zu werden. Ein Beispiel hierfür ist die neuseeländische Marketingstrategie, mit der das Land der wachsenden Bedeutung Chinas als Herkunftsmarkt Rechnung trägt (Kasten 1).

Die grosse Bedeutung heranwachsender Generationen und ihrer Vorlieben für einzigartige, individuelle und nachhaltige Reiseerlebnisse könnten $\mathrm{zu}$ einer Abkehr vom traditionelleren, von Sonne, Meer, Sand und Attraktionen geprägten Tourismus führen. Die Generation $\mathrm{Z}$ beispielsweise scheint bei ihren Reiseentscheidungen stark von sozialen Medien und den Empfehlungen Gleichgesinnter beeinflusst zu werden. Mitglieder dieser Generation sind daran interessiert, im Urlaub Risiken einzugehen und einmalige Erfahrungen zu machen, mögen aber auch Reisen, die ganz auf Entspannung abzielen (Globetrender, 2017). Auch wenn dieser Risikoappetit mit nahendem Ruhestandsalter der Generation $\mathrm{Z}$ abnehmen dürfte, werden nachfolgende Generationen diese Vorliebe wahrscheinlich übernehmen.

Um diese sich wandelnden Trends für sich nutzen zu können, müssen die Entscheidungsträger in Politik und Tourismusbranche darüber nachdenken, wie sie die Reisenden wirksamer beeinflussen und gegebenenfalls an abgelegenere Reiseziele heranführen können, an denen ihnen vielfältige und individuelle Erlebnisse ausserhalb der traditionellen Tourismusdestinationen angeboten werden. Dies käme auch der soziokulturellen und wirtschaftlichen Entwicklung der lokalen Gemeinden zugute.

Die Reisebereitschaft und/oder -fähigkeit der Mitglieder dieser Gruppen könnte 2040 allerdings durch mangelnde Kaufkraft beeinträchtigt werden, da die wirtschaftlichen Umstände es ihnen allgemein schwer gemacht haben, ebenso einfach wie frühere Generationen Wohlstand zu erwerben (Dobbs et al., 2016). Tatsächlich wurden die Millennials durch die weltweite Rezession schwer getroffen, die ihre berufliche Entwicklung behindert hat. Heute sehen sie sich einer sich verändernden Arbeitswelt gegenüber, die oft prekär und zunehmend automatisiert ist. Hinzu kommt eine ganz allgemein grössere Ungleichheit. Diese sich ändernden Umstände können auch bis zu einem gewissen Grad den Trend hin zu kürzeren Reisen und die wachsende Beliebtheit preiswerterer Reisemöglichkeiten wie Billigfluglinien, Mitwohn- und Mitfahrplattformen, Hostels usw. erklären. In die Bewertung der Reisevorlieben heranwachsender Generationen in den kommenden Jahrzehnten müssen all diese Überlegungen einfliessen.

\section{Kritische Unsicherheiten}

Wenn strategische Vorhersagen getroffen und beispielsweise Szenarien ausgearbeitet werden sollen, müssen zunächst mögliche Wendepunkte beachtet werden, an denen sich der Verlauf der betreffenden Trends ändern kann. Im Folgenden ist eine Reihe kritischer Unsicherheiten aufgeführt, die die erwartete Entwicklung der Besuchernachfrage bis zum Jahr 2040 verändern können:

- Es ist nicht sicher, ob die weltweite Mittelschicht tatsächlich nachhaltig wächst. Technologien und Automatisierung könnten sich negativ auf die Arbeitsmärkte der Schwellenländer auswirken und potenziell zu grösserer Ungleichheit und geringerer Kaufkraft vieler Menschen führen. Unvorhersehbare geopolitische und makroökonomische Umstände könnten die Nachfrage nach Tourismusangeboten weiter dämpfen.

- Das schnelle Wachstum der Schwellenländer und ihrer Mittelschichtbevölkerungen könnte infolge des Gegensatzes zum langsamen Wachstum in den Industrieländern zu unausgeglichenen Angebots- und Nachfragesituationen führen. 
- Das Anwachsen älterer Bevölkerungsgruppen insbesondere in den OECD-Ländern könnte zu Arbeitskräftemangel führen, durch den sich die wachsende Nachfrage im Tourismus nicht decken liesse und der das langfristige Wachstum beeinträchtigen könnte. Auch Anhebungen des Rentenalters, um Engpässe am Arbeitsmarkt zu überwinden, könnten die Tourismusnachfrage negativ beeinflussen.

- Obwohl zu erwarten ist, dass die Senioren in den kommenden Jahren ihre Ausgaben steigern und die Nachfrage nach Tourismusprodukten beflügeln werden, könnte dieser Trend durch Unsicherheiten über die künftige Rentenentwicklung beeinträchtigt werden. Ausserdem ist unklar, welchen Einfluss eine instabile berufliche Situation und unsichere wirtschaftliche Umstände auf die Tourismusausgaben der Millennials und der Generation Z haben werden.

\section{Plausible Zukunftsszenarien}

Dieser Absatz untersucht auf Grundlage der genannten kritischen Unsicherheiten die drei plausiblen Zukunftsszenarien, die die sich wandelnde Besuchernachfrage bis zum Jahr 2040 beeinflussen könnten.

\section{Das Aufkommen des geizigen Touristen}

- Der weltweite demografische Wandel hat zu einem deutlichen Nachfragerückgang im Tourismusbereich geführt. Häufige wirtschaftliche Rezessionen und eine Periode allgemein schwachen makroökonomischen Wachstums haben die Kaufkraft gesenkt, Innovationen behindert und Protektionismus hervorgebracht.

- Die westlichen Volkswirtschaften haben aufgrund alternder Bevölkerungen und mangelnder wirtschaftlicher Entwicklung stagniert. Die rapide voranschreitende Überalterung der Gesellschaft hat zu akutem Arbeitskräftemangel, auch in der Tourismusbranche, geführt. In vielen Ländern wurde das Ruhestandsalter angehoben, um den Arbeitsmarkt zu entlasten. Der spätere Ruhestand hat die Tourismusbranche aufgrund der geringeren Nachfrage durch Rentner und Pensionäre zusätzlich geschwächt.

- Bei jungen Reisenden sieht die Situation ähnlich düster aus. Immer mehr kurzfristige Jobs und prekäre Beschäftigungsverhältnisse sowie weltweite Ungleichheit erschweren es den Millennials und der Generation Z zunehmend, Wohlstand $\mathrm{zu}$ erwerben. Wegen ihres geringeren Einkommens und fehlender Ersparnisse sind diese Gruppen preisbewusster und haben nur wenig Kaufkraft für Reisen zur Verfügung.

- Obwohl die Wirtschaft in den Schwellenländern gewachsen ist, besitzt die neue weltweite Mittelschicht, die weitestgehend aus Menschen aus Asien besteht, im Vergleich zu Reisenden aus den traditionellen Industrieländern weniger Kaufkraft. Dieser insgesamt relativ begrenzte Wohlstand der Verbraucher mindert die Nachfrage nach personalisierten und hochwertigen Tourismuserlebnissen.

\section{Das Zeitalter futuristischer Reisender}

- Weltweit wachsender wirtschaftlicher Wohlstand, insbesondere infolge des Wachstums der Mittelschicht in den Schwellenländern, hat die Nachfrage nach Tourismusangeboten angeheizt und in der Branche zu schnellen Innovationen geführt. 
- Reisende aus verschiedenen Bevölkerungssegmenten suchen aktiv nach vielfältigen und individuellen Reiseerlebnissen. Um den verschiedenartigen Wünschen dieser Reisenden nachzukommen, hat sich die Branche weiterentwickelt und bietet älteren Menschen, Abenteurern sowie generationenübergreifenden Familien und verschiedenen kulturellen Gruppen jeweils eigene Optionen zu unterschiedlichen Preisen an. Darüber hinaus können die Reisenden individuelle, für ihre spezifischen Interessen massgeschneiderte Erlebnisse zusammenstellen.

- Um das Potenzial der wachsenden Reisenachfrage aus den asiatischen Mittelschichten zu maximieren, arbeiten asiatische und westliche Reiseunternehmen immer stärker zusammen, um den Markt zum Nutzen sowohl der Reisenden als auch der Unternehmen voll zu erschliessen. Möglich wurden solche Kooperationen aufgrund einer bisher unerreichten geopolitischen Stabilität.

- Hinsichtlich des «universellen Designs» wurden grosse Fortschritte erzielt. Barrierefreiheit und Inklusion sind zu wichtigen Aspekten bei der Schaffung neuer Einrichtungen und Erfahrungen geworden. Dies war entscheidend, um die Bedürfnisse sehr vielfältiger Reisender aus verschiedenen Altersgruppen mit unterschiedlichen Fähigkeiten/Einschränkungen und Vorlieben zu befriedigen. Auch Informationen sind in vielen verschiedenen Sprachen leichter zugänglich und können abhängig von den Bedürfnissen der verschiedenen Touristengruppen spezifisch angepasst werden.

\section{Weiter auf dem Pfad inkrementeller Innovationen}

- Die neue weltweite Mittelschicht aus den Schwellenländern sowie die alternden Bevölkerungsgruppen aus den Industrieländern haben zu verstärkter Nachfrage nach Tourismusangeboten geführt.

- Während ältere Reisende mehr Mittel erübrigen und sich hochwertige Erlebnisse leisten können, haben die Millennials und die Generation $\mathrm{Z}$ weniger verfügbares Einkommen und sind preisbewusster. Obwohl ausserdem den Mitgliedern der weltweiten Mittelschicht mehr Geld zur Verfügung steht, das sie für Tourismus ausgeben können, sind sie nicht so wohlhabend wie die Mitglieder der Mittelschicht aus den traditionell entwickelten Ländern. Um den unterschiedlichen Profilen dieser Gruppen von Reisenden gerecht zu werden, versucht die Tourismusbranche, sich schnell anzupassen und unterschiedlich bepreiste Produkte und Erlebnisse zu entwickeln, die den vielfältigen Erwartungen entsprechen.

- Die gewachsene Tourismusnachfrage hat auch zu stärkerem Wettbewerb in der Branche geführt, der die Auswahl vergrössert und die Produkte für die Verbraucher preiswerter gemacht hat. Auch die Technologie hat sich weiterentwickelt und zu bewussterem Verhalten und mehr Wettbewerb geführt: Die Reisenden können ihre Reisen nun aus unterschiedlichen Optionen individuell zusammenstellen. Insbesondere jüngere Reisende suchen und wählen ihre Reiseoptionen gerne online. Obwohl sich die Mobilität insgesamt erhöht hat, bleiben geopolitische Umstände wie die persönliche Sicherheit und eingeschränkte Visavergabe zentrale Überlegungen für die Auswahl von Reisezielen durch die Verbraucher.

- Überbordender Tourismus wird insbesondere für die beliebtesten Reiseziele zu einem immer kritischeren Problem. Die Tourismusbranche wie auch politische Entscheidungsträger stehen vor der ständigen Herausforderung, Lösungen für 
dieses Problem zu finden, um die Lebensqualität der Einheimischen zu schützen und nachhaltiges Wirtschaften zu ermöglichen.

- Im Jahr 2040 sind Informationen in den verschiedensten Sprachen einfacher zu erhalten als je zuvor. Dies hilft Reisenden aus fremden Ländern. Trotz Fortschritten bei der Barrierefreiheit und Inklusion an Tourismuszielen bleibt noch Potenzial für weitere Innovationen in diesem Bereich, um Reiseangebote zu schaffen, die rundum barrierefrei und gastfreundlich sind.

\section{Analyse der Szenarien}

Die zu erwartende Zunahme des internationalen Reiseverkehrs und die wachsende Tourismusnachfrage in den kommenden Jahren - insbesondere in Verbindung mit technologischen Weiterentwicklungen - werden zu einer Reihe von Problemfeldern in Zusammenhang mit digitaler Kompetenz, Inklusion und Barrierefreiheit führen. Werden beispielsweise alle Mitglieder der Gesellschaft ausreichend digital versiert sein, um die auf uns zurollende Welle technologischer Innovationen voll für sich zu nutzen, oder werden bestimmte Untergruppen der Bevölkerung bei dieser Revolution im Abseits stehen? Können wir alle Verbraucher im Tourismusbereich auf die gleiche Weise ansprechen oder benötigen manche Gruppen, wie zum Beispiel ältere Menschen, zusätzliche Unterstützung?

Eine wichtige Frage, die wir uns stellen müssen, ist, wie im Interesse von Verbrauchern unterschiedlichen Alters, mit unterschiedlichen Vorlieben und kulturellen Hintergründen für Barrierefreiheit und Inklusion gesorgt werden kann. Aus der Bevölkerungsalterung ergibt sich, dass viele ältere Reisende mit eingeschränkter Beweglichkeit zu kämpfen haben und Unterstützung benötigen werden ${ }^{4}$. Gleichzeitig nimmt der Tourismus infolge der wachsenden Mittelschicht in den Schwellenländern zu. Beide Entwicklungen erfordern erhebliche Investitionen in unterstützende Infrastruktur (z. B. Unterkünfte, barrierefreie Verkehrsmittel, verständliche Beschilderung und Kommunikationsmittel). Es ist wichtig festzuhalten, dass kulturell bedingte unterschiedliche Vorlieben zwischen asiatischen sowie europäischen und nordamerikanischen Touristen auch bestimmend für die Wahl bevorzugter Reiseziele und die wahrgenommene Authentizität der jeweiligen Reisen sein könnten. Weitere Fragen ergeben sich aus dem Zusammenhang zwischen wachsender Tourismusnachfrage und nachhaltigem Tourismus und den daraus möglicherweise erwachsenden Konflikten.

Sollten die Touristen jedoch aufgrund wirtschaftlicher und demografischer Entwicklungen finanziell unter Druck geraten - und ihr Reiseverhalten deswegen ändern -, könnte es in der Tat zu einem Rückgang des weltweiten Tourismus kommen. Wird der traditionelle Tourismus für viele Menschen unerschwinglich, ist es wahrscheinlich, dass sie im Allgemeinen weniger Fernreisen buchen und sich stattdessen auf weniger kostenintensive inländische oder regionale Erlebnisse konzentrieren. Ausserdem könnte das Interesse an «virtuellen Reisen» zunehmen, die durch Technologien für virtuelle und erweiterte Realität möglich werden und reale Reisen ersetzen. Andererseits könnten Technologien auch zu mehr Reisen führen: Erlebnisse in der virtuellen Realität könnten als Hilfsmittel für die Vermarktung von Reisezielen eingesetzt werden, anstatt die Reisen zu diesen Zielen zu

4 Deutschland begegnet diesem Problem mit dem bundesweiten Kennzeichnungs- und Zertifizierungssystem „Reisen für Alle“ für barrierefreie touristische Angebote entlanf der touristischen Leistungskette. Mit «Discover Germany - BarrierFree» bietet die Deutsche Zentrale für Tourismus umfassende und behindertengerechte Online-Informationen für Reiseinteressierte an.. 
ersetzen. Reisende, die ihre Ressourcen sparsam einsetzen möchten, könnten mit den Echtzeit-Informationen dieser Plattformtechnologien ihre Reisen so anpassen, dass sie zu einem spezifischen Budget passen.

Personalisierte und authentische Reisen könnten zu attraktiven preisgünstigen Optionen für all jene werden, die weniger verfügbares Einkommen für Reisen aufwenden können. Touristen könnten eher bereit sein, herausfordernde oder unbequeme Reisebedingungen wie überfüllte Verkehrsmittel, gemeinsam genutzte Unterkünfte oder Flüge mit vielen Zwischenstopps hinzunehmen. Hochwertige Unterkünfte könnten für die Menschen weniger wichtig werden, und sie könnten die Unterkunft nur als einen Ort zum Schlafen sehen. Sie würden dann in Hostels oder sehr preiswerten Hotels übernachten und sich im Ausgleich eher Tagesaktivitäten wie dem Ausgehen oder anderen Erlebnissen widmen. Tourismusanbieter könnten darauf reagieren, indem sie die Öffnungszeiten bestimmter Attraktionen verlängern und ihre Marketingmassnahmen für Hostels, Bahnreisen und andere preiswerte Optionen modernisieren. Diese Personalisierung könnte auch besonders spezialisierte Reisevorlieben begünstigen, etwa Radfahrer oder Läufer (z. B. jene, die an Rennen im Ausland oder an organisierten Touren teilnehmen) oder aber Gourmands (d. h. Personen, die besonders gerne essen und trinken). Grösseres Wissen über die betreffenden Gruppen und ihre Reisepräferenzen wird für die Anbieter von Waren und Dienstleistungen in der Tourismusbranche immer wichtiger werden.

Ein Szenario, in dem die Verbraucher die Früchte digital bedingter Veränderungen ernten, würde das Reisen in der Tat schnell und gastfreundlich machen, auch wenn die Touristen wahrscheinlich bald sofortigen Zugang zu allen Waren und Dienstleistungen erwarten würden - einschliesslich Reservierungen, Attraktionen, virtueller Realität und anderer Optionen. Ausserdem wirft die erwartete Vorliebe heranwachsender Generationen für die Personalisierung ihrer Reiseerlebnisse, die mittels neuer digitaler Plattformen möglich wird, auch Fragen des Datenschutzes auf.

Während der demografische Wandel und neue Verbraucherpräferenzen digitale Erlebnisse zu einem grossen Erfolg machen könnten, ist es auch möglich, dass sie zu einem Nachfrageschub bei «analogen» Erfahrungen im echten Leben führen, die Technologie nicht ersetzen kann. Es gibt beispielsweise bereits Startup-Unternehmen, die Abendessen und Nachtleben gemeinsam mit Einheimischen anbieten. Man könnte sich ein breites Spektrum von Erlebnissen des «digitalen Entzugs» vorstellen, mit dem die Reisenden der Forderung nach ständiger Online-Erreichbarkeit und -Präsenz entgehen möchten. Beispielsweise werden Campingausflüge ins Hinterland, Hiking auf abgelegenen Inseln mit eingeschränktem Mobiltelefonempfang und Aufenthalte in Klöstern bereits jetzt als alternative Urlaubsvarianten, bei denen man sich «ausklinken» und wirklich entspannen kann, immer beliebter (National Geographic, 2017).

In diesem Fall wird menschliche Arbeit in der Zukunft des Tourismus aufgewertet werden müssen. Professionelle Reiseführer werden beispielsweise die Qualität ihrer Leistung verbessern müssen, um das Reiseerlebnis ihrer Kunden aufzuwerten, anstatt lediglich Informationen anzubieten. Auch eine Nachfrage nach spezialisierten Beratern, die vor dem Hintergrund bestimmter persönlicher Interessen Einblicke in besonders interessante Aspekte eines bestimmten Reiseziels bieten, könnte sehr wahrscheinlich sein und würde neue Arbeitsplätze im Tourismussektor schaffen. Bedenken hinsichtlich eines Stellenabbaus im Tourismus aufgrund der Bevölkerungsalterung und von Automatisierungstechnologien könnten durch diese Nachfrage in einem derartigen Szenario teilweise gegenstandslos werden. 
Mögliche politische Massnahmen

1. Die Entscheidungsträger auf allen Regierungsebenen sollten zum Ausgleich eines drohenden Ungleichgewichts zwischen Angebot und Nachfrage ihre Investitionsstrategien innerhalb der einzelnen Reiseziele sowie reisezielübergreifend überdenken, wobei von einem deutlichen Wachstum der Tourismusnachfrage auszugehen ist. Für die Regierungen sollten die Förderung strategischer Investitionen und eine langfristige Planung der physischen Infrastruktur Vorrang haben. Die betreffenden Strategien sollten allerdings facettenreich sein und auch andere Aspekte von Reisezielen beachten, die bei schnell wachsender Tourismusnachfrage unter Druck geraten könnten.

2. Die politischen Entscheidungsträger und die Tourismusbranche sollten wegen der in vielen Teilen der Welt alternden Bevölkerungen Vorbereitungen für eine wachsende Nachfrage von älteren Touristen treffen. Aus Regierungssicht sollte sich diese Vorbereitung weitgehend auf Anforderungen an die Barrierefreiheit und auf Infrastrukturinvestitionen konzentrieren, mit denen Personen mit eingeschränkter Beweglichkeit, körperlichen Behinderungen und kognitiven Einschränkungen unterstützt werden können. Ausserdem sollten Möglichkeiten erkundet werden, wie auch im Digitalzeitalter im digitalen Bereich unterschiedlich versierte Besucher angesprochen werden können.

3. Die politischen Entscheidungsträger und die Tourismusbranche sollten vor dem Hintergrund der $\mathrm{zu}$ erwartenden Zunahme der Anzahl Reisender aus Schwellenländern gemeinsam umfassende Strategien zur Förderung des interkulturellen Verständnisses und Bewusstseins entwickeln. Das Bemühen um interkulturelles Verständnis sollte auch die Bereitstellung von Informationen in anderen Sprachen sowie Technologien einschliessen, mit denen EchtzeitÜbersetzungen möglich sind.

4. Die Destinationen sollten überdenken, wie Reiseerlebnisse verpackt und vermarktet werden, da sich der demografische Wandel wahrscheinlich dramatisch auf die Art und Weise der Wahl von Reiseziel und Reiseerlebnis auswirken wird. Dabei wäre insbesondere auf jüngere Reisende und heranwachsende technisch versierte Generationen zuzugehen. Innovative digitale Kampagnen unter Einbezug sozialer Medien, um den Austausch von Reiseerfahrungen zu fördern, werden immer wichtigere Bestandteile von Marketingstrategien in der Tourismusbranche werden.

5. Auch Möglichkeiten, authentische und personalisierte Reiseerlebnisse zu entwickeln und $z \boldsymbol{u}$ bewerben, sollten durch Regierung und Reisebranche gemeinsam wahrgenommen werden. Einzigartige Erlebnisse ausserhalb der ausgetretenen Pfade von normalen Hotelunterkünften und hochstrukturierten geführten Ausflügen werden im Zuge der Suche der Menschen nach «Low-Tech»und authentischen Erfahrungen wahrscheinlich immer beliebter werden. Bei der Vermittlung dieser Möglichkeiten kann Technologie eine entscheidende Rolle spielen. Technologiebasierte Plattformen, die sich in diesem Bereich engagieren, könnten wertvolle Partner sein. 


\section{Nachhaltiges Wachstum des Tourismus}

\section{Abbildung 2. Wichtige Entwicklungen in Zusammenhang mit einem nachhaltigen Wachstum des Tourismus}

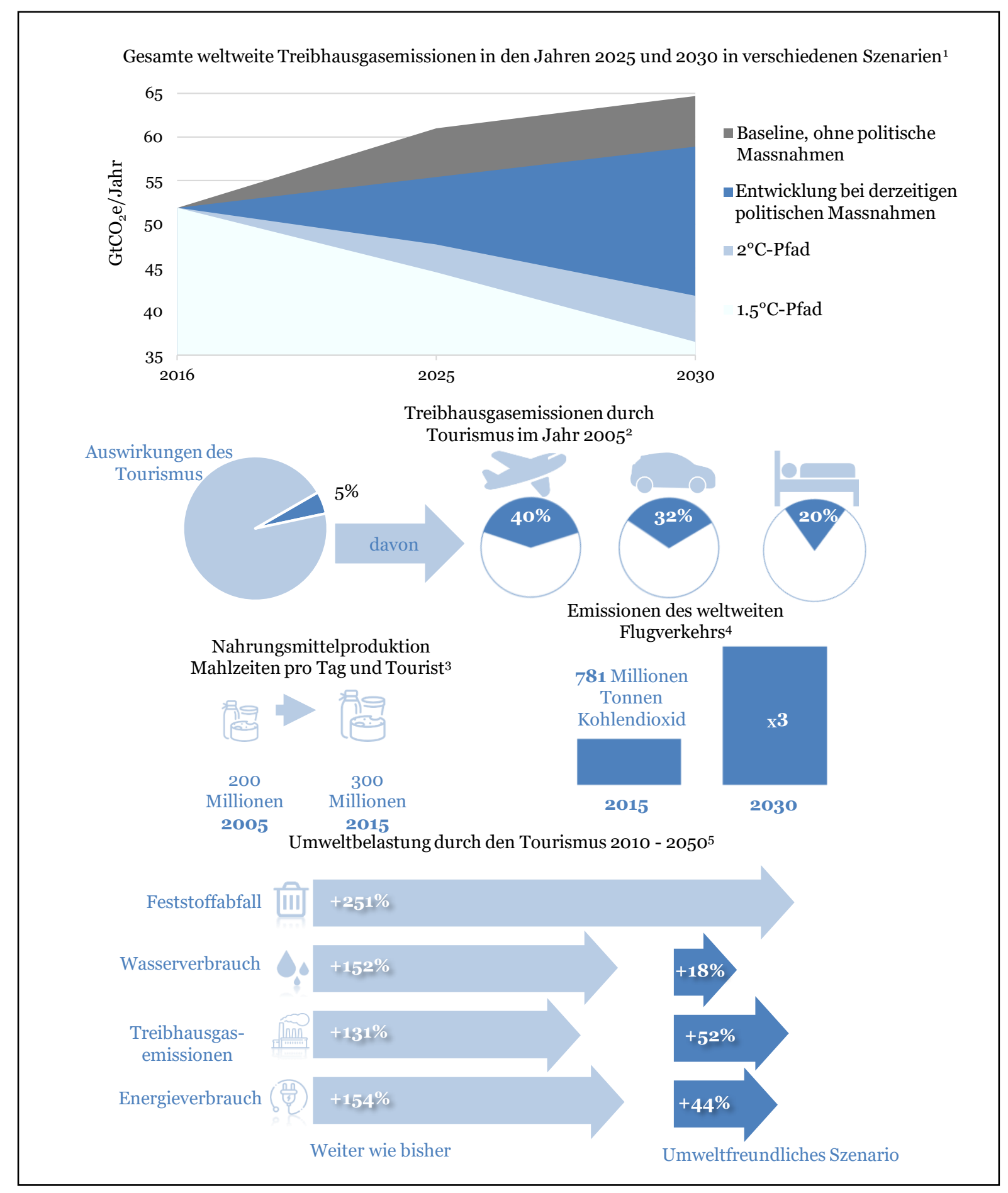

OECD-Infografik, basierend auf verschiedenen Quellen: 1. UNEP (2017); 2. UNWTO (2017b); 3. UNWTO-UNEP (2008); 4. CREST (2016); 5. UNEP-UNWTO (2010). Einige der Symbole wurden durch Freepik von www.flaticon.com entworfen. 
Tourismus wird weithin als menschliche Aktivität anerkannt, die von natürlichen Ressourcen abhängt. Gleichzeitig trägt er aber zum Verbrauch dieser Ressourcen selbst bei. Wie viele andere Sektoren auch ist der Tourismus massgeblich am Energieverbrauch und dem Ausstoss von Treibhausgasen beteiligt. Darüber hinaus trägt er zum Trinkwasser- und Landverbrauch, zur Schädigung der Umwelt und zu nicht nachhaltiger Produktion von Nahrungsmitteln bei. Auch auf die weltweite Artenvielfalt wirkt er sich auf vielerlei Art aus. Die Zusammenhänge zwischen Tourismus und diesen Ressourcen können direkter oder indirekter Art sein. Auch wenn alle touristischen Aktivitäten letztendlich lokal ablaufen, summieren sie sich doch zu weltweit signifikanten Phänomenen.

Gleichzeitig kann Tourismus aber auch das Bewusstsein für kulturelle Werte und den Wert der Umwelt stärken. Er kann dazu beitragen, geschützte Bereiche zu finanzieren und zu pflegen, und er kann deren wirtschaftlichen Wert und ihre Bedeutung steigern. Tourismus, der sich auf breit angelegtes Engagement der betreffenden Interessengruppen und auf die Grundsätze nachhaltiger Entwicklung stützt, kann wegen der durch ihn geschaffenen Arbeitsplätze und Möglichkeiten der wirtschaftlichen Entwicklung sowohl in städtischen als auch in ländlichen Räumen zu mehr integrativem Wachstum beitragen und die gesellschaftliche Integration fördern.

Tourismus kann eine wichtige Rolle beim Übergang zu einer kohlenstoffarmen und ressourcenschonenden Wirtschaft spielen. Wegen seiner bereichsübergreifenden Natur und seiner engen Verknüpfung mit vielen verschiedenen Sektoren führen auch kleine Verbesserungen zu grossen Wirkungen. Die UN hat das Jahr 2017 in Anerkennung des Potenzials des Tourismus, die Agenda 2030 für nachhaltige Entwicklung - durch die durchgängige Etablierung eines nachhaltigen Verbrauchs und ressourcensparender Produktionsmuster, die $\mathrm{zu}$ verbesserten wirtschaftlichen, gesellschaftlichen und Umweltschutzergebnissen führen - voranzutreiben, zum «Internationalen Jahr des nachhaltigen Tourismus für Entwicklung» erklärt.

\section{Wichtige Fakten und Vorhersagen}

Die gesamten weltweiten Treibhausgasemissionen im Jahr 2016 werden auf rund $51,9 \mathrm{GtCO}_{2} \mathrm{e} / \mathrm{Jahr}$ geschätzt. Man geht bei einem Ausgangsszenario ohne Änderung der bisherigen Politik davon aus, dass dieser Wert bis 2025 auf 61,0 und bis 2030 auf 64,7 steigen wird. Im Pariser Abkommen aus dem Jahr 2015 ist das spezifische Ziel festgelegt, die weltweite Erwärmung verglichen mit der vorindustriellen Zeit deutlich unterhalb von $2{ }^{\circ} \mathrm{C}$ zu halten und Massnahmen zu ergreifen, um die Erwärmung auf $1,5^{\circ} \mathrm{C}$ zu begrenzen (UNEP, 2017).

Die Schätzungen der dem Tourismus zuzurechnenden Emissionen schliessen alle inländischen und internationalen Freizeit- und Geschäftsreisen ein, wobei der Schwerpunkt auf der Beförderung zum und vom Zielort, der Unterbringung und den Aktivitäten am Zielort liegt. Alles in allem trägt der Tourismussektor schätzungsweise $5 \% \mathrm{zu}$ den weltweiten Treibhausgasemissionen bei (UNWTO, 2017b). Eine noch vollständigere Analyse müsste auch Nahrungsmittel und Getränke, die Errichtung und den Erhalt von Infrastrukturen sowie Verkäufe und Dienstleistungen an und für Touristen beinhalten.

Für etwa drei Viertel des Gesamtaufkommens durch den Tourismus ist der Reiseverkehr verantwortlich (Flüge rund 40\%, Kraftfahrzeuge rund 32\%), gefolgt von Übernachtungen (über 20\%) und Kreuzfahrtschiffen. Die Emissionen des internationalen Flugverkehrs sind seit 1990 um 83\% gestiegen und betrugen im Jahr 2015 schätzungsweise 781 Millionen Tonnen Kohlendioxid (ATAG, 2016). Schätzungen zufolge werden sich die Emissionen 
des Sektors bei unveränderter Entwicklung bis zum Jahr 2035 verdreifachen (CREST, 2016).

Der Tourismus ist sowohl von Trinkwasserressourcen abhängig als auch ein wichtiger Faktor für den lokalen Trinkwasserverbrauch. Touristen brauchen und verbrauchen Wasser, um zu duschen oder die Toilette zu benutzen, wenn sie beispielsweise Ski laufen (Kunstschneeproduktion) oder Spas, Saunas, Wellnessbereiche oder Swimmingpools besuchen. Auch für den Unterhalt von Hotelgärten und Golfplätzen wird Trinkwasser verbraucht. Hinzu kommt das für den Bau der Tourismusinfrastrukturen (einschliesslich der Unterkünfte) sowie die Nahrungsmittel- und Kraftstoffproduktion verbrauchte Wasser. Ändert sich die Verfügbarkeit oder die Qualität der Wasserressourcen, kann sich dies negativ auf den Tourismus auswirken (OECD, 2015).

Der zunehmende Tourismus und der Trend hin zu hochwertigeren Unterkünften und wasserintensiveren Aktivitäten sowie die kleiner werdenden Wasserressourcen werden Letztere an vielen Reisezielen verstärkt belasten. Die touristische Entwicklung könnte in der Folge aufgrund nachlassender Wasserqualität und höherer Kosten für die Trinkwasserversorgung schwieriger werden oder nicht mehr möglich sein. Die Auswirkungen werden letztendlich von mehreren Faktoren abhängen, darunter die relative Trinkwasserknappheit an bestehenden und potenziellen Tourismuszielen, der Wettbewerb mit anderen Wirtschaftszweigen wie der Landwirtschaft oder Biokraftstoffen sowie die Struktur der Tourismusbranche (z. B. kleine Gasthäuser ggü. grossen Hotelanlagen) und die Höhe des Wasserverbrauchs pro Übernachtung. Es wurde bereits über regionale Konflikte berichtet, die sich am Wasserverbrauch entzündeten (ITP, 2013). In Zukunft dürften sich diese aufgrund der wachsenden Nachfrage und der abnehmenden Vorräte verstärken.

Die Nahrungsmittelproduktion und Abfallminimierung wirken sich in vielerlei Hinsicht auf die Nachhaltigkeit aus. Nach Schätzungen von UNWTO-UNEP (2008) fielen allein im Jahr 2005 beispielsweise 25 Milliarden «Touristentage» an. Bei durchschnittlich drei Mahlzeiten pro Reisendem und Tag macht das täglich rund 200 Millionen Mahlzeiten. Aufgrund des Anstiegs der Auslandsreisen um über 50\% bis zum Jahr 2016 erhöht sich diese Zahl in Richtung 300 Millionen pro Tag. Die Hotels üben somit einen erheblichen Einfluss auf die Nahrungsmittelproduktion aus. Sie können die nachhaltige Produktion von Nahrungsmitteln und die Abfallminimierung direkt beeinflussen und durch Vorschriften betreffend die regionale Beschaffung oder den Einkauf biologisch angebauter Nahrungsmittel fördern. Die Initiative der Hotelkette Scandic, nur noch organischen und fair gehandelten Kaffee einzukaufen, betrifft beispielsweise 20 Millionen Tassen Kaffee, die jährlich serviert werden (Gössling et al., 2011).

Ebenso wie gut geplante touristische Entwicklung zum wirtschaftlichen und soziokulturellen Wohlergehen der gastgebenden Gemeinden beitragen kann, kann schnelles und ungeplantes Wachstum des Tourismus negative Auswirkungen mit sich bringen, wie Überfüllung. Diese können sowohl die Gemeinden als auch die Umwelt, von der der Tourismus abhängt, in Mitleidenschaft ziehen. So bringen einige Studien touristisches Wachstum ebenso mit dem Niedergang der traditionellen Kultur in Verbindung wie mit einer Zunahme von Glücksspiel, Drogenhandel und sogar Prostitution. Ausserdem bestehen Anhaltspunkte, die darauf hindeuten, dass verstärkter Tourismus zu höheren Grundsteuern und höheren Lebenshaltungskosten in den gastgebenden Gemeinden führen kann, die die Einheimischen nicht mehr aufbringen können (Kim et al., 2013).

Das exponentielle Wachstum der Sharing Economy im Tourismusbereich ist ein typisches Beispiel. Peer-to-Peer-Plattformen können das wirtschaftliche Wachstum vorantreiben, 
Arbeitsplätze entstehen lassen und Mehrwert schaffen, indem sie Touristen dazu bringen, sich zu verstreuen und an weniger bekannte Destinationen zu reisen. Sie können aber auch für negative externe Effekte sorgen. Insbesondere Mitwohngelegenheiten können die Nachbarschaft und die Einheimischen durch Lärm und andere Störungen beeinträchtigen. Ausserdem können sie zusätzlichen Druck auf den lokalen Wohnungsmarkt ausüben. Schlimmstenfalls kann sich schlecht gesteuertes Wachstum dieser Dienstleistungen auch nachteilig auf das historische Geflecht der Reiseziele auswirken und den Reiz bestimmter Gegenden als Wohn- und Urlaubsorte beeinträchtigen (OECD, 2016b).

Der OECD-Bericht zu umweltfreundlichen Innovationen im Tourismus (Green Innovation in Tourism, OECD, 2013) ging auf die durch die Branche wahrgenommene Kundenzurückhaltung ein, für umweltfreundliche Produkte oder Dienstleistungen etwas mehr zu bezahlen. Die Ansichten der Kunden ändern sich jedoch vielleicht. Laut den Ergebnissen einer Studie aus dem Jahr 2015 waren 66\% der Kunden weltweit bereit, für nachhaltig wirtschaftende Marken mehr Geld auszugeben. Im Jahr 2014 betrug dieser Anteil noch 55\%. Bei den Millennials lag der Wert mit 73\% (nach nur 50\% im Vorjahr) sogar deutlich höher (Nielsen, 2015). Trotz der wachsenden Zahl der Reisenden, die für Nachhaltigkeit auch einen höheren Preis akzeptieren würden, gibt es in manchen Ländern noch immer einen grossen Anteil, für den dies nicht in Frage kommt (López-Sánchez and Pulido-Fernández, 2016). Ein wichtiger Kaufentscheidungen beeinflussender Faktor ist das Markenvertrauen. Dies erklärt die grosse Beliebtheit unabhängiger Zertifizierungsprogramme im Bereich des nachhaltigen Tourismus. Akkreditierungsprogramme wie der «Grüne Stern» in der Türkei erfüllen einen doppelten Zweck. Sie ermutigen einerseits die Anbieter von Unterkünften, mehr auf Nachhaltigkeit und Umweltschutz zu achten, und stärken andererseits das Vertrauen der Kunden in das umweltfreundliche Verhalten der akkreditierten Tourismusunternehmen.

Das World Travel and Tourism Council (WTTC) würdigt in jedem Jahr Tourismusziele und -unternehmen für bewährte Vorgehensweisen im Bereich der Nachhaltigkeit, die der Gemeinschaft, der Umwelt, Innovationen und Menschen zugute kommen. In seinem neuesten Bericht identifiziert das WTTC eine Reihe wichtiger Entwicklungen, die Einblicke in die Zukunft des nachhaltigen Tourismus bieten (WTTC, 2016):

- Sowohl die Anzahl als auch die Qualität der Bewerbungen aus städtischen Destinationen haben erheblich zugenommen, was das Wachstum des Städtetourismus sowie den verstärkten Einsatz des Tourismus durch städtische Verwaltungen für die wirtschaftliche Entwicklung unterstreicht.

- Der Schutz und Erhalt der Artenvielfalt ist im Zeitverlauf ein durchgehend vorrangiges Anliegen geblieben. Infolge weltweit geforderter Klimaschutzmassnahmen werden nun aber auch der Klimawandel und die Treibhausgasemissionen mehr und mehr als kritische Elemente jeder Nachhaltigkeitsinitiative angesehen.

- Sozialunternehmen engagieren sich teilweise aufgrund der Rolle der sozialen Medien und mobilen Technologien, mit denen Menschen schnell und einfach interagieren können, immer mehr im Tourismussektor.

- Der Aspekt «Mensch» ist im Tourismussektor stärker in den Vordergrund getreten, was zu einer grösseren Bedeutung von Beschäftigung, Ausbildung und Beteiligung der Mitarbeitenden als wichtigen Treibern für die Entwicklung der Branche geführt hat. 
- Es wird grösserer Wert auf die Messung und Bewertung von Nachhaltigkeitsinitiativen gelegt, was wiederum die Standards in diesem Bereich insgesamt angehoben hat.

\section{Implikationen für den Tourismussektor}

Der Reise- und Tourismussektor wird in den kommenden Jahrzehnten die Folgen des Klimawandels zu spüren bekommen. In vielen Ländern werden bestehende Tourismusangebote in Frage gestellt werden, da sich das physische Umfeld ändert und extreme Wetterereignisse zur Norm werden. So spielt sich beispielsweise ein grosser Teil des internationalen Tourismus in Küstenregionen ab, die erheblich durch Stürme, Überschwemmungen und Sturmfluten bedroht sind. Reiseziele in südlichen Regionen werden wahrscheinlich während des Sommers mit extremen Hitzewellen zu kämpfen haben, während sich die Schneeperioden in nördlichen Regionen, die auf den Wintersport angewiesen sind, verkürzen. In vielen Ländern wird es also potenziell zu stärkeren saisonalen Schwankungen kommen. Sowohl die Regierungen als auch die Tourismusbranche müssen daher ernsthaft überdenken, wie das Reiseangebot langfristig gestaltet werden kann und wie der Tourismus langfristig zu steuern ist (Kasten 2).

Es wird immer wichtiger, dass Regierungen und die Branche proaktiv zusammenarbeiten, um für nachhaltige Entwicklung zu sorgen und Attraktionen so zu verwalten, dass sie sowohl den Einheimischen als auch den Touristen kurz- und langfristig nutzen und Freude bereiten. 
Kasten 2. Programm zur nachhaltigen Entwicklung von Reisezielen in Schweden

Im Jahr 2012 bewarben sich über 40 regionale und lokale Organisationen bei der Schwedischen Agentur für Wirtschafts- und Regionalentwicklung (Tillväxtverket) um die Teilnahme an einer vierjährigen Initiative zur Stärkung und Entwicklung nachhaltiger Tourismusziele in Schweden. Ausgewählt wurden die fünf Regionen Bohuslän, Kiruna, Stockholmer Schären, Vimmerby und Åre. Jede Region besitzt einen einzigartigen Charakter und einzigartige Entwicklungsbedürfnisse. Neben ihren gemeinsamen Zielen verfolgen sie alle auch eigene, spezifische Ziele. Das Projekt hatte ein Gesamtbudget von EUR 6,4 Millionen, von denen die einzelnen Destinationen jeweils rund EUR 1 Million erhielten. Die Destinationen leiteten Massnahmen zur Verlängerung der Tourismussaison, qualitativen Verbesserung der Unterkünfte, Entwicklung neuer nachhaltigerer Produkte und Dienstleistungen, besseren Barrierefreiheit und allgemeinen Verbesserung der Qualität und Wettbewerbsfähigkeit der jeweiligen Reiseziele ein.

Das Projekt machte die Vorteile einer landesweiten Initiative deutlich, die für Glaubwürdigkeit und Status sorgt und gleichzeitig praktische Massnahmen vorantreiben kann. Die einzelnen Regionen konnten durch Weitergabe von Wissen, klare Kommunikation und gezielte Massnahmen mehr Besucher aus dem Ausland anziehen und Programme für eine nachhaltige Entwicklung aufbauen, die sowohl gesellschaftliche Aspekte als auch Umweltschutzfaktoren berücksichtigten. Das Programm ist als Beitrag zum nachhaltigen Entwicklungsziel 12 der UN anerkannt.

Im Jahr 2016 wurde ein neues Programm ins Leben gerufen, das bis 2019 laufen soll und sieben Projekte in Schweden beinhaltet, die sich auf kulturellen und naturnahen Tourismus konzentrieren.

Angesichts von bis zum Jahr 2030 schätzungsweise 1,8 Milliarden ausländischen Touristen und potenziell der vierfachen Zahl inländischer Touristen stellt der Übergang zu einer kohlenstoffarmen und ressourcensparenden Wirtschaft die tourismuspolitischen Entscheidungsträger vor eine ganze Reihe von Chancen und Herausforderungen. Unter anderem müssen die aktuellen und potenziellen Auswirkungen unterschiedlicher Formen des Tourismus auf die Umwelt und die natürlichen Ressourcen besser verstanden werden. Ausserdem müssen in der gesamten Wertschöpfungskette die richtigen Anreize zur Förderung von Nachhaltigkeit gesetzt werden, und es muss gezeigt werden, dass umweltfreundliches Handeln auch wirtschaftlich lukrativ sein kann.

Um bessere Ressourceneffizienz zu erreichen, umweltfreundliche Investitionsstrukturen zu schaffen und sektorübergreifende Synergien zu nutzen, müssen verschiedene Nachhaltigkeitstreiber beachtet werden (UNEP, 2011). Hierzu gehören i) Energie - höhere Kosten und Kohlendioxidzuschläge, staatliche Anreizprogramme, Ökolabel sowie Verordnungen/Gesetze für mehr Energieeffizienz; ii) Wasser - Preisstrukturen, die die Wasserknappheit widerspiegeln und verantwortungsvollen Umgang mit Wasser belohnen sowie iii) Artenvielfalt - Regulierung hinsichtlich sensibler Ökosysteme sowie eine nationale Politik, die mittels Tourismus Einnahmen generiert, mit denen kritische biologische Lebensräume geschützt werden können. Der Tourismus könnte im Rahmen eines derartigen umweltfreundlichen Investitionsszenarios im Vergleich zu einem ungesteuerten Szenario einen grösseren Beitrag zum BIP-Wachstum leisten und gleichzeitig den Wasser- und Energieverbrauch ebenso senken wie die $\mathrm{CO}_{2}$-Emissionen. 
Tourismuspolitik muss in diesem Kontext und aufgrund ihrer bereichsübergreifenden und fragmentierten Natur innerhalb eines breiteren politischen Rahmens gesehen werden. Unterstützung und Führung durch politische Entscheidungsträger auf höchster Ebene kann dazu beitragen, dass sichergestellt ist, dass auch die Auswirkungen des Tourismus auf durch diesen betroffene Politikfelder und Initiativen berücksichtigt werden. Die Verknüpfungen verschiedener Politikfelder untereinander führen zu einem Politik-Mix, der bestimmt, wie sich der Tourismus kurz-, mittel- und langfristig entwickelt.

Erforderlich ist somit ein integrierter Regierungsansatz, an dem sich auch die Branche und die Zivilgesellschaft mit Beiträgen und Unterstützung beteiligen, um den vielfältigen Herausforderungen zu begegnen, vor denen die Tourismusbranche steht. Hierzu gehören der Schutz, die Verwaltung und die Verbesserung der natürlichen und kulturellen Ressourcen ebenso wie die Entwicklung der Infrastrukturen und der Kompetenzen, die für die Befriedigung der zu erwartenden künftigen Nachfrage erforderlich sind. Ein derartiger Ansatz wird dazu beitragen, die Langlebigkeit des Tourismus als wirtschaftliche und gesellschaftliche Kraft mittels Konzentration auf ökologische Nachhaltigkeit, Inklusion, Vielfalt, Innovation und strategische Produktivitätssteigerungen zu sichern, anstatt nur zu reagieren oder zu versuchen, durch Anpassungen oder Verschiebungen in Richtung neuer Marktchancen kurzfristige Ziele zu erreichen.

\section{Kritische Unsicherheiten}

Im Folgenden werden kritische Unsicherheiten genannt, die den erwarteten Wachstumspfad des nachhaltigen Tourismus bis zum Jahr 2040 verändern könnten:

- Ungünstige Umweltbedingungen und die Folgen des Klimawandels könnten sich in vielen Destinationen negativ auf den Tourismussektor auswirken, insbesondere wenn extreme Wetterbedingungen häufiger werden (und z. B. zu Überschwemmungen an den Küsten und zu gefährlichen Hitzewellen in südlichen Regionen führen).

- Schlecht gesteuertes Wachstum touristischer Dienstleistungen könnte sich auch nachteilig auf das historische Geflecht der Destinationen auswirken und den Reiz bestimmter Gegenden als Wohn- und Urlaubsorte beeinträchtigen.

- Nachhaltiger Tourismus könnte eine wichtige Rolle beim Übergang zu einer kohlenstoffarmen und ressourcenschonenden Wirtschaft spielen. Es besteht jedoch die Gefahr, dass die höheren Kosten eines nachhaltigen Tourismus einige Reisende abschrecken, die nicht mehr Geld ausgeben möchten. Dies würde zu einem relativen Nischenmarkt innerhalb des Tourismusgeschäfts führen.

- Die übergreifende Natur der genannten Aspekte hat eine grössere Komplexität zur Folge. Die internationale Zusammenarbeit und zwischenstaatliche Ansätze in Umweltfragen könnten kritische Faktoren sein. Um grössere Ressourceneffizienz zu erreichen, könnte es erforderlich sein, die Kosten zu erhöhen (z. B. im Luftverkehr) und das Angebot bei bestimmten touristischen Aktivitäten einzuschränken (z. B. durch eine Begrenzung der Besucherzahlen in empfindlichen Ökosystemen). 


\section{Plausible Zukunftsszenarien}

1. Ein Zeitalter gesellschaftlicher und umweltpolitischer Verantwortungslosigkeit

- Das Versprechen und die Beliebtheit nachhaltiger Tourismusangebote sind geschwunden - im Wesentlichen aufgrund der höheren Kosten, die Umweltbewusstsein und gesellschaftlich verantwortliches Handeln auf Reisen verursachen. Nachhaltiger Tourismus ist zu einem Nischenmarkt geworden, während viele Touristen nicht bereit sind, bei ihrer nächsten Reise zusätzliches Geld auszugeben, um den gastgebenden Gemeinden und lokalen Ökosystemen «etwas zurückzugeben». Der Tourismussektor investiert wie viele andere Branchen nur sehr wenig in Nachhaltigkeit, worunter die Umwelt zu leiden hat.

- Durch überbordenden Tourismus hervorgerufene Umweltprobleme haben viele Destinationen und Wahrzeichen völlig zerstört: Korallenriffe sind dauerhaft abgestorben, beliebte Küstenregionen wurden überflutet und Reiseziele im Süden sehen sich den Grossteil des Jahres extremen und gefährlichen Hitzewellen ausgesetzt. Extremes Wetter in Verbindung mit jahrelanger hoher und unkontrollierter Besuchernachfrage hat historische Monumente geschädigt und die traditionelle Kultur an den weltweit bekanntesten Reisezielen verdrängt.

- Regulatorische Massnahmen zur Verringerung des $\mathrm{CO}_{2}$-Ausstosses haben Flugreisen für den Durchschnittsreisenden unerschwinglich gemacht. Im Bemühen, einige der Umweltzerstörungen infolge des Klimawandels in den Griff zu bekommen, haben die Regierungen die Vorschriften für den Flugverkehr verschärft, und die Flugpreise sind massiv gestiegen. In aus kleinen Inseln bestehenden Reisezielen, deren Tourismus nahezu ausschliesslich vom Flugverkehr abhängig ist, ist die lokale Wirtschaft zusammengebrochen.

\section{Umweltfreundliches Wachstum: die inhärente Nachhaltigkeit des Reisens}

- Nachhaltiger Tourismus blüht nach wie vor, da die Menschen mehr als je zuvor umweltfreundliche und gesellschaftsbewusste Reisen buchen und unternehmen. Nachhaltiger Tourismus wird nicht mehr als Nischenmarkt angesehen. Vielmehr ist das Reisen mit nur wenigen Vorbehalten inhärent nachhaltig geworden. Diese grosse Beliebtheit hat die Preise weitgehend nach unten getrieben und nachhaltigen Tourismus auch für den Durchschnittsreisenden zugänglich und erschwinglich gemacht.

- Verschiedene Wirtschaftszweige auf der ganzen Welt haben ihre Einstellung zu wirtschaftlichem Wachstum überdacht und sich ressourcenschonendem und kohlenstoffarmem Wirtschaften verschrieben. Der Tourismussektor stellt keine Ausnahme dar: Hotels arbeiten energieeffizient und fühlen sich verpflichtet, in den lokalen Gemeinden menschenwürdige Arbeitsbedingungen $\mathrm{zu}$ bieten. Der Grossteil des Landverkehrs erfolgt elektrisch, und die meisten Touristen jeden Alters verbinden irgendeine Art der freiwilligen Leistung oder Wohltätigkeit mit ihren Reisen im eigenen Land oder im Ausland.

- Da die Destinationen auf der ganzen Welt beginnen, Nachhaltigkeit ernster zu nehmen, sind Fortschritte für Gesellschaft, Umweltschutz und Wirtschaft zu beobachten. Natürlich haben sich die Landschaften und Ökosysteme im Lauf der Zeit irreversibel verändert. Die Tourismusdestinationen und die Betreiber haben 
jedoch das Beste daraus gemacht. Sie profitieren von längeren Zeiten, in denen warmes Strandwetter herrscht und steuern die Nachfrage nach gefährdeten Wahrzeichen sorgfältig.

\section{Polarisierter Fortschritt: unterschiedliche Ansichten zu Nachhaltigkeit}

- Der nachhaltige Tourismus wächst weiterhin, wenn auch langsamer als während seines ersten Beliebtheitsschubs in den frühen 2000er und 2010er Jahren. Die Wahrnehmung des nachhaltigen Tourismus als unerschwingliches Nischenangebot wurde deutlich aufgeweicht und viele Reisende - insbesondere aus den jüngeren Generationen - tun ihr Möglichstes, um der Gemeinschaft etwas zurückzugeben.

- Der Tourismussektor berücksichtigt nun stärker die gesellschaftlichen Probleme, die der Tourismus verursacht, und bietet menschenwürdige Arbeitsplätze an, bindet die lokalen Gemeinden besser ein und fördert die traditionelle Kultur. Das Endziel eines Tourismus, der als Ganzes inhärent nachhaltig ist, hat der Sektor jedoch noch nicht erreicht. Er kämpft noch immer sehr damit, seine Auswirkungen auf die Umwelt zu begrenzen.

- Das Ausmass, in dem die einzelnen Länder ihren Tourismussektor in Richtung Nachhaltigkeit gewandelt haben, hängt zu grossen Teilen vom regulatorischen und gesetzgeberischen Umfeld ab, in dem der Sektor operiert. Obwohl weltweit die meisten Staaten das Pariser Abkommen unterzeichnet und ratifiziert haben und sich bemühen, ihre Emissionen $\mathrm{zu}$ senken, sind manche deutlich weiter vorangekommen als andere. Die entsprechenden Inkonsistenzen im Ansatz führen weiterhin zu Herausforderungen: Da sich der Klimawandel nicht an Grenzen hält, schädigen seine Folgen nach wie vor viele Destinationen irreparabel.

\section{Analyse der Szenarien}

Damit der Tourismus weltweit gesehen wirklich nachhaltig wird, werden sowohl innerhalb der einzelnen Länder als auch grenzüberschreitend erhebliche Zusammenarbeit zwischen den verschiedenen Regierungsebenen sowie intensive Abstimmung mit der Branche erforderlich sein. Auf internationaler Ebene könnte dies bedeuten, dass die Regierungen gemeinsam Strategien entwickeln, wie sich nachhaltige Tourismusziele erreichen liessen (z. B. die Ziele für nachhaltige Entwicklung der UN, das OECD Policy Statement on Tourism Policies for Sustainable and Inclusive Growth (Positionspapier zu einer Tourismuspolitik im Interesse eines nachhaltigen und integrativen Wachstums)). Es sind jedoch auch Schritte auf nationaler und subnationaler Ebene erforderlich. Ausserdem kommt es neben Strategien zur Verhinderung nicht nachhaltiger Praktiken auch darauf an, Massnahmen zur Anpassung an Umweltveränderungen zu ergreifen. So hat die Regierung des australischen Bundesstaats Queensland beispielsweise im Jahr 2017 nach eingehender Beratung mit den betreffenden Interessengruppen den «Queensland Tourism Climate Change Response Plan» ins Leben gerufen, einen umfassenden, speziell für den Tourismus geltenden Anpassungsplan, in dem vorrangige Massnahmen in Reaktion auf sechs Klimagefahren und Risiken für den Tourismus in diesem Bundesstaat festgelegt sind.

Die Tourismusbranche wird kurzfristig wahrscheinlich weiterhin Produkte mit stark unterschiedlicher Nachhaltigkeit anbieten. Es wird Reiseziele und Anbieter geben, die grossen Wert auf gesellschaftliche, wirtschaftliche und ökologische Nachhaltigkeit legen, und viele andere, die dies nicht tun. Die Verbraucher werden sich also entscheiden können, ob sie nachhaltig verreisen möchten oder nicht. Dies erfordert transparente Zertifizierungsund Akkreditierungsmassnahmen, mit denen sich sicherstellen lässt, dass die Verbraucher 
sich mit ihrem Urlaubsort vertraut machen können und wissen, wofür ihr an diesem Ort ausgegebenes Geld verwendet wird.

Derartige Prozesse unterliegen vielen Herausforderungen. Da der Tourismus naturgemäss weltweit stattfindet, müssen Zertifizierungs- und Akkreditierungssysteme im Tourismussektor länderübergreifend standardisiert sein, um wirksam zu sein. Dessen ungeachtet wird es schwierig sein, den Verbrauchern konsistente Informationen über nachhaltige Destinationen und Dienstleistungen anzubieten, weil sich die Indikatoren für Nachhaltigkeit ebenso wie die Messansätze zwischen den verschiedenen Destinationen stark unterscheiden können.

Ausserdem gibt es zwar bereits entsprechende Zertifizierungssysteme auf dem Markt, jedoch in solcher Vielzahl, dass sie den Verbraucher nicht ausreichend von ihrer Vertrauenswürdigkeit und Werthaltigkeit überzeugen können. Stattdessen verlassen sich die Verbraucher mehr und mehr auf Online-Bewertungsmechanismen, über die vertrauenswürdige Verbraucher ihre Erfahrungen weitergeben. Dabei ist es allerdings unwahrscheinlich, dass die betreffenden Bewerter die im Hintergrund stehende Nachhaltigkeit der Anbieter vollständig verstehen. Sie konzentrieren sich stattdessen auf das vordergründige Kundenerlebnis. In einem idealen System wäre es vielleicht möglich, die Verbraucher Kriterien aufstellen $\mathrm{zu}$ lassen, in deren Rahmen Waren und Dienstleistungen nach Nachhaltigkeitsgesichtspunkten bewertet werden.

Angesichts der Dominanz der Technologie in diesen Peer-to-Peer-Mechanismen gibt es vielleicht Mittel und Wege, um die bestehende Technologie für bessere Transparenz hinsichtlich eines nachhaltigen Tourismus einzusetzen. Die italienische Stadt Florenz bietet mit «Viva Firenze» (http://www.vivafirenze.it/en) die erste nicht gewinnorientierte Reservierungs-Website an, an der sich jedes beliebige Hotel beteiligen kann. Die Website arbeitet mit dem gleichen Einnahmenmodell wie andere Buchungs-Websites, hat sich jedoch für ein nachhaltigeres Vertriebsmodell entschieden. Die Verbraucher können sich bei der Online-Buchung für ein durch eine regionale gemeinnützige Organisation durchgeführtes Projekt entscheiden, dem aus den Buchungskosten eine Spende zukommen soll. Man könnte sich vorstellen, dass diese Idee in grösserem Rahmen durch ein OnlineTool oder eine App übernommen wird, in dem/der die Kunden genau sehen, wie viel ihres Geldes in der lokalen Wirtschaft verbleibt.

Mittelfristig kann der Eindruck entstehen, dass wirklich nachhaltiger Tourismus wahrscheinlich für manche Verbraucher unerschwinglich sein wird. Die Millennials beispielsweise könnten angesichts der jüngsten wirtschaftlichen Entwicklung besonders hart getroffen werden. Diejenigen, die sich Auslandsreisen leisten können, werden positive Erfahrungen machen, da viele Reisende zusätzliche Möglichkeiten finden werden, die ihren persönlichen Werten entsprechen, und die ihnen den Eindruck vermitteln, Teil einer Gemeinschaft zu sein und dem Allgemeinwohl zu dienen. Unter jenen, die sich keine Fernreisen leisten können, werden alternative Tourismusformen an Beliebtheit gewinnen. Technologien, die mit virtueller Realität arbeiten, könnten nützliche Hilfsmittel sein, um Reiseerlebnisse aus der Ferne zu ermöglichen. Darüber hinaus könnten Destinationen sehr viele Möglichkeiten finden, Tourismusmöglichkeiten im Inland $\mathrm{zu}$ entwickeln und zu bewerben.

Nachhaltige Dienstleistungen im Tourismus könnten mittels der Förderung nachhaltiger Wertschöpfungsketten grössere Chancen für die wirtschaftliche Entwicklung und menschenwürdige Arbeitsplätze in den Gemeinden bieten. Allerdings setzt dies auch regelmässige Investitionen seitens der Arbeitgeber voraus, mit denen sichergestellt wird, dass sich die Mitarbeitenden weiterbilden und mit der sich wandelnden Branche Schritt 
halten können. Gleichzeitig ist es möglich, dass Destinationen in der Aussenwahrnehmung ihre Authentizität verlieren, wenn sie dazu verpflichtet werden «grün» zu werden und sich dies auf eine Art manifestiert, die nicht den lokalen Traditionen und der lokalen Kultur entspricht.

Sollten die Preise für nachhaltige Produkte langfristig sinken, bestünde noch immer die Chance, dass der Tourismus ein weiteres Mal den Massenmarkt anspricht. Damit einher geht das anhaltende Risiko eines überbordenden Tourismus, der dem Konzept der Nachhaltigkeit selbst direkt widerspricht. Die Regierungen werden mit dieser Herausforderung sehr sorgfältig umgehen müssen. Das portugiesische Programm Valorizar wurde ins Leben gerufen, um die Nachfrage innerhalb des Landes ausgewogener zu verteilen. Es unterstützt Investitionen im Hinterland und soll diese Regionen für Touristen attraktiver machen, die sich bisher am liebsten in den Küstenregionen aufhalten. In ähnlicher Weise bietet das vielseitig verwendbare Travel Ticket in Amsterdam den Besuchern uneingeschränkten Zugang zu verschiedenen Verkehrsmitteln, mit denen sie die Stadt erkunden können. Es wurde auf das Umland erweitert, um zu mehr Ausflügen in die Region anzuregen und den intensiven Tourismus im historischen Stadtzentrum zu dämpfen.

Allerdings kann es schwierig sein, Ideen für gute politische Massnahmen so einzuführen, dass es allen Beteiligten gefällt. Sollten die politischen Entscheidungsträger beispielsweise im Interesse der Nachhaltigkeit längere Aufenthalte fördern wollen, indem sie die Anbieter von Unterkünften anregen, für kurze Aufenthalte (z. B. eine bis zwei Übernachtungen) deutlich höhere Preise zu verlangen, wäre es ohne zusätzliche Anreize wohl schwer, bereitwillige Partner in der Branche zu finden, die das entsprechende Risiko eingehen wollen.

Dynamische Preisgestaltung - bei der die Preise entsprechend Angebot und Nachfrage in Echtzeit angepasst werden - könnte ein nützliches Mittel sein, überbordenden Tourismus zu begrenzen und in diesem Sektor Nachhaltigkeitsziele auf eine Art zu erreichen, die den Betroffenen eher entspricht. Dieses Mittel eignet sich nachweislich für die bessere Steuerung der Nachfrage nach bestimmten Attraktionen während der Hochsaison. Es könnte jedoch auch eingesetzt werden, um die Nachfrage in verschiedenen Unterbereichen des Tourismus in Ländern und Regionen insgesamt zu glätten. In der Schweiz wird beispielsweise seit einiger Zeit mit von der Wettervorhersage abhängigen dynamischen Preisen für Skilifte experimentiert.

Weltweit denken Regierungen bereits seit langem über die Auswirkungen eines überbordenden Tourismus nach, insbesondere an Destinationen, die schon seit Jahrzehnten mit diesem Problem kämpfen. Aus diesen Überlegungen sind einige interessante potenzielle Lösungen entstanden. In Frankreich hat die Regierung beispielsweise die Schulferien gestaffelt, sodass sich die Nachfrage an beliebten Tourismuszielen (z. B. Skigebiete und Küstenregionen) zeitlich verteilt. Diese Massnahme zeigt exemplarisch eine erfolgreiche Zusammenarbeit zwischen politischen Entscheidungsträgern und der Branche und könnte als Vorbild für andere Destinationen dienen. Kroatien hat einen Dialog zwischen der Kreuzfahrtbranche und lokalen Gemeinden angestossen, um Zeitpläne abzustimmen, sodass nicht viele Schiffe gleichzeitig in einzelnen Häfen für Überfüllung sorgen.

Interessant ist auch eine Idee aus Griechenland, das Angestellten im öffentlichen Dienst zusätzliche Urlaubstage bietet, wenn diese ihren Urlaub zwischen Oktober und Mai nehmen und damit einen Ausgleich für die Urlaubs-Hochsaison schaffen. Allerdings wird diese Möglichkeit, wenn auch innovativ, wohl nur von wenigen Angestellten in Anspruch 
genommen. Dies wirft wichtige Fragen über das Ausmass auf, in dem das Verhalten Einzelner beeinflusst werden kann - insbesondere in Hinblick auf ausgeprägte Reisevorlieben.

\section{Mögliche politische Massnahmen}

1. Förderung einer stärkeren horizontalen und vertikale politischen Koordination und einer besseren Integration multipler politischer Konzepte, um einen strategischeren und koordinierteren Ansatz für nachhaltiges Wachstum des Tourismus zu unterstützen. Langfristige Strategien und politische Konzepte, die sich auf hochwertige Arbeitsplätze und neue Stellen, den Aufbau von Kompetenzen, Unternehmertum, Innovationen, wirkungsvolle Investitionen und integrierte Entwicklung der Regionen konzentrieren, sind für nachhaltiges und integratives Wachstum des Tourismus entscheidend - Wachstum, das aktuelle und künftige wirtschaftliche, gesellschaftliche und ökologische Auswirkungen berücksichtigt und den Bedürfnissen von Besuchern, Branche, Umwelt und gastgebenden Gemeinden gleichermassen gerecht wird.

2. Enge Zusammenarbeit mit Tourismusbranche und lokalen Gemeinden, um an Destinationen, deren Umwelt und gesellschaftliche Situation gefährdet ist oder sein wird, zur besseren Steuerung der Touristenströme beizutragen und die touristische Entwicklung in alternativen Gegenden zu fördern, sodass die Vorteile des Massentourismus breiter gestreut und seine möglichen nachteiligen Folgen minimiert werden. Mögliche Ansätze wären die Einführung dynamischer Preismechanismen, die die Nachfrage verteilen und/oder die tatsächlichen Kosten tourismusbezogener Aktivitäten besser wiedergeben können, die Verminderung der Saisonalität, um Gefahren durch überbordenden Tourismus zu begrenzen, und der Einsatz von Technologien zur besseren Steuerung der Besucherzahlen 5 .

3. Bereitstellung stabiler und langfristiger Marktsignale (z. B. Preisbelastung von Kohlenstoff oder andere Marktinstrumente, die die externen Effekte in Zusammenhang mit Umweltauswirkungen widerspiegeln), die ein Kernelement einer starken und umfassenden Strategie für umweltfreundliches Wachstum sind. Die betreffenden Signale werden den Unternehmen bessere Anreize bieten, umweltfreundliche Innovationen zu übernehmen und zu entwickeln. Sie werden dazu beitragen, das Engagement von Regierungen in Richtung eines umweltfreundlicheren Wachstums beurteilen zu können. Ausserdem werden sie effizienzsteigernd auf die Ressourcenallokation wirken, da Märkte für umweltfreundliche Innovationen geschaffen werden, und die Kosten für den Umgang mit Umweltproblemen senken.

4. Eine wichtige Aufgabe der Regierungen ist es, bestehende Informationslücken zu schliessen. Dazu müssen sie Massnahmen ergreifen, um Tourismusunternehmen und die Öffentlichkeit besser über potenzielle oder wahrgenommene Investitionskosten für Unternehmen sowie über den Nutzen einer Übernahme und Unterstützung nachhaltiger Geschäftspraktiken für Umwelt, Gesellschaft und Wirtschaft zu informieren.

\footnotetext{
${ }^{5}$ So führt beispielsweise die Parkleitung in Cinque Terre in Norditalien derzeit einen Versuch mit einer App durch, mit der interessierte Besucher in Echtzeit sehen können, wie viele Menschen auf bestimmten Wegen unterwegs sind. So sollen während Spitzenzeiten zusätzliche Besucher abgeschreckt werden (BBC, 2018).
} 
5. Allgemeine Übernahme von Investitions- und Finanzierungspraktiken, die einen nachhaltigen Tourismus unterstïtzen, um einen reibungsloseren Übergang zu einer grünen. emissionsarmen und klimaresilienten Tourismuswirtschaft $\mathrm{zu}$ ermöglichen. $\mathrm{Zu}$ den konkreten politischen Massnahmen könnten die Übernahme von Nachhaltigkeitskriterien in öffentliche Finanzierungen und Investitionshilfen, Anreize für private Investitionen in ressourcenschonende Infrastruktur, der Aufbau von Kapazitäten und die Verbesserung horizontaler und vertikaler Abstimmung sowie die Verbesserung der Datenlage und der Analysen betreffend umweltbewusste Finanzierung und Investitionen in die Entwicklung des nachhaltigen Tourismus gehören. 


\section{Basistechnologien}

\section{Abbildung 3. Wichtige Trends bei Basistechnologien}

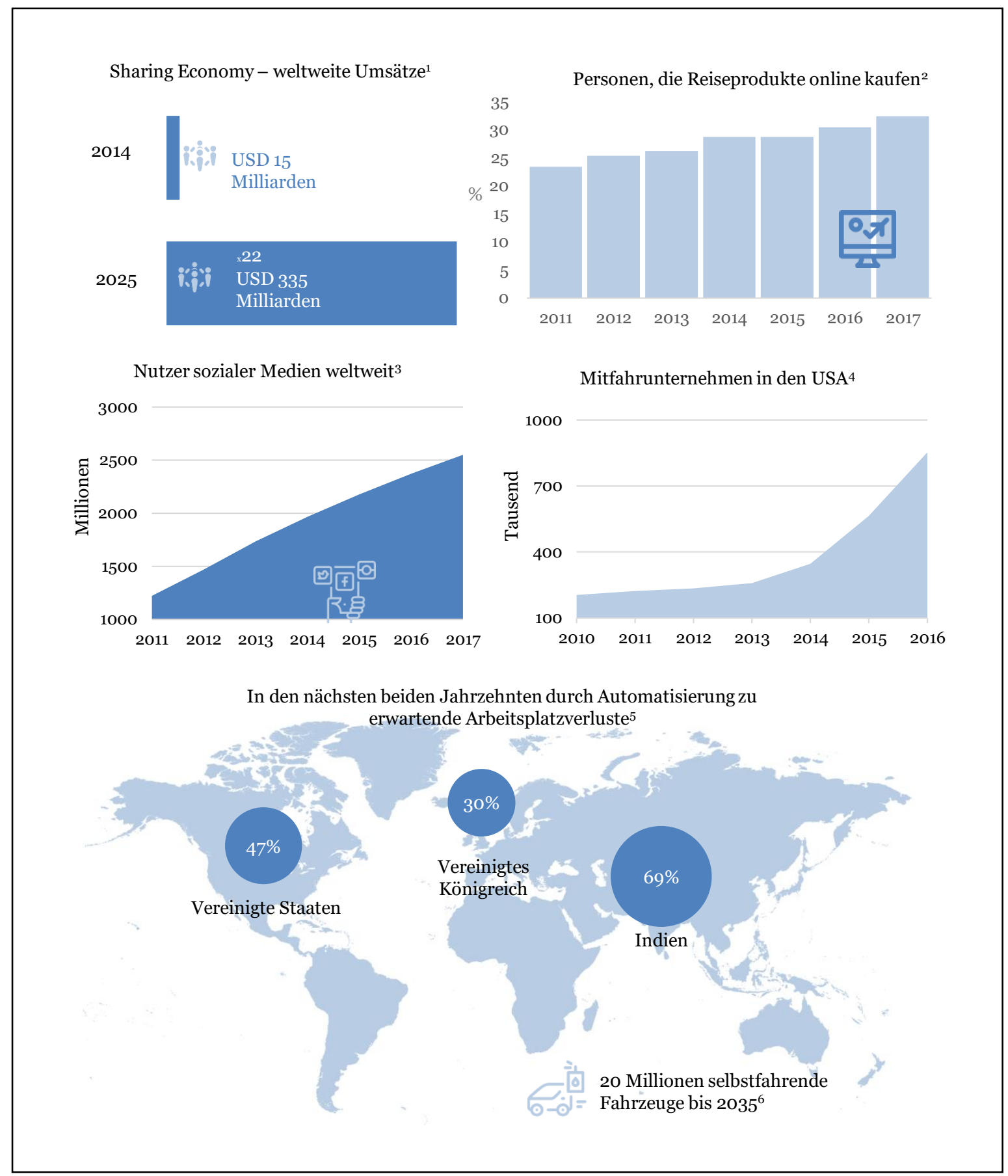

OECD-Infografik, basierend auf verschiedenen Quellen: 1. PwC (2015); 2. OECD-Datensatz: ICT Access and Usage by Households and Individuals (Zugang zu und Verwendung von IKT durch Haushalte und Einzelpersonen, abgerufen im Juni 2018); 3. UNWTO/GTERC (2017); 4. Hathaway und Muro (2017); 5. Frey und Osborne (2013) und Kim (2016); 6. IHS Markit (2016). Einige der Symbole wurden durch Freepik von www.flaticon.com entworfen. 
Märkte und Wirtschaftszweige unterliegen weltweit weiterhin Umbrüchen durch neue Technologien. Die Geschwindigkeit und das Ausmass, in dem dies geschieht, sind enorm. Von der «Sharing Economy» über das Internet der Dinge bis hin zu autonomen Fahrzeugen, künstlicher Intelligenz, Blockchain-Technologie und Big-Data-Analysen gibt es viele neue und neu entstehende Innovationen, die die Erschliessung neuer Möglichkeiten für Menschen auf der ganzen Welt versprechen.

Zusammengenommen können all diese Entwicklungen das Reisen erschwinglicher, effizienter und für viele Menschen zugänglicher machen. Das Umdenken hinsichtlich Vermittlern dürfte bedeuten, dass sich lange bewährte Tourismusmodelle in Bereichen wie Unterkünften oder Reisebüros weiterhin radikal ändern werden. Eine immer grössere Zahl Reisender wird über technologische Plattformen direkt Kontakt mit den Dienstleistern aufnehmen, anstatt die Vermittlung eines Hotels, einer Buchungsagentur oder eines Reisebüros in Anspruch zu nehmen.

Die politischen Entscheidungsträger müssen überlegen, wie sie ein unterstützendes Umfeld schaffen können, das angesichts des Aufkommens neuer Technologien innovationsfreundlich ist, und wie sie möglicherweise Nutzen aus der einfacheren Kontaktaufnahme von Touristen mit einem vielfältigeren Angebot an Geschäftspartnern und Destinationen ziehen können. Gleichzeitig werden sich neue Technologien aber auch auf komplexe und weniger gut verstandene Art und Weise auf die Arbeitskräfte in der Tourismusbranche auswirken. So könnte beispielsweise das Entstehen neuer Technologien, die menschliche Tätigkeiten durch maschinelles Lernen und künstliche Intelligenz ersetzen können, die Art, wie Menschen arbeiten und was sie tun, und allgemeiner die Anzahl der zur Verfügung stehenden Arbeitsplätze radikal ändern. Die politischen Entscheidungsträger müssen überdenken, wie diese schnellen Änderungen gesteuert und mögliche negative Auswirkungen begrenzt werden können.

Technologische Fortschritte haben das Reisen in den vergangenen Jahrzehnten für viele Menschen erschwinglicher, zugänglicher und einfacher gemacht. Die Technologie der Zukunft hat das Potenzial, das gesamte Erscheinungsbild des Tourismus grundlegend zu ändern (z. B. durch integriertes Ticketing, mobile Zahlungssysteme). Angesichts der Verbesserung der Technologie für virtuelle Realität ist es beispielsweise denkbar, dass virtueller Tourismus für manche Reisenden physische Reisen entweder ergänzen oder ganz ersetzen könnte. Umgekehrt können analoge, naturnahe Erlebnisse auf Reisen für viele Menschen, die immer digitaler und vernetzter leben, eine Chance sein, sich «auszuklinken» und eine willkommene Alternative zu rein digitalen Erfahrungen zu erleben.

Noch ist nicht klar, wie sich die Verhaltensweisen der Menschen vor dem Hintergrund dieser Paradigmen verändernden Technologien entwickeln werden. Sicher ist hingegen, dass Technologien einerseits grosse Chancen und andererseits grosse Herausforderungen für politische Entscheidungsträger bedeuten, die sicherstellen wollen, dass ihre nationalen und lokalen Wirtschaftsräume gut aufgestellt sind, um in der Welt des Tourismus von 2040 gut abzuschneiden.

\section{Wichtige Fakten und Vorhersagen}

Digitale Plattformen werden oftmals eingesetzt, um informierte Reiseentscheidungen zu treffen. Sie machen die Planung und Buchung von Reisen einfacher und bequemer für die Reisenden, und ihr Einfluss dürfte in den kommenden Jahrzehnten noch weiter wachsen. Insbesondere soziale Medien werden als wirkungsvolles Hilfsmittel für die Beeinflussung der Entscheidungen heranwachsender Generationen wie der Millennials oder der Generation $\mathrm{Z}$ eingesetzt. So zeigt beispielsweise ein neuerer Bericht der Online- 
Reiseplattform Expedia, dass 27\% der Millennials vor der Buchung Informationen zu einer geplanten Reise in sozialen Medien gepostet haben, um Meinungen einzuholen. 36\% der Benutzer aus der Generation Z haben ein Reiseziel speziell deshalb gewählt, weil sie in sozialen Medien das Posting eines anderen Benutzers über dieses Reiseziel gesehen haben (Expedia, 2018).

Die wachsende Verbreitung sozialer Medien bietet natürlich Chancen für das Marketing der Destinationen. Doch für jene (Gemeinden, Kultur- oder Naturattraktionen), die empfindlich oder aber unvorbereitet oder ungeeignet sind, um mit schnellem Wachstum des Tourismusverkehrs aufgrund der plötzlichen Beliebtheit auf einer oder mehreren Plattformen umzugehen, kann sie auch eine Bedrohung darstellen. Andererseits kann Technologie auch Lösungen für die erforderliche höhere Agilität von Naturschutzmassnahmen bieten. Trotz potenzieller Herausforderungen ist davon auszugehen, dass die Digitalisierung ausserordentlich vorteilhaft für den Tourismussektor sein wird. Zwischen 2015 und 2016 hat sie schätzungsweise USD 305 Milliarden an Mehrwert beigetragen.

Im gleichen Zeitraum hat die Digitalisierung in Flugverkehr, Reise- und Tourismusbranche schätzungsweise USD 100 Milliarden von traditionellen Marktteilnehmern hin zu neuen Wettbewerbern umgeschichtet und für Kunden und Gesamtgesellschaft USD 700 Milliarden Mehrwert geschaffen (WEF, 2017). Obwohl digitale Plattformen für die Verbraucher bequem sein können und die Unterkunftskapazitäten erhöhen können, führen die damit verbundenen Umbrüche im traditionellen System auch zu Herausforderungen.

In Deutschland beispielsweise stellt die Digitalisierung im Tourismussektor KMU, die mit der sich wandelnden Verbrauchernachfrage Schritt halten wollen, vor grosse Probleme. Umfragen aus dem Jahr 2015 innerhalb des Sektors zeigen, dass 60\% der Deutschen das Internet als Informationsquelle oder für das Buchen ihrer Urlaube genutzt haben und die Internetnutzung während des Urlaubs weiterhin ansteigt. Die Wettbewerbsfähigkeit der Anbieter von Tourismusdienstleistungen wird in wachsendem Mass von ihrer Fähigkeit abhängen, nicht nur sofortigen Zugang zum Internet zu bieten, sondern auch mit ihrer digitalen Präsenz und ihren Inhalten den sich ändernden Bedürfnissen der Kunden gerecht zu werden. Die Situation wird noch dadurch verschärft, dass laut einer Umfrage der Deutschen Industrie- und Handelskammer (DIHK) digitale Marketingkanäle im Tourismussektor häufiger genutzt werden als in der deutschen Wirtschaft insgesamt (28\%): Die wichtigsten Nutzer sind das Hotelgewerbe (66\%), Reisebüros (59\%) sowie Gaststätten (41\%). Die DIHK schätzt, dass nahezu ein Viertel der Tourismusunternehmen, die ihre Produkte auch online anbieten, über 50\% ihrer Umsätze über digitale Kanäle erzielen können.

Insbesondere die Sharing Economy ist in den letzten fünf Jahren schnell gewachsen und macht nun einen erheblichen Teil des Gesamtaufkommens aus. Besonders stark war dieses Wachstum bei Verkehr und Unterkünften. Es erstreckt sich aber auch auf viele andere Sektoren. In den fünf wichtigsten Sektoren der Sharing Economy könnten die Umsätze zwischen 2014 und 2025 weltweit von USD 15 Milliarden auf USD 335 Milliarden ansteigen (PwC, 2015). Mitwohnplattformen wie Airbnb, HomeAway und Couchsurfing sind $\mathrm{zu}$ bedeutenden Wettbewerbern der Hotelbranche geworden - Airbnb wird mit geschätzten USD 30 Milliarden bewertet und ist damit auf Augenhöhe mit den Hotelketten Hilton mit USD 19 Milliarden und Marriott mit USD 35 Milliarden. Das über Airbnb getätigte Buchungsvolumen wächst auch weiterhin rapide an, von 4 Millionen Übernachtungen im Jahr 2011 über 40 Millionen im Jahr 2014 bis hin zu voraussichtlich 
80 Millionen im Jahr 2017 (Duryee, 2012; Somerville, 2015). Im Jahr 2011 nutzte nur einer von zehn Reisenden aus den Vereinigten Staaten private Unterkünfte. Im Jahr 2015 war es schon jeder Dritte (Quinby, 2016). Allerdings gibt es auch Bedenken hinsichtlich der Qualität der Mitwohnunterkünfte im Vergleich zu Hotelzimmern. In manchen Ländern gab es gesetzgeberische Fortschritte bei der Regulierung des Mitwohnens, viele weitere Länder überlegen jedoch noch, wie am besten auf das Aufkommen und Anwachsen dieses Phänomens zu reagieren wäre.

Gleiches gilt für Mitfahrvermittlungen, bei denen trotz ihres erheblichen Wachstums in den vergangenen Jahren ähnliche Probleme auftreten. Das anhaltende schnelle Wachstum von Mitfahrvermittlern wie Uber, Lyft und BlaBlaCar bietet Reisenden zusätzliche Möglichkeiten, preiswerter und effizienter voranzukommen. In den Vereinigten Staaten wuchsen die Mitfahrunternehmen zwischen 2010 und 2014 um 69\% und alleine im Jahr 2015 noch einmal um 63\% (Hathaway und Muro, 2017). Die Mitfahrunternehmen experimentieren mit neuen Angeboten wie Fahrten mit Fahrern, die fliessend Englisch sprechen oder grenzüberschreitenden Fahrten, um zusätzliche Touristen als Kunden zu gewinnen (Sawers, 2016).

Es ist davon auszugehen, dass künftig auch Ess- und Reiseerlebnisse im Bereich der Sharing Economy an Bedeutung gewinnen werden, während die Kunden sich mehr und mehr mit dem Gedanken anfreunden, auf Reisen bei Privatpersonen zu essen (über Plattformen wie BonAppetour und VizEat) oder Ausflüge oder personalisierte Erlebnisse über Plattformen wie Vayable, ToursbyLocals oder seit Kurzem über die Funktion «Entdeckungen» von Airbnb zu buchen. Über Letztere werden Ausflüge und einzigartige Erlebnisse mit einheimischen Gastgebern angeboten.

Schnelle Fortschritte in der Automatisierung, vorangetrieben durch Robotertechnik, maschinelles Lernen und künstliche Intelligenz, sind auf dem besten Weg, in den beiden kommenden Jahrzehnten die Arbeitsmärkte rund um die Welt grundlegend zu verändern. Sie könnten bis zu 69\% der heutigen Arbeitsplätze in Indien, 47\% in den Vereinigten Staaten und 30\% im Vereinigten Königreich verschwinden lassen (Frey und Osborne, 2013; Kim, 2016). Allerdings werden diese Umwälzungen in allen Sektoren von der Produktion bis hin zum Einzelhandel und der Verwaltung in vielen Bereichen wahrscheinlich auch effizientere und preiswertere Waren und Dienstleistungen hervorbringen.

Im Jahr 2015 eröffnete in Japan das erste Hotel mit Robotern als Personal. Das Unternehmen hinter dieser Idee plant bis 2021 die Eröffnung von 100 weiteren Standorten (Kikuchi, 2017). Die zunehmende Durchdringung der Wirtschaft mit Automatisierung wird viele Arbeitsplätze im Tourismussektor betreffen, von Reisevermittlern bis hin zu Hotelmitarbeitenden. Gleichzeitig erleichtert Echtzeit-Übersetzungssoftware Reisen in Gebiete, deren Sprache die Touristen nicht sprechen. Tatsächlich können ÜbersetzungsApps bereits jetzt Beschilderungen übersetzen und werden in den kommenden Jahren wohl in der Lage sein, darüber hinaus auch gesprochene Texte zu übersetzen (NITB, 2013). Einerseits könnten den Touristen dadurch mehr Möglichkeiten zur Verfügung stehen, andererseits könnte es sich auf die Arbeit von Reiseführern auswirken.

Darüber hinaus setzen Unternehmen im Tourismussektor Big Data und vorausschauende Analysen ein, um mehr über das Verbraucherverhalten zu erfahren und ihre Reiseangebote entsprechend anzupassen. Die Branche entwickelt bereits virtuelle Assistenten, die Reisende mithilfe künstlicher Intelligenz bei der einfacheren Ausflugsbuchung unterstützen (Boztas, 2017; Levere, 2016). Big Data kommt auch zum Einsatz, um Dienstleistungen effizienter zu gestalten und gezielter anzubieten. Die betreffenden Daten 
werden verwendet, um das Einkaufsverhalten nachzuverfolgen und die Nachfrage nach Dienstleistungen vorherzusagen (Song und Liu, 2017). So können Daten, die über die Websites sozialer Medien gewonnen werden, Entscheidungen innerhalb des Sektors beeinflussen (Miah et al., 2017). Andererseits bringt die verstärkte Nutzung von Big Data auch Bedenken hinsichtlich Datenschutz sowie Richtigkeit und Missbrauch der betreffenden Daten mit sich.

Selbstfahrende Fahrzeuge (Autonomous Vehicles, AV) sind in mehreren Ländern bereits versuchsweise auf den Strassen unterwegs. Es wird angenommen, dass diese Technologie bis zum Jahr 2025 oder schon früher in grösserem Massstab eingesetzt werden kann (Keating, 2017; Assis, 2017). Die Verkaufszahlen von AVs könnten bis zum Jahr 2035 über 20 Millionen erreichen (IHS Markit, 2016). Eine umfassende Nutzung von AVs könnte sich sowohl innerhalb der grossen städtischen Zentren als auch im zwischenstädtischen oder Regionalverkehr entscheidend auf die Reisemobilität und den Tourismus auswirken.

Die Blockchain-Technologie, die hauptsächlich als Grundlage von Kryptowährungen wie Bitcoin bekannt ist, könnte in einer Reihe von Sektoren in vielen verschiedenen Anwendungen eingesetzt werden. Mit dieser Technologie können Benutzer beispielsweise ihre Rechte an Daten sicher registrieren und Transaktionen effizienter und vertrauenswürdiger durchführen. Die Blockchain könnte im Tourismus eingesetzt werden, um bessere Formen des Identitätsmanagements umzusetzen oder sicherere, effizientere Kommunikation zwischen Reisenden und allen nur denkbaren Anbietern von Reisedienstleistungen $\mathrm{zu}$ gewährleisten - von Fluggesellschaften bis hin $\mathrm{zu}$ Kundenbindungsprogrammen (Gjerding, 2017; Aitken, 2016).

Ausserdem könnte sie die Kosten für den Umtausch von Fremdwährungen bei Auslandsreisen senken. Tatsächlich würden bei Verwendung von Kryptowährungen wie Bitcoin keinerlei Gebühren mehr anfallen, und es müssten auf Auslandsreisen keine Fremdwährungen mehr erworben werden, was Auslandsreisen potenziell attraktiver machen würde. Dies gilt insbesondere für Schwellenländer, in denen man sich mit Kryptowährungen wirksam gegen inflationsgefährdete Währungen absichern könnte und somit an Sicherheit gewönne. Die Blockchain-Technologie hat auch das Potenzial, Kundenbindungsprogramme für Vielreisende $\mathrm{zu}$ verändern und $\mathrm{zu}$ vereinfachen (Kowalewski et al., 2017).

Virtuelle Realität (VR) wird derzeit hauptsächlich in Videospielen eingesetzt. Der Tourismus ist jedoch ein Sektor, auf den sie offensichtlich erhebliche Auswirkungen haben könnte. Mit ihr könnte man einfach neue und exotische Gegenden besuchen, ohne den Komfort der eigenen vier Wände verlassen zu müssen. Die Abwägung zwischen dem Potenzial und der Förderung virtueller Reiseerlebnisse mittels VR einerseits und den Interessen derjenigen entlang der traditionellen Wertschöpfungskette im Tourismus andererseits wird für viele Marketing betreibende Unternehmen wahrscheinlich zu einem wichtigen Entscheidungskriterium werden. 


\section{Kasten 3. Australien in $360^{\circ}$ erleben}

Im Jahr 2016 produzierte Tourism Australia eine Reihe von Videos, mit denen OnlineBenutzer einige der landesweit berühmtesten Orte erleben konnten, darunter die Zwölf Apostel, den Hafen von Sydney, Whitehaven Beach und die Gold Coast. Insgesamt wurden im Rahmen der neuesten Iteration der weltweiten Marke «There's Nothing like Australia», der plattformübergreifenden «Aquatic and Coastal Campaign», 18 Videoclips entwickelt. Das Material sollte den Betrachter mit einer mobilen $360^{\circ}$-Technologie und Betrachtung über leicht erhältliche Virtual-Reality-Headsets in Erlebnisse wie Helikopterflüge, Kajakfahrten, Schnorcheln und Segeln eintauchen lassen. Es kann aber auch ohne diese Geräte online angesehen werden, auch mit Apps für das Mobiltelefon.

Mit dieser «immersiven» VR-Technologie sollen Reiseinteressierte angeregt werden, die einzigartigen Wassersport- und Strandurlaubsziele in Australien zu besuchen und zu erleben. Die Zielmärkte sind Länder wie die Vereinigten Staaten, das Vereinigte Königreich, China, Indien, Japan, Südkorea, Singapur, Indonesien, Malaysia und Neuseeland. Mit über 10 Millionen Abrufen in den wenigen Monaten seit ihrem Start und einer um 64\% gestiegenen Nutzung der Website Australia.com war die weltweite Marketinginitiative bislang ein Erfolg. Neu aufkommende VR-Technologien eröffnen den Verbrauchern neue Möglichkeiten, Zielorte kennenzulernen. Sie lassen sie dank einer deutlich anziehenderen Art, Geschichten zu erzählen, tiefer als alle anderen Medienplattformen eintauchen und eine Beziehung zum Reiseziel aufbauen.

Tourism Australia arbeitete mit TNS und Google Think Board zusammen, um das Potenzial von VR als Marketing- und Werbehilfsmittel für das Tourismusgeschäft und Marketing betreibende Unternehmen an den Destinationen $\mathrm{zu}$ verstehen. Forschungsergebnisse zeigen, dass VR-Erlebnisse ein Reiseziel zum Leben erwecken und dazu beitragen können, dass Reisende Destinationen in Betracht ziehen, an die sie sonst nie gedacht hätten. Laut ihren Schätzungen planen 25\% der Reisenden, in Zukunft VR als Hilfe bei der Auswahl des Urlaubsziels einzusetzen (22\% in den Vereinigten Staaten, 25\% im Vereinigten Königreich und 30\% in Australien). Den Rückmeldungen zufolge gewinnen die Reisenden mit dieser Technologie ein gutes Gefühl für das Reiseziel, können die angebotenen Erlebnisse einschätzen und ihre Erwartungen besser abstimmen. Das höchste Verbraucherinteresse schienen VR-Inhalte zu wecken, die sich auf die Natur und die Tierwelt sowie auf Wassersport- und Strandangebote bezogen (www.australia.com/360).

In Kanada hat Destination BC eine immersive VR-Tour durch den Great Bear Rainforest entwickelt, die sich insbesondere an die Reisewirtschaft und an Medienpartner richtet. Tourism Australia bietet in ähnlicher Weise hochauflösendes Videomaterial der beliebtesten australischen Tourismusziele für immersive VR-Erlebnisse an (Kasten 3). Auch einige Hotelketten haben mit VR-Möglichkeiten experimentiert, über die Destinationen erkundet werden können, ohne je den Fuss vor die Tür des eigenen Zimmers zu setzen.

Virtuelle Tourismuserlebnisse könnten immer mehr zu einer Möglichkeit des alternativen Vor-Ort-Erlebens von Zielen werden, die für den physischen Besuch durch Touristen aus ökologischen oder kulturellen Gründen als zu sensibel angesehen werden. So wird es beispielsweise ab dem 26. Oktober 2019 verboten sein, den als UNESCO-Welterbe registrierten Felsen Uluru in Zentralaustralien zu besteigen, der den Anangu - den 
Aborigines, denen der Park traditionell gehört - heilig ist. VR könnte für künftige Reisende eine Möglichkeit sein, den Uluru intensiver zu erleben, und gleichzeitig einen Beitrag zur lokalen Wirtschaft leisten. Jegliche VR-Aktivitäten wären natürlich nicht auf die Besteigung des Uluru begrenzt, sondern würden sich auch auf andere Bereiche des Parks erstrecken, in denen dessen Kultur- und Naturwerte erlebbar sind.

Erweiterte Realität (Augmented Reality, AR) könnte den Sektor ähnlich stark wandeln, indem Reisende und Dienstleister Technologien wie Hologramme oder mobile Apps einsetzen, die Situationen im realen Leben virtuelle Elemente hinzufügen. Mögliche Anwendungsgebiete der AR für die Verbesserung des Besuchererlebnisses sind der einfachere Zugang zu Navigationsinformationen, Übersetzungen und sogar virtuelle Interaktionen mit historischen Persönlichkeiten. Das Internationale Zentrum für Höhlenmalerei in der Nähe von Montignac im Südwesten Frankreichs beispielsweise ist eine riesige Anlage in der dortigen Landschaft, die eine Nachbildung des Höhlensystems von Lascaux im Originalmassstab enthält. Die Anlage ist mit der neuesten Digitaltechnik ausgestattet, was dazu beiträgt, empfindliche archäologische Funde zu schützen.

\section{Implikationen für den Tourismussektor}

Naturgemäss ist nicht vorhersagbar, wie sich bereits vorhandene Basistechnologien weiterhin entwickeln. Ebenso wenig sind neue und noch unbekannte Technologien vorhersehbar. Dies erschwert es politischen Entscheidungsträgern heute, konkrete Massnahmen zu treffen müssen. Der schnelle technologische Wandel innerhalb der Gesellschaft, der sich wahrscheinlich noch ausweiten und beschleunigen wird, macht Anpassungen an bestehenden Ansätzen und neue politische Massnahmen umso schwieriger. Technologische Innovationen könnten das Tourismuserlebnis entweder radikal oder inkrementell verändern, ebenso die Art und Weise, in der Menschen innerhalb des Sektors arbeiten. Dies wirft Fragen hinsichtlich der bestmöglichen Steuerung dieses Wandels auf.

Allerdings scheinen neue und vorhergesehene aufkommende Technologien gewisse wichtige Gemeinsamkeiten zu haben, von denen sich die Politik leiten lassen kann. Digitale Technologien werden dazu beitragen, die Menschen stärker und schneller als je zuvor mit Informationen, anderen Menschen und Erfahrungen in Kontakt zu bringen. Wahrscheinlich werden Märkte und Abläufe in vielen verschiedenen Bereichen dadurch effizienter. In vielen Sektoren, einschliesslich des Tourismussektors, werden diese Änderungen mit grosser Wahrscheinlichkeit zu Umbrüchen führen und kurzfristig gesehen viele Arbeitskräfte aus ihren gewohnten Arbeitsmustern verdrängen. Zunehmende Versiertheit und die Fähigkeit, in einem Umfeld mit einem Übermass an Informationen datenbasierte Entscheidungen zu treffen, werden zunehmend wichtiger.

Neue Technologien könnten die Möglichkeit eröffnen, Reisenden stark massgeschneiderte Produkte und Erlebnisse anzubieten, da Touristen zunehmend transparentere und vergleichbarere Informationen abrufbereit parat haben, wenn sie sich entscheiden, wo sie übernachten, wie sie an ein Reiseziel gelangen oder wo sie essen können. Andererseits könnte der Aufstieg digitaler Plattformen und Portale im Reise- und Tourismusbereich auch die Gewinnmargen bestehender Tourismusanbieter in allen Sektoren von der Beförderung über die Unterbringung bis hin zur Verpflegung unter Druck setzen.

Die politischen Entscheidungsträger werden überlegen müssen, wie und ob sie verstärkt auf digitale Strategien setzen möchten, um Dienstleistungen im Tourismus in einem weltweiten Umfeld $\mathrm{zu}$ vermarkten und bereitzustellen, in dem dieser Ansatz wahrscheinlich vorherrschend sein wird. Österreich beispielsweise präsentierte im 
September 2017 eine Digitalisierungsstrategie für den österreichischen Tourismus. Manche Destinationen werden wohl eher ihre Angebote für Reiseerlebnisse bewusst differenzieren, indem sie verstärkt analoge und Offline-Optionen für Orte und Ziele anbieten, die von Besuchern aufgrund der besten Online-Bewertungen überlaufen werden.

Für politische Entscheidungsträger wird es von vorrangiger Bedeutung sein, weiterhin Wert auf Zukunftssicherheit $\mathrm{zu}$ legen und vorausschauend $\mathrm{zu}$ erkennen, wie Basistechnologien im Tourismussektor neue Chancen erschliessen und $\mathrm{zu}$ neuen Herausforderungen führen. Es sollten regelmässige Prüfungen durchgeführt werden, in die die Standpunkte aller wichtigen Interessengruppen, einschliesslich der Innovatoren, einfliessen und die zeigen, in welcher Weise bestimmte Sektoren anfällig für Umbrüche sind und wie sie möglicherweise neu ausgerichtet werden können, um den jeweils anstehenden Umbrüchen stets voraus zu sein.

Eine zweite wichtige Priorität sollte die Stärkung der regulatorischen und ComplianceRahmenbedingungen sein, um sie toleranter gegenüber Innovationen und angesichts schneller technologischer Veränderungen reaktionsfreudiger zu gestalten. Diese Ansätze müssen im Kontext der übergeordneten wirtschafts- und gesellschaftspolitischen Rahmenbedingungen betrachtet werden, die zwangsläufig die Arbeit nationaler, subnationaler und lokaler Regierungen sowie die Tätigkeitsbereiche der verschiedensten Sektoren überlappen und berühren - vom Wohnungsbau über den Verkehr bis hin zu Sicherheitsüberlegungen. 


\section{Kasten 4. Projekt «Intelligente Destinationen» in Spanien}

Eine «intelligente Destination» ist ein innovatives Tourismusziel, das für die nachhaltige Entwicklung eines Touristenbereichs modernste Technologie einsetzt, die für jeden zugänglich ist, die Interaktion der Besucher mit ihrem Umfeld und ihre Integration in dieses Umfeld fördert und die Qualität des Erlebnisses an der Destination verbessert, während gleichzeitig die Lebensqualität der Einheimischen verbessert wird.

Die Initiative wurde im Auftrag des spanischen Staatssekretariats für Tourismus durch SEGITTUR entwickelt und beworben, um die Position Spaniens als weltbekanntes Tourismusziel zu stärken. (SEGITTUR ist ein Unternehmen in Staatsbesitz, dessen Aufgabe in der Förderung der Erforschung und Entwicklung von Innovationen und neuen Technologien in der spanischen Tourismusbranche besteht.) Die entwickelte Methodik stärkt Innovationen, Nachhaltigkeit und Wettbewerbsfähigkeit auf lokaler Ebene durch die Entwicklung und den Einsatz von IKT mit dem Ziel, differenzierte und hochgradig wettbewerbsfähige Dienstleistungen zu schaffen.

Orte, die «intelligente Destinationen» werden möchten, müssen eine Strategie umsetzen, die auf mehr Wettbewerbsfähigkeit durch nachhaltigere Nutzung natürlicher und kultureller Attraktionen, die Schaffung zusätzlicher innovativer Ressourcen und Effizienzsteigerungen bei ihren Produktions- und Vertriebsprozessen abzielt. $\mathrm{Zu}$ den Themen, die als Teil der Initiative angesehen werden, zählen das Sicherstellen einer nachhaltigen Entwicklung, die Steuerung der Tragfähigkeit der Destinationen, Beiträge zur besseren saisonalen und räumlichen Verteilung der Touristenströme, die Steigerung der Profitabilität, das Sicherstellen der Beteiligung der Einheimischen am durch den Tourismus generierten Wohlstand sowie eine höhere Zufriedenheit der Touristen.

Auf dem Weg zur «intelligenten Destination» werden die Betroffenen mit enormen Herausforderungen und Möglichkeiten konfrontiert, die sorgfältig in Betracht gezogen, priorisiert und ausgewählt werden müssen. Georeferenzierte Daten, Big Data, das Internet der Dinge, Open Data und viele andere Datenquellen und -konzepte sind grundlegende Elemente im Rahmen des Wandels hin $\mathrm{zu}$ intelligenteren, nachhaltigeren und wettbewerbsfähigeren Tourismusdestinationen, die den Bedürfnissen aller beteiligten Interessengruppen entsprechen (www.segittur.es/en/inicio/index.html).

Ein dritter wichtiger Punkt, dem sowohl im Tourismussektor als auch in einem grösseren Zusammenhang Rechnung getragen werden muss, ist die bestmögliche Berücksichtigung des Datenschutzes und der Sicherheit in einer immer stärker vernetzten, datenintensiven Welt. Reisende, die mehr Daten angeben, könnten von Vorteilen wie einer schnelleren Abfertigung und kürzeren Sicherheitskontrollen profitieren. Wahrscheinlich wird aber auch die Nachfrage nach der Entwicklung angemessener Sicherheitsmassnahmen wachsen, die gewährleisten, dass die Daten nicht unbefugt genutzt werden.

Neue Technologien haben sich schon immer und zunehmend stärker auf die Wertschöpfungsketten im Tourismus ausgewirkt und werden dies auch weiterhin tun. Die anhaltende Weiterentwicklung der Geschäftsmodelle in diesem Sektor wird für viele Unternehmer neue Chancen eröffnen, während sie andere behindern dürfte. Für die Unternehmen wird es in diesem Umfeld kritisch sein, sich stärker auf Kommunikation, Vernetzung und Kompetenzen zur Steuerung von Partnerschaften zu konzentrieren. Um die Gelegenheit ergreifen und den Reisenden bessere Dienstleistungen anbieten zu können, 
sollte die Entwicklung entsprechender Strategien in enger Zusammenarbeit mit Regierungsstellen daher oberste Priorität besitzen (Kasten 4).

\section{Kritische Unsicherheiten}

Die folgenden kritischen Unsicherheiten könnten bis zum Jahr 2040 die Auswirkungen von Basistechnologien auf den Tourismus verändern.

- Es ist schwer vorherzusagen, wie schnell und wie umfassend Technologien wie künstliche Intelligenz eingesetzt werden. Die Prognosen verschiedener Studien hinsichtlich des Anteils der Stellen, die innerhalb der beiden nächsten Jahrzehnte der Automatisierung zum Opfer fallen werden, reichen von rund 5\% bis hin zu fast der Hälfte der Arbeitsplätze.

- Die Rolle der vorherrschenden digitalen Plattformen hinsichtlich der Beherrschung des Zugangs zu bestimmten Aktivitäten wie Flug- und Unterkunftsbuchungen könnte das Erscheinungsbild der Reisebranche dramatisch verändern. Ob und wie traditionelle Marktteilnehmer wie Fluggesellschaften und Hotels mit den etablierten Technologiegiganten konkurrieren können, könnte entscheidend für ihre langfristigen Gewinnaussichten und ihre Bedeutung in einer Welt mit immer weniger Zwischenhändlern werden.

- Angesichts potenziell immer stärker werdender populistischer Einstellungen könnten Daten und Technologien in Handelsstreitigkeiten zwischen einzelnen Ländern als Druckmittel eingesetzt werden. Sollte es für Technologieunternehmen problematisch werden, grenzüberschreitend auf Kundendaten zuzugreifen und diese weiterzugeben, könnten sie eine weniger wichtige Rolle in der Tourismusbranche spielen und wären weitgehend auf Werbung und die Informationsvermittlung beschränkt. Dies könnte traditionellen Vermittlern die Chance eröffnen, auf ihren inländischen Märkten eine entscheidende Rolle zu spielen.

\section{Plausible Zukunftsszenarien}

\section{Bereitwillige Annahme einer technologischen Utopie}

- Das Reiseerlebnis ist durch eine Vielzahl von Basistechnologien deutlich aufgewertet worden. Verbraucher mit Mobilitätsproblemen oder finanziellen Beschränkungen können schnell und preiswert auf immersive virtuelle Realität zurückgreifen, um Reiseziele auf der anderen Seite der Welt zu erleben, ohne jemals ihr Zuhause verlassen zu müssen. Mit der gleichen Technologie können anspruchsvolle Verbraucher eine Reihe Reisemöglichkeiten erkunden, bevor sie sich für ein bestimmtes Ziel und bevorzugte Dienstleister entscheiden. Sie können aus einem vielfältigen Ökosystem unterschiedlicher Möglichkeiten wählen, das sowohl von Technologiegiganten als auch von kleineren, spezialisierten Unternehmen bevölkert wird.

- Persönliche digitale Assistenten mit künstlicher Intelligenz bieten reibungslos Reiseinformationen und Beratung zu Flug- und Übernachtungsmöglichkeiten in Echtzeit an und durchsuchen eine Vielzahl von Angebotsplattformen, um das beste Preis-Leistungs-Verhältnis zu finden. Simultanübersetzungsgeräte sorgen dafür, dass sich jeder ungeachtet seiner Fremdsprachenkenntnisse fliessend unterhalten kann. 
- Kryptowährungen sind allgegenwärtig und senken die Transaktionskosten für den Währungsumtausch auf praktisch Null. Die Blockchain-Technologie wird darüber hinaus für Reisepässe sowie die sichere Authentifizierung von Reisenden und Visa eingesetzt und lässt die Erinnerung an lange Schlangen und Wartezeiten an den Sicherheitskontrollen verblassen. Flugreisen sind, was die Wartezeiten anbelangt, so schnell und einfach wie das Besteigen eines Linienbusses. Hyperloop und Elektroautos haben den Kohlendioxidausstoss der meisten inländischen und regionalen Verkehrsmittel dramatisch gesenkt. Fortschritte in der Solartechnik und bei Elektroantrieben für Flugzeuge haben auch den Kohlendioxid-Fussabdruck von Auslandsreisen dramatisch verkleinert, sodass die meisten Menschen öfter und preiswerter verreisen können.

\section{Kampf gegen eine kapitalistische Hightech-Dystopie}

- Der Tourismus ist zum Spielfeld einer kleinen, wohlhabenden Elite geworden. Angesichts von Sorgen hinsichtlich der Verschlechterung und Übersättigung beliebter Tourismusdestinationen haben Gastgeberländer drastische Massnahmen zur Verringerung der Besucherzahlen ergriffen. Die meisten Besucher müssen sich mit unbefriedigenden Virtual-Reality-Simulationen der echten Attraktionen zufriedengeben. Nur diejenigen, die sich einen heftigen Aufpreis leisten können, erhalten Zugang zu bestimmten Gebieten oder Attraktionen an bestimmten Destinationen.

- Ein dramatischer Zusammenbruch der Arbeitsmärkte in den entwickelten Volkswirtschaften als Folge von künstlicher Intelligenz und Robotik, die viele gut bezahlte Arbeitsplätze ersetzen und bei vielen anderen Arbeitsplätzen Druck auf Löhne und Gehälter ausüben, hat verfügbares Einkommen für die übergrosse Mehrheit der Bürger zu einer Seltenheit gemacht. Diejenigen, die es sich leisten können, Reisen zu unternehmen, reisen typischerweise keine langen Strecken oder sind gezwungen, auf möglichst preiswerte Angebote eines der wenigen riesigen digitalen Anbieter von Flugbuchungen zurückzugreifen. Die betreffenden Flüge haben sich aufgrund des geringen Online-Wettbewerbs stark verteuert und sind für den durchschnittlichen Reisenden ein seltener Luxus.

- Häufige und um sich greifende Hackerangriffe auf die elektronische Infrastruktur durch private Akteure, die Chaos stiften und personenbezogene Daten gewinnbringend nutzen wollen, machen Reisevorbereitungen nun langwieriger als je zuvor. Lange Wartezeiten an Flughäfen und sogar im Bahn- und Busverkehr schrecken viele Menschen vom Reisen ab. Es gibt keinen international koordinierten Prozess für höhere Datensicherheit oder einen reibungsloseren Ablauf der Sicherheitskontrollen.

\section{Gefangen in technologischer Kurzsichtigkeit}

- Infolge des anhaltenden technischen Fortschritts hat sich die Tourismusbranche erheblich weiterentwickelt. Durch Fortschritte bei künstlicher Intelligenz und Datenanalyse können Reiseerlebnisse basierend auf persönlichen Vorlieben personalisiert werden, und die Unternehmen sind nun besser in der Lage, verschiedenartige Bedürfnisse der Reisenden aus verschiedenen Ländern, Altersgruppen und Kulturen zu befriedigen. Ausserdem haben technologische Entwicklungen zu einer besseren Integration vieler Dienstleistungen geführt, sodass den Reisenden nun hochwertigere Echtzeitinformationen zur Verfügung 
stehen. Die Sharing Economy ist weiter aufgeblüht, was zu einem Anstieg von Peer-to-Peer-Transaktionen geführt hat, die den Reisenden den Zugang zu erschwinglichen, nicht-traditionellen Unterkunfts- und Beförderungsmöglichkeiten erleichtern.

- Ausserdem haben technologische Fortschritte komplexe Innovationen im Bereich der virtuellen und erweiterten Realität ermöglicht. Während diese Technologien jedoch das Marketing der Destinationen verbessert haben, werden sie von den Reisenden nicht als echter Ersatz für das persönliche Reisen zu beliebten Tourismuszielen angesehen. Dies bedeutet, dass Probleme wie überbordender Tourismus und Umweltbedrohungen noch immer nicht überwunden sind.

- Eine weitere nach wie vor bestehende Herausforderung für politische Entscheidungsträger ist es, die Verbraucherdaten zu schützen und ihre Verwendung durch die Unternehmen zu regulieren, ohne dabei Innovationen zu behindern. Die Regierungen kämpfen noch immer mit der zunehmend globalen Natur der Technologiegiganten, und es bestehen nach wie vor Konflikte in Zusammenhang mit der internationalen Zusammenarbeit bei der Besteuerung. Globalen Plattformen wird weiterhin vorgeworfen, in der Tourismusbranche Monopole aufzubauen, da die Interaktionen zwischen kleinen Reiseanbietern und den Verbrauchern dramatisch zurückgegangen sind. Automatisierung und künstliche Intelligenz haben zu keinem grossen Stellenabbau in der Tourismusbranche geführt. Von vielen Arbeitskräften wird jedoch grössere Technologiekompetenz erwartet.

\section{Analyse der Szenarien}

Der technologisch bedingte Wandel des Tourismussektors ist unvermeidlich. Die etablierten Akteure werden gezwungen sein, Technologie einzusetzen, um zu überleben. Die Reisenden werden sich einerseits nach wie vor auf Technologie verlassen und andererseits manchmal Mühe haben, mit ihrer schnellen Entwicklung Schritt zu halten. Dieses unvermeidliche Wachstum wird besonders in der Sharing Economy zu spüren sein, und es werden wahrscheinlich weitere Tausch- und Vermittlungsplattformen entstehen. Obwohl diese Angebote kostengünstig sind und den Verbrauchern viele Möglichkeiten bieten, werden Markteintritte durch die Kultur der Online-Bewertungen behindert. Wenn sich die Kunden bei der Online-Auswahl einer Dienstleistung oder Unterkunft beispielsweise auf gute Bewertungen verlassen wollen, werden sie kaum auf neue Angebote zurückgreifen, für die noch keine Bewertungen vorliegen. Obwohl es ausserdem Probleme in Zusammenhang mit diesen Vermittlern geben kann, ist angesichts des Wachstums und der immer beherrschenderen Stellung dieser Marktteilnehmer kaum eine Alternative vorstellbar.

Wahrscheinlich wird auch die virtuelle Realität (VR) im Tourismus zunehmend an Bedeutung gewinnen. VR ist ein interessanter Fall, da ein schmaler Grat zwischen dem Einsatz der Technologie für die Erleichterung verschiedener Reiseerlebnisse und dem vollständigen Ersetzen realer Reisen durch VR besteht. Der Einsatz von VR könnte zum Beispiel sinnvoll sein, wenn Reiseinteressenten verschiedene potenzielle Destinationen erst einmal kennenlernen möchten, bevor sie sich für ihr nächstes Ferienreiseziel entscheiden. Man könnte sich aber auch eine Welt vorstellen, in der die VR-Technologie so weit entwickelt ist, dass einige Menschen gar kein Bedürfnis mehr verspüren zu reisen, weil sie die gleiche Erfahrung in der Bequemlichkeit der eigenen vier Wände machen können. Dieses Szenario wäre besonders dann wahrscheinlich, wenn Auslandsreisen für viele Menschen beispielsweise aufgrund von Restriktionen, die dem Tourismus auferlegt 
werden, unerschwinglich würden. Sollte sich die Tourismusbranche in diese Richtung entwickeln, können aus den betreffenden technologischen Fortschritten neue Herausforderungen für die Politik, beispielsweise rund um geistiges Eigentum, erwachsen. Wohlhabendere Destinationen und weltweit agierende Technologieunternehmen könnten die Hauptprofiteure dieses Wandels sein.

Sollte der internationale Tourismus teuer und restriktiv werden, könnten die Destinationen die Möglichkeit haben, den inländischen Tourismus stärker zu entwickeln. Die Regierungen müssten in diesem Fall strategisch über die Finanzierung und Planung von Infrastrukturen nachdenken, die einer steigenden inländischen Tourismusnachfrage gerecht werden. Beispielsweise könnten an verschiedenen Transitstationen Bike-SharingMöglichkeiten angeboten werden, die die Optionen der Reisenden innerhalb einer Destination verbessern. Intermodaler Verkehr und integriertes Ticketing/Smartcards könnten das Reisen über die traditionellen Destinationen hinaus erleichtern. Während Reisebeschränkungen alternative Tourismusformen vorantreiben könnten, könnten sie aber auch allgemeine Ablehnung aufgrund der gestiegenen Kosten nach sich ziehen.

Ein weiteres Problem ist die zunehmend beherrschende Stellung «digitaler Giganten»Privatunternehmen, die einen immer grösseren Marktanteil in der Tourismusbranche auf sich vereinen und die sich oftmals in Richtung von Monopolanbietern innerhalb der Branche entwickeln. Es besteht allgemeines Einverständnis, dass diese Marktakteure in gewissem Mass reguliert werden müssen, insbesondere hinsichtlich Datennutzung und Sicherheit. Allerdings werden die Regierungen bei jeglichen Regulierungsversuchen intensiven Lobbyismus von dieser Seite $\mathrm{zu}$ erwarten haben. Eine weitere besorgniserregende Entwicklung ist der mögliche Kontrollverlust der politischen Entscheidungsträger angesichts der wachsenden Dominanz der Informationstechnik (IT). Anders gesagt, die Tourismusministerien könnten langsam durch die IT-Ministerien übernommen werden.

$\mathrm{Zu}$ all diesen Problemfeldern kommen noch die zahlreichen Fallstricke der bestehenden Regierungsprozesse hinzu, die nicht angemessen an den schnellen technologischen Wandel angepasst sind, den sie in den Griff bekommen sollen. Die Gesetzgebungsprozesse sind beispielsweise viel zu langwierig. In vielen Fällen sind Gesetze, nachdem sie formuliert und verabschiedet wurden und die betreffenden Verordnungen in Kraft sind, schon wieder seit Jahren veraltet. Ausserdem sind viele Bestimmungen inkonsistent. Das regulatorische Umfeld sieht beispielsweise für zwei Personen, die Eintrittskarten kaufen - einer persönlich vor Ort, der andere online über sein Smartphone - vollkommen unterschiedliche Bestimmungen vor, selbst wenn der Online-Kauf direkt am Veranstaltungsort erfolgt. Diese Bestimmungen sorgen in der Branche für viel Frustration und den Wunsch nach der Einführung besserer Alternativen durch die Regierungen. Schliesslich sorgen auch die kurzen Legislaturperioden und die ständige Konzentration auf Wahlkämpfe für viel Ineffektivität.

Eine mögliche Verschiebung in der Beschäftigungssituation innerhalb des Sektors infolge des technologischen Wandels steht als ständige Bedrohung im Raum. Es erscheint wahrscheinlich, dass manche Stellen verschwinden werden, insbesondere im Bereich der Tourismusdienstleistungen. Automatisierung und künstliche Intelligenz könnten im Hintergrund stattfindende Arbeiten in Hotels und Restaurantküchen leicht ersetzen. Bei vielen Arbeitsplätzen im Verkehrsbereich sieht es ähnlich aus. Diese könnten durch selbstfahrende Fahrzeuge und transaktionale Belegung in der Nähe von Touristenattraktionen ebenfalls wegfallen. 
Die Arbeitsplätze innerhalb des Sektors werden vermutlich eine sehr viel höhere technologieorientierte Basiskompetenz erfordern, als dies gegenwärtig der Fall ist. Um zu gewährleisten, dass die Arbeitskräfte für die künftigen Stellen in der Tourismusbranche gut gerüstet sind, werden sowohl die Arbeitgeber als auch die Regierungen erheblich investieren müssen. Estland beispielsweise hat massiv in die Vorbereitung seiner Arbeitskräfte auf die zu erwartende Welle technologischer Veränderungen investiert. Um einem Programmierermangel im IT-Bereich zu begegnen, bietet die Regierung kostenlose Kurse und Schulungen für die Befriedigung der Nachfrage nach diesem Kompetenzprofil an. Ausserdem wird ausländischen Arbeitskräften, die Lücken füllen können, der Zuzug gestattet. Gleichzeitig investiert die Regierung auch erheblich, um die Jugend und ältere Menschen in der Verwendung von Technologien fit zu machen.

Weitere vielversprechende Strategien der Regierung betreffen die Notwendigkeit, flexibler und rascher auf technologischen Wandel reagieren zu können. So bietet beispielsweise das kroatische E-Visitor-Programm, ein technologiebasiertes Informationssystem für das Einund Auschecken von Touristen, eine kostenlose Internetanwendung mit Anbindung an die landesweiten Fremdenverkehrsämter. Ausserdem liefert es tourismusbezogene Daten an eine zentrale Datenbank (Croatia National Tourist Board, 2018). Das Programm war ein wichtiger erster Schritt im Rahmen weitreichenderer Bemühungen der kroatischen Regierung um eine Digitalisierung im Tourismus. Es wird auch wichtig sein, im Zuge der Diskussion des technologischen Wandels die Rolle der Entwicklungsländer zu berücksichtigen. Länder wie Indien beispielsweise, wo grosse Teile der Bevölkerung ohne Elektrizität leben, könnten in den kommenden Jahren vor überproportional grosse Herausforderungen gestellt werden.

\section{Mögliche politische Massnahmen}

1. Die politischen Entscheidungsträger sollten Strategien ins Auge fassen, um Innovationen zu fördern, mit denen sich die Chancen neu entstehender Technologien nutzen lassen und die gewährleisten, dass proaktive und konsultative Regulierungsmechanismen entwickelt werden, die diese Technologien in geordnete Bahnen lenken. Der Einsatz von IKT im Tourismussektor lässt sich mittels einer Innovationskultur fördern, gestützt durch regulatorische und Compliance-Rahmenbedingungen, die Investitionen anziehen, eine Startup-Kultur begünstigen und schnell auf technologische Veränderungen reagieren ${ }^{6}$.

2. Die politischen Entscheidungsträger sollten Massnahmen ergreifen, um kleinen und mittleren Unternehmen (KMU) den Übergang in die digitale Wirtschaft zu erleichtern. Der digitale Wandel kann KMU neue Möglichkeiten bieten, auf einfache Weise internationale Märkte zu erschliessen und direkt mit Kunden auf der ganzen Welt in Kontakt zu treten. Ein wichtiges Element dieses Prozesses ist die Vereinfachung des Zugriffs von KMU auf technisches Wissen und spezialisierte Informationen (z. B. Verbindungen mit Dienstleistern und Technologieanbietern einschliesslich Forschungszentren und Universitäten, um die Einführung von IKT, Lernmöglichkeiten und Innovationen zu fördern).

\footnotetext{
${ }^{6}$ Paris\&Co rief beispielsweise im Jahr 2013 das «Welcome City Lab» ins Leben - eine Plattform, die Paris als weltweit führenden Standort für Innovationen im Städtetourismus stärken soll. Das Lab umfasst Anlaufförderung für Startup-Unternehmen einschliesslich Coaching und Geschäftsentwicklung, eine Akademie für spezifische tourismusrelevante Kompetenzen, Experimente mit neuen Produkten und Dienstleistungen sowie die Vorhersage neuer Trends.
} 
3. Die politischen Entscheidungsträger müssen eng mit Industrie, Hochschulen, Universitäten und Schulungseinrichtungen zusammenarbeiten, um sicherzustellen, dass die Arbeitskräfte im Tourismus der Zukunft die Anforderungen eines im Wandel befindlichen Sektors erfüllen und das Rüstzeug besitzen, um mit neuen Technologien zu arbeiten und sich an sie anzupassen. Insbesondere KMU werden bei ihren Bemühungen, technisch versierte Mitarbeitende zu gewinnen und zu halten, Unterstützung benötigen (z. B. durch Netzwerke, in denen sie Mentoring und Geschäftsunterstützung erhalten, sowie durch Zugang zu geeigneten Schulungen).

4. Um mit dem technologischen Wandel Schritt zu halten, werden auch die Regierungen Anstrengungen hinsichtlich Rekrutierung und Weiterbildung unternehmen müssen, um Mitarbeitende anzuziehen und zu halten, die die neu entstehenden Technologien hochkompetent beherrschen. Besondere Bedeutung wird dem innerhalb der Tourismusministerien zukommen, in denen die entsprechende technologische Expertise möglicherweise noch nicht vorhanden ist, die aber benötigt wird, um mittels neuer Technologien ihre Ziele im Tourismus zu erreichen.

5. In einer Zeit, in der Technologie eine immer grössere Rolle für touristische Erlebnisse spielt, wird die internationale Zusammenarbeit zu einem unverzichtbaren Bestandteil aller Bemühungen im Hinblick auf Datensicherheit und Schutz der Privatsphäre. Dies erfordert als weltweites und grenzüberschreitendes Phänomen kontinuierliche Gespräche über verschiedene Regierungsebenen innerhalb der einzelnen Länder hinweg, wie auch diplomatische Bemühungen und länderübergreifende Zusammenarbeit ${ }^{7}$.

7 Die Datenschutz-Grundverordnung (DSGVO) der EU - ein modernisierter Rahmen für die Datenschutzgesetzgebung, der im Mai 2018 in Kraft getreten ist - ist in dieser Hinsicht ein vielversprechender Schritt in die richtige Richtung. Die DSGVO führt eine Reihe von Reformen ein, die die Chancengleichheit der Unternehmen verbessern und Einzelpersonen grössere Kontrolle über ihre personenbezogenen Daten geben (Europäische Kommission, 2018). 


\section{Reisemobilität}

Abbildung 4. Wichtige Trends bei der Reisemobilität

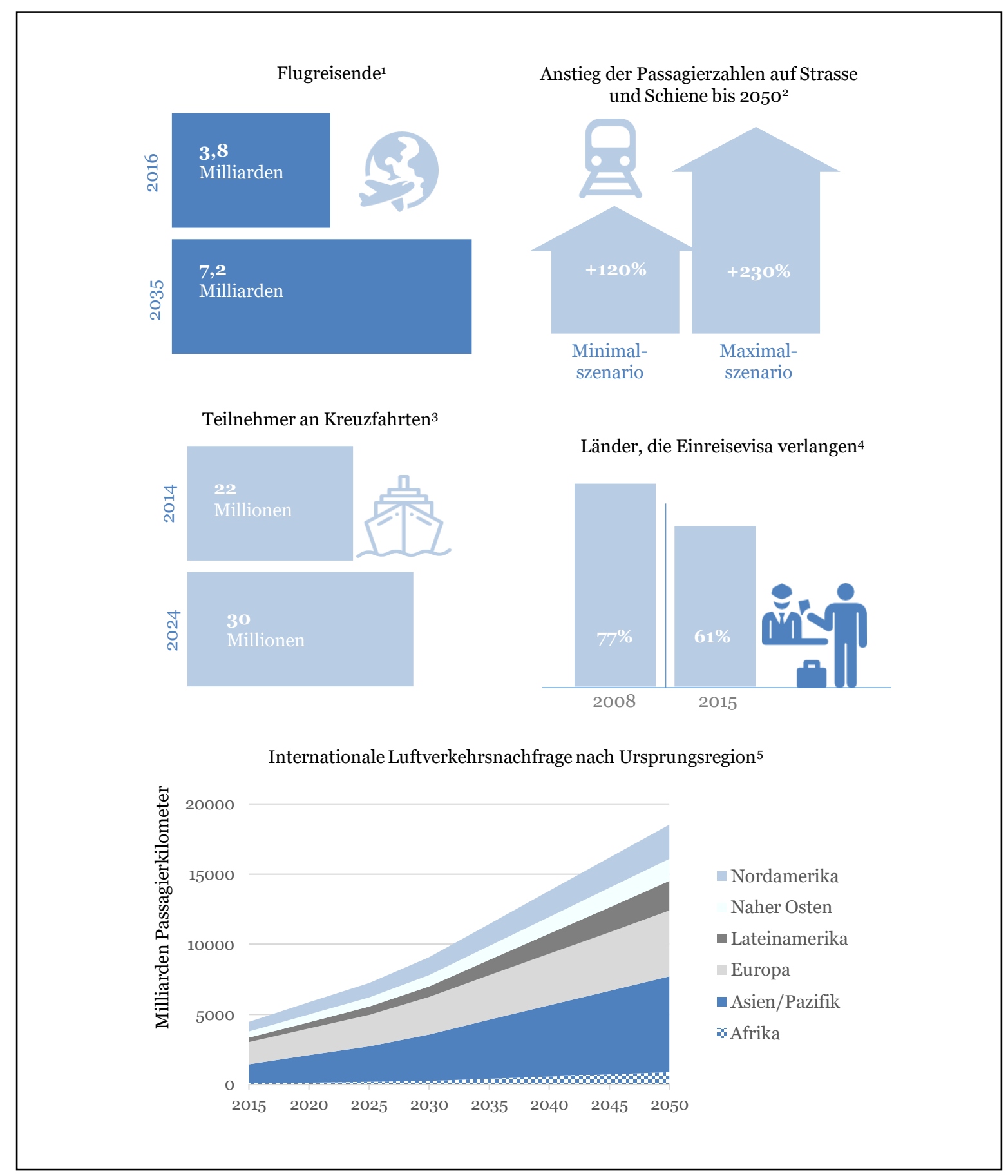

OECD-Infografik, basierend auf verschiedenen Quellen: 1. IATA (2016); 2. OECD/ITF (2015); 3. CLIA (2015), 4. UNWTO (2016b); 5. OECD/ITF (2017); Baseline-Szenario. Einige der Symbole wurden durch Freepik von www.flaticon.com entworfen. 
Verkehr ist ein wesentlicher Bestandteil des Tourismussystems. Er spielt eine entscheidende Rolle, um Touristen effizient von ihren Wohnorten zu den Reisezielen und von dort zu den einzelnen Attraktionen zu bringen. Verkehr verbindet die einzelnen Märkte in touristischen Regionen zu Destinationen und ermöglicht die internen Bewegungen der Besucher zwischen den einzelnen Bestandteilen ihres touristischen Erlebnisses (z. B. Unterkunft, Attraktionen, kommerzielle Dienstleistungen). Er kann ein wichtiger Bestandteil der Attraktion oder schon für sich genommen ein Erlebnis sein. Der Standort, die Kapazität, die Effizienz und die Verbindungsmöglichkeiten der Verkehrsmittel können eine wichtige Rolle für die physische Entwicklung einer Destination spielen. Sie wirken sich auf die Mobilität der Besucher und die Möglichkeit aus, touristische Erlebnisse innerhalb der Destinationen miteinander zu verbinden.

Die Synergien zwischen Verkehrs- und Tourismuspolitik sind erheblich und liegen auf der Hand. Die Regierungen spielen eine wichtige Rolle bei der Nutzung der Verknüpfungen zwischen beiden Politikfeldern. Obwohl die Verkehrspolitik darauf abzielt, für gute Verbindungen und nahtlose Beförderung zu sorgen, die sowohl die kurz- als auch die langfristigen Bedürfnisse der Wirtschaft und der Gemeinden befriedigen, wirkt sie sich auch auf Touristen aus, die sich an einem Reiseziel bewegen. Um zwischen Städten oder grenzübergreifend integrierte, multimodale Verkehrssysteme (einschliesslich Land-, Seeund Luftverkehr) bereitstellen zu können, sind abgestimmte Massnahmen einer Vielzahl von Interessengruppen erforderlich, die technischen, institutionellen und finanziellen Aspekten Rechnung tragen (OECD, 2016c).

Der Verkehr war immer ein wichtiger Wegbereiter für den internationalen Tourismus, der die Verbraucher zu kommerziellen Dienstleistern und die Anbieter an die weltweiten Märkte bringt. Der Zustrom von Touristen kann die Verkehrsinfrastruktur sowie die zugehörigen Dienstleistungen wie Strassen, Busse, Eisenbahnen, den Seeverkehr und vielleicht am wichtigsten - den Luftverkehr jedoch erheblich belasten.

Aus Sicht des internationalen Tourismus ist die dominierende Rolle des Luftverkehrs bei der Beförderung der Touristen zu ihren Reisezielen ganz klar. Im Jahr 2015 beispielsweise lag der Anteil des Luftverkehrs laut Schätzungen der UNWTO bei etwas mehr als der Hälfte (54\%) aller Ankünfte aus dem Ausland. Der Strassenverkehr machte 39\%, der Verkehr auf dem Wasser 5\% und der Schienenverkehr 2\% aus (UNWTO, 2016a). Während Luft- und Strassenverkehr mit Abstand die beliebtesten Beförderungsvarianten für Auslandsreisende darstellen, spielen Schiene und Wasser, und in Erweiterung davon Kreuzfahrtterminals und internationale Bahnhöfe, eine wichtige Rolle bei der Verteilung der Besucher auf und rund um ihre gewählten Destinationen.

Das rasche Wachstum des Tourismus und des Luftverkehrs in den letzten Jahrzehnten ist insbesondere auf zwei wichtige Faktoren zurückzuführen: i) höhere Einkommen und eine entstehende Mittelschicht in den Schwellenländern, die höhere Konsumausgaben einschliesslich Reisen (mit beliebigen Verkehrsmitteln) ermöglichen, sowie ii) ein verbessertes Preis-Leistungs-Verhältnis des Luftverkehrs infolge technischer Fortschritte in der Luft- und Raumfahrt und der Liberalisierung des Marktes. Die Liberalisierung im Luftverkehr hat zu stärkerem Wettbewerb geführt, die Erschliessung neuer Flugrouten begünstigt und zum Aufkommen neuer Geschäftsmodelle für Fluggesellschaften beigetragen, wie Charter- oder Billigfluglinien, die den Wettbewerb in der Luftfahrtbranche beflügelt haben (ICAO, 2013).

Das für die kommenden 20 bis 25 Jahre vorhergesagte Wachstum des Tourismus verspricht enorme wirtschaftliche Vorteile und Arbeitschancen in Destinationen auf der gesamten Welt. Allerdings basieren das Wachstum und der Erfolg des Sektors darauf, dass die 
Menschen sicher und frei grenzüberschreitend reisen können (WEF, 2016). Die Reisemobilität ist von einer Reihe interner und externer Faktoren abhängig, die für die Branche und politische Entscheidungsträger Chancen und Herausforderungen gleichermassen bedeuten. Sie alle müssen durch die Tourismuspolitik und die entsprechenden Strategien berücksichtigt werden, um ein nachhaltiges Wachstum des Sektors zu gewährleisten.

Insbesondere Massnahmen, die das Reisen vereinfachen, einschliesslich der Zoll- und Einreisebestimmungen sowie der Visaanforderungen für Besucher, sind wesentliche Komponenten, wenn es darum geht, einfache Mobilität zwischen Destinationen sicherzustellen. Werden diese Prozesse zeitaufwendig, teuer oder bürokratisch gestaltet, können sie von Reisen zum jeweiligen Ziel abschrecken. Im Gegensatz dazu kann die Attraktivität einer Destination gesteigert werden, indem die betreffenden Prozesse verschlankt und effizienter gestaltet werden.

Selbstverständlich hängen die Grenz- und Sicherheitsmassnahmen von übergeordneten externen Faktoren wie geopolitischen Instabilitäten und einem gestiegenen Risiko von Terroranschlägen ab. Die Welt ist in eine Phase signifikanter Unsicherheit eingetreten, in der protektionistische Ansichten an Boden gewinnen und viele Länder sich auf sich selbst zurückziehen. Die Reisemobilität ist stark von diesem geopolitischen Wandel betroffen, der naturgemäss nicht vorhersagbar ist und auf den sich kein Sektor problemlos vorbereiten kann.

\section{Wichtige Fakten und Vorhersagen}

Die Anzahl der Auslandsreisen wird in den kommenden Jahrzehnten voraussichtlich erheblich steigen. Insbesondere der Flugverkehr dürfte sich bis zum Jahr 2035 nahezu verdoppeln und von 3,8 Milliarden auf 7,2 Milliarden Passagiere anwachsen (IATA, 2016). Das International Transport Forum (ITF) geht davon aus, dass sich die Anzahl der Passagierkilometer bis 2030 auf 9 Billionen verdoppeln wird. Angetrieben wird diese Entwicklung durch das starke Wachstum in der Region Asien/Pazifik, auf die nach 30\% im Jahr 2015 dann $40 \%$ des weltweiten Passagieraufkommens entfallen werden (OECD/ITF, 2017).

Das ITF sagt bis zum Jahr 2050 auch ein starkes Wachstum des weltweiten Passagierverkehrs auf Strasse und Schiene voraus. Die Schätzungen reichen abhängig von der Entwicklung der Kraftstoffpreise und der Verkehrspolitik der Städte von $120 \%$ bis 230\%. Haupttreiber dieses Wachstums sind die Nicht-OECD-Staaten, in denen die Passagierzahlen voraussichtlich zwischen $240 \%$ und $450 \%$ ansteigen werden (OECD/ITF, 2015). Auch die Kreuzfahrtbranche ist in den letzten 30 Jahren stark gewachsen. Nachdem der Grossteil der Nachfrage zunächst aus Nordamerika kam, ist seit Kurzem auch aus Europa und dem Rest der Welt wachsende Nachfrage zu verzeichnen. Cruise Lines International (CLIA) schätzt, dass die weltweite Nachfrage nach Kreuzfahrten in den zehn Jahren zwischen 2004 und 2014 von 13,1 Millionen auf 22 Millionen Passagiere angestiegen ist (+68\%). Allein im Jahr 2014 betrug das Wachstum 3,4\%. Es ist davon auszugehen, dass die weltweiten Passagierzahlen im Jahr 2018 die Marke von 25 Millionen überschreiten und im Jahr 2024 bis auf 30 Millionen ansteigen werden (CLIA, 2015).

Das starke Wachstum, das der Luftverkehr in den vergangenen Jahrzehnten weltweit verzeichnen konnte, dürfte sich zwischen 2030 und 2050 hauptsächlich aus zwei Gründen abschwächen. Erstens wird das langsamere Wachstum nach 2030 durch das prognostizierte Wachstum von BIP und Bevölkerungszahlen getrieben, das jedoch schwach oder sogar negativ sein dürfte. So dürfte beispielsweise China im Jahr 2030 sein 
Bevölkerungsmaximum erreichen. Zweitens erreicht das Verkehrsnetz allmählich seinen Sättigungszustand, und es sind immer weniger potenzielle neue Verbindungen denkbar. Dies gilt insbesondere für die längsten Fernstrecken, die sich nicht gut für die Übernahme von Billigflugmodellen eignen. Grössere Wachstumsmöglichkeiten bestehen noch in den regionalen Luftverkehrsnetzen (OECD/ITF, 2017).

In Asien bedeutet das zum Beispiel, dass die Passagierzahlen an etablierten Langstreckenflughäfen voraussichtlich langsamer wachsen werden als an den weniger bedeutenden und oft regionalen Flughäfen. Viele dieser regionalen Flughäfen sind noch weitgehend vom inländischen Verkehr abhängig und haben erst vor Kurzem mit der Abfertigung von Auslandsflügen begonnen. Ihr Wachstum wurde durch das Aufkommen von Regionalflügen begünstigt, die insbesondere durch Billigfluglinien angeboten werden. So hat sich beispielsweise die Anzahl der internationalen Flüge am Flughafen Chongqing zwischen 2010 und 2015 verfünffacht, während das Passagieraufkommen in der Region in den nächsten beiden Jahrzehnten um voraussichtlich $15 \%$ steigen wird. Dem gegenüber stehen die Regionen Peking und Schanghai mit weniger als 5\% Wachstum bei den internationalen Passagierzahlen in den vergangenen Jahren, eine Zahl, die auch in absehbarer Zukunft nicht steigen dürfte (OECD/ITF, 2017).

Für kürzere Strecken könnte ein wachsendes Angebot an Hochgeschwindigkeitszügen mit etablierten Netzen in Europa und einem schnell wachsenden Netz in China der Luftfahrtbranche verstärkt Konkurrenz machen. Dies gilt umso mehr, als der Bahnverkehr als praktische und umweltfreundlichere Alternative angesehen wird. In der Europäischen Union beispielsweise hat der Bahnverkehr in den Jahrzehnten vor der Wirtschaftskrise grösstenteils infolge des Ausbaus eines Hochgeschwindigkeits-Streckennetzes erheblich zugenommen. Auf bestimmten Verbindungen zwischen grossen Städten (z. B. ParisLondon und Paris-Brüssel) haben Hochgeschwindigkeitszüge bei den meisten Passagieren mittlerweile das Flugzeug als Verkehrsmittel erster Wahl weitgehend oder sogar vollständig abgelöst (OECD/ITF, 2017).

Obwohl alte wie auch neue Destinationen von der positiven Entwicklung des internationalen Luftverkehrs, und allgemeiner vom Wachstum der weltweiten Luftfahrtbranche, profitieren dürften, bringt das massive Wachstum der Passagierzahlen auch erhebliche Herausforderungen mit sich.

Mehr internationale Reisende bedeuten beispielsweise auch, dass sich der Druck auf den Tourismussektor, sich angesichts des Klimawandels anzupassen, noch verstärken wird. Derzeit ist der Tourismus nur für rund 5\% der weltweiten Treibhausgasemissionen verantwortlich. Doch ein Grossteil davon ist dem Flugverkehr zuzurechnen, der allein im Jahr 2015 für einen Ausstoss von 781 Millionen Tonnen $\mathrm{CO}_{2}$ verantwortlich war (ATAG, 2016). Sollten sich Reisen und der Tourismus auf dem bisherigen Pfad weiterentwickeln, wird der Sektor zu einer immer bedeutenderen Quelle von Treibhausgasemissionen werden.

Der Klimawandel selbst führt aber noch zu weiteren Risiken. Bis 2080 könnten die täglichen Durchschnittstemperaturen um rund drei Grad und die maximalen Tagestemperaturen um vier bis acht Grad ansteigen. Bei derart extremen Hitzewellen wäre in Zukunft wohl ein Drittel der Flugzeuge gezwungen, am Boden zu bleiben, was kostspielige Annullierungen und Verspätungen nach sich zöge (Coffel et al., 2017). Ausserdem ist davon auszugehen, dass extreme Wetterereignisse insbesondere auf einigen beliebten Transatlantikstrecken zu häufigeren und schwereren Turbulenzen führen werden (Williams, 2017). Sowohl die Regierungen als auch die Reisebranche müssen erneut 
darüber nachdenken, wie der Luftverkehr und die betreffenden Regulierungen diesen Bedrohungen gerecht werden können.

Sicherheits- und Grenzmassnahmen wirken sich nicht nur erheblich auf die Reisemobilität, sondern auch auf das Kundenerlebnis aus. Laut Berichten der IATA zählen lange Wartezeiten an Sicherheitskontrollen für Reisende zu den ärgerlichsten Erlebnissen. Die betreffenden Beschwerden werden in den kommenden Jahren wohl eher zunehmen (WEF, 2016). In den Vereinigten Staaten beispielsweise hat das United States Department of Homeland Security (Heimatschutzministerium) bereits darauf hingewiesen, dass die entsprechenden Unannehmlichkeiten insbesondere während der Hochsaison unvermeidlich seien (Hetter and Pearson, 2016).

Auch das Weltwirtschaftsforum hält Einreisevisa für «eine der schlimmsten bürokratischen Ineffizienzen, unter denen Reisende zu leiden haben» und die Menschen davon abhalten können, bestimmte Reiseziele zu besuchen (WEF, 2016). Tatsächlich gibt es Hinweise, die nahelegen, dass Länder, die ihre Visavergabeprozesse verbessert haben, einen Anstieg der Anzahl von Auslandsreisenden zwischen 5\% und 25\% verzeichneten, mit allen damit verbundenen positiven Auswirkungen auf die gesamte Wirtschaft (UNWTO und WTTC, 2012). Insgesamt gesehen versuchen die meisten Länder, ein Gleichgewicht zwischen der Vereinfachung des Reisens und der Aufrechterhaltung oder Verbesserung der Sicherheit ihrer Grenzen zu finden. Mittlerweile gilt zudem für bestimmte Reisende in immer weniger Ländern Visumpflicht. Im Jahr 2008 verlangten Tourismusziele im Durchschnitt von 77\% der Weltbevölkerung ein Einreisevisum. Diese Zahl fiel bis zum Jahr 2015 auf nur 61\% (UNWTO, 2016b).

Reisen und Tourismus sind ausserdem hochgradig anfällig für Terrorismus, Pandemien und andere grosse Krisen. Beispiele hierfür sind der H1N1-Ausbruch im Jahr 2009 in Mexiko, der in der Tourismusbranche zu Verlusten in der Grössenordnung von USD 5 Milliarden führte, sowie die Terroranschläge vom 11. September 2001 in den Vereinigten Staaten, nach denen es sechs Jahre dauerte, bis das Vorkrisenniveau wieder erreicht wurde (WEF, 2016). Ein neueres Beispiel ist der Ausbruch von MERS (Middle East Respiratory Syndrome) im Jahr 2015, in dessen Verlauf über 54'000 Menschen ihre Reisen nach Südkorea stornierten. Laut Schätzungen von Wirtschaftswissenschaftlern betrugen die wirtschaftlichen Auswirkungen für die Region mehrere Milliarden US-Dollar (Misrahi, 2015).

Naturkatastrophen wie der Hurrikan Maria, der im Jahr 2017 die karibischen Inseln einschliesslich Puerto Rico verwüstete, werden den Vorhersagen zufolge in den kommenden Jahren regelmässiger auftreten und noch zerstörerischer werden. Solche Stürme können die Verkehrsnetze nicht nur direkt nach dem Ereignis, sondern auch für ausgedehnte Zeiträume lahmlegen und Auswirkungen auf den internationalen und inländischen Verkehr und die Erreichbarkeit haben.

Politische Instabilität kann Reisende in besonderer Weise davon abhalten, bestimmte Reiseziele zu besuchen, an denen eine tatsächliche oder wahrgenommene Gefahr besteht. Dies wird in den kommenden Jahren zu einzigartigen Herausforderungen führen, da angesichts des Wachstums der weltweiten Mittelschicht immer mehr Reisen in Schwellenländern beginnen oder enden werden. Auf diese Länder, in denen das Risiko politischer Instabilität tendenziell höher ist, werden 2030 nahezu 57\% der internationalen Anreisen entfallen (WEF, 2016). 


\section{Implikationen für den Tourismussektor}

Bei wirkungsvoller Steuerung können Synergien von Verkehr und Tourismus die Mobilität der Reisenden zu und in den Destinationen verbessern, das Besuchererlebnis aufwerten und dazu beitragen, die wirtschaftliche Tragfähigkeit der lokalen Verkehrssysteme und dienstleistungen zu sichern und sowohl den Einheimischen als auch den Touristen zugute kommen. Indem Regierungen die mittel- bis langfristigen Bedürfnisse der Tourismusbranche als Teil ihrer Verkehrs- und Infrastrukturplanung begreifen, lassen sich die sozioökonomischen Vorteile des Tourismus besser maximieren und breiter streuen. Zudem können die Auswirkungen des Besucheraufkommens im Zeitverlauf gesteuert werden.

Das künftige Wachstum des Tourismus und das Wachstum des Luftverkehrs sind eng miteinander verknüpft. Die Wachstumsraten werden stark vom anhaltenden Wachstum von Weltwirtschaft und Welthandel, der wachsenden Mittelschicht in den Entwicklungsländern sowie sinkenden Ticketpreisen und Betriebskosten in der Luftfahrt abhängen. Letztere werden durch neue Flugzeugtechnologien, Verbesserungen im Ressourcenmanagement der Fluggesellschaften und die Kraftstoffkosten beeinflusst. Die Überfüllung des Luftraums und der Flughäfen könnte das Wachstum bestimmter Märkte auch begrenzen (OECD, 2016c).

Die politischen Entscheidungsträger müssen Agilität beweisen, um wirksam auf diese und andere Entwicklungen reagieren $\mathrm{zu}$ können und neue politische Konzepte und Vorgehensweisen einzuführen, die die Mobilität der Reisenden verbessern und Vertrauen inspirieren und dabei gleichzeitig nachhaltiges Wachstum des Tourismus fördern sowie die Sicherheit und Integrität der Grenzen sichern oder verbessern. Als Beispiele liessen sich der wahrscheinliche Bedarf an mehr Konsistenz und stärkerer Harmonisierung internationaler Standards für die persönliche Sicherheit und die Betriebssicherheit sowie internationale Transportbestimmungen anführen, die geopolitischen Machtverschiebungen gerecht werden (z. B. im Luftverkehr). Die Regierungen könnten es auch als erforderlich ansehen, ankommenden (z. B. mittels Einschränkungen bei der Visavergabe) oder abgehenden Reiseverkehr (z. B. mittels Begrenzungen des Kohlendioxid-Fussabdrucks oder Verpflichtung zum Ausgleich der erzeugten Emissionen) einzuschränken oder zu begrenzen, um internationalen Verpflichtungen zur Senkung von Emissionen nachzukommen und/oder nachhaltige Entwicklungsziele zu erreichen.

Insbesondere die Luftverkehrsbranche wird infolge des Klimawandels und der wachsenden Nachfrage nach Flugreisen vor erheblichen Herausforderungen stehen. Aktuelle Studien legen nahe, dass sich die Branche möglicherweise auf geringere Gewinnspannen einstellen oder den Kampf gegen den Klimawandel aggressiver führen muss, indem sie leichtere Flugzeuge einführt oder emissionsärmere Triebwerke entwickelt (Williams, 2017; Coffel et al., 2017).

Wahrscheinlich werden aber weltweite marktbasierte Massnahmen, die den Kohlendioxidpreis berücksichtigen, mit die wirksamsten Mechanismen für die Senkung der Emissionen darstellen. Sie dürften sich sowohl auf Nah- als auch auf Fernreiseziele auswirken. Es gibt Belege dafür, dass die Erhöhung des Reisepreises der einzige Weg sein könnte, um eine signifikante Senkung der Treibhausgasemissionen zu bewirken. Die politischen Optionen zur Verringerung der Auswirkungen des Tourismus auf den Klimawandel müssen jedoch im Kontext der weiter gefassten Bedeutung des Tourismus innerhalb der Wirtschaftsstruktur eines Landes gesehen werden. Allgemeiner gesagt, sie müssen die komplexen Dimensionen berücksichtigen, auf denen die Verbindung eines Landes mit der Weltwirtschaft beruht (OECD/UNEP, 2011). 
Die leichte Zugänglichkeit von Destinationen wird weiterhin eine wesentliche Rolle für die allgemeine Wettbewerbsfähigkeit und die Streuung der Vorteile des Tourismus über die grossen Zentren hinaus spielen. Bei der Verbesserung der Mobilität von Touristen kommt es grundlegend auf die Verfügbarkeit geeigneter Infrastrukturen und angemessener Verkehrsmittel an. Damit der Tourismus sein Potenzial als Motor des Wirtschaftswachstums ausspielen kann, sind Zugang zu den Herkunftsmärkten und multimodale Verkehrssysteme innerhalb des Landes erforderlich, die Bequemlichkeit, ausreichend Kapazität, Zuverlässigkeit und Verkehrsverbindungen zu allen Arten von Destinationen (z. B. integrierte Badeorte oder kleine isolierte Öko-Lodges) bieten. Durch Förderung der Entwicklung intermodaler Knotenpunkte und Übergänge können nationale und subnationale verkehrspolitische Konzepte nicht nur dazu beitragen, Besucherströme anzuziehen, $\mathrm{zu}$ steuern und $\mathrm{zu}$ leiten, sie können auch den Wechsel zu umweltfreundlicheren Beförderungsmöglichkeiten begünstigen. Dies wiederum kann dazu beitragen, den guten Ruf von Reisezielen als nachhaltige Destinationen zu festigen.

Viele der Schwierigkeiten, die bei der Bewältigung infrastruktureller Herausforderungen eine Rolle spielen, können auf Governance-Probleme zurückgeführt werden, die sich über Planung, Politik, Regulierung, Finanzierung, Beschaffung und Verwaltung von Infrastrukturen hinweg erstrecken. Es kann nicht genug betont werden, wie wichtig es ist, die verschiedenen Institutionen miteinander zu koordinieren, um das reibungslose Funktionieren multimodaler Verkehrssysteme zu gewährleisten. Für bessere Entscheidungen und die Schaffung von Anreizen für Investitionen in Verkehrsverbindungen sind auf allen Regierungsebenen gute Governance und Zusammenarbeit mit der Privatwirtschaft erforderlich. Anstatt einzelner Verkehrsmittel und der entsprechenden Netzwerke müssen ganze Mobilitätssysteme betrachtet werden.

Neben einer Diversifizierung des touristischen Angebots kann die bessere Anbindung regionaler und ländlicher Räume eine weitere Funktion erfüllen und der Überfüllung und der Belastung der Infrastruktur in den grossen Tourismuszentren entgegenwirken. Die genannten Herausforderungen sind bei beliebten Touristenzielen wie Barcelona, Amsterdam und Santorini unübersehbar. Für all diese Ziele ist es schwierig, mit dem massiven Zustrom von Touristen zurecht $\mathrm{zu}$ kommen. Initiativen zugunsten der Verkehrsinfrastruktur könnten sich vorteilhaft auf die Planung der Destinationen auswirken und überbordendem Tourismus durch besseren Zugang zur Zielorten im Umland entgegenwirken.

Angesichts des zu erwartenden Wachstums der Region Asien als Herkunftsmarkt für den weltweiten Tourismus setzen etliche Länder gezielte Initiativen zur Verbesserung der Mobilität und leichteren Zugänglichkeit um. Beispielsweise schlossen die Vereinigten Staaten und die Volksrepublik China im November 2014 ein wechselseitiges Visaabkommen, welches die immer intensiveren wirtschaftlichen und zwischenmenschlichen Beziehungen zwischen beiden Ländern stärken soll. Die beiden Länder vereinbarten, die Gültigkeitsdauer kurzfristiger Touristen- und Geschäftsvisa, die Bürgern des jeweils anderen Landes erteilt werden, von einem auf zehn Jahre zu verlängern - die längste nach US-Recht zulässige Gültigkeitsdauer. Gleichzeitig wurde die Gültigkeitsdauer von Studenten- und Austauschvisa von einem Jahr auf fünf Jahre verlängert. Diese Vereinbarung stärkt die Handels-, Investitions- und Geschäftsbeziehungen, indem sie das Reisen vereinfacht und den Zugang zu den jeweiligen Wirtschaftsräumen erleichtert. Seit Einführung der Regelung wuchs die chinesische Nachfrage nach Visa für die Vereinigten Staaten gegenüber dem Vergleichszeitraum des Jahres 2014 um über 50\% (OECD, 2016b). 
Das Jahr 2017 wurde durch die australische und die chinesische Regierung zum «chinesisch-australischen Jahr des Tourismus» ausgerufen, um den Tourismus zwischen beiden Ländern zu fördern. Australien führte im Dezember 2016 versuchsweise ein Visum für Vielreisende aus China ein, das bis zu zehn Jahre lang gültig ist, und wiederholte kurze Aufenthalte von bis zu drei Monaten zu touristischen oder geschäftlichen Zwecken ermöglicht. Zu den weiteren australischen Initiativen hinsichtlich des chinesischen Marktes zählen die Online-Beantragung von Visa, die versuchsweise Einführung einer beschleunigten Bearbeitung von Visumsanträgen (innerhalb von 48 Stunden) sowie vereinfachte chinesische Beantragungsoptionen durch einen Dienstleistungspartner. Mit ähnlicher Absicht wurde das Jahr 2018 zum EU-China-Tourismusjahr erklärt. Die Ziele sind, i) weniger bekannte Destinationen zu bewerben, ii) das Reise- und Tourismuserlebnis zu verbessern, iii) Chancen für verstärkte wirtschaftliche Zusammenarbeit zu eröffnen und iv) als Ausgangspunkt für Fortschritte bei der leichteren Visavergabe und besseren Flugverbindungen zwischen der EU und China zu dienen. Darüber hinaus haben auch die Regierungen von Kanada und China das Jahr 2018 offiziell zum kanadisch-chinesischen Jahr des Tourismus ausgerufen, mit dem Ziel, die gegenseitigen Besuche bis zum Jahr 2025 gegenüber $2015 \mathrm{zu}$ verdoppeln.

Ein weiteres Beispiel für die Art innovativer Massnahmen, die nationale Regierungen und die Branche umsetzen möchten, um die grenzüberschreitende Mobilität zu verbessern, ist das vor Kurzem durch das Airports Council International (ACI) und die IATA vorgestellte Programm. Die «Smart Security Strategy» (intelligente Sicherheitsstrategie) zielt mehrgleisig darauf ab, die Sicherheitsmassnahmen an der Grenze im Interesse besserer Mobilität zu modernisieren (Kasten 5). 


\section{Kasten 5. «Smart Security Strategy» am Flughafen}

Sicherheitskontrollen zählen für Reisende nach wie vor zu den unangenehmsten Erfahrungen. Zudem ist ein Grossteil der Technik und der konventionellen Massnahmen an der Grenze inzwischen veraltet und ineffizient. Angesichts des bis zum Jahr $2040 \mathrm{zu}$ erwartenden Wachstums im Luftverkehr, der sich entwickelnden Sicherheitsbedrohungen und der Unzufriedenheit der Passagiere mit Warteschlangen und intrusiven Massnahmen haben das Airports Council International (ACI) und die IATA eine strategische Partnerschaft geschlossen, um eine «Smart Security Strategy», eine intelligente Sicherheitsstrategie, zu entwickeln. Die beiden Organisationen unterzeichneten eine Absichtserklärung, laut der sie ihre jeweiligen Ressourcen und ihr Fachwissen einsetzen werden, um «den Weg von der Vorfahrt bis zum Boarding zu verbessern» (IATA, 2013).

Smart Security ist eine dreigleisige Strategie, die risikobasierte Sicherheitskonzepte, fortschrittliche Screening-Technologien und innovative Abläufe miteinander verbindet, um die Sicherheitsprozesse zu verschlanken und die Passagiererfahrung zu verbessern. $\mathrm{Zu}$ den vorrangigen Bestandteilen zählen die Kontrolle der Fluggäste und des Bordgepäcks, alternative Erkennungsverfahren, das Umfeld und die Verwaltung der Kontrollpunkte, die zentrale Bildverarbeitung sowie die risikobasierte Differenzierung. Verbesserungen in den betreffenden Bereichen, wie fortschrittliche Erkennungsalgorithmen, können dazu beitragen, die Sicherheitsmassnahmen für neue Entwicklungen der Bedrohungslage und der Anforderungen in der Luftfahrt «zukunftssicher» zu machen (ACI und IATA, 2017).

Smart Security wurde in mehreren internationalen Flughäfen wie Amsterdam Schiphol, London Heathrow und Melbourne International versuchsweise eingeführt. Umfragen zur Zufriedenheit der Fluggäste belegen den Erfolg dieser Versuche (Future Travel Experience, 2016). ACI und IATA haben inzwischen die zweite Welle dieser Entwicklung angestossen und sind mit Workshops und Veranstaltungen auf der ganzen Welt im Begriff, ihr Wissen weiterzugeben.

Visa, die für mehrere Destinationen gleichzeitig gelten, werden immer häufiger. Beispiele sind der Schengenraum in Europa, das East Africa Tourist Visa, ein geplantes gemeinsames Visum der ASEAN-Staaten sowie visumfreies Reisen, wie es innerhalb der Westafrikanischen Wirtschaftsgemeinschaft (ECOWAS) gehandhabt wird, wo die Bürger der 15 Mitgliedsländer für Reisen innerhalb der Region kein Visum benötigen. Diese Konzepte können die Kosten dramatisch senken, die Attraktivität der Destinationen steigern, die Belastung durch Bearbeitung, Sicherheitskontrollen und Verwaltung auf mehrere Länder verteilen sowie die Sicherheit und Datenweitergabe innerhalb der betreffenden Regionen verbessern.

Auch Programme für vertrauenswürdige Reisende wie die APEC Business Travel Card (ABTC) werden als Mittel zur Effizienzsteigerung und der Nutzung von Big Data immer beliebter. Das ABTC-Programm trägt beispielsweise dazu bei, die Integrität und Sicherheit der Grenzen der teilnehmenden Länder zu schützen, indem die Anzahl der Reisenden mit geringem Risiko - Reisende, die mit den «Beobachtungslisten» anderer teilnehmender Länder abgeglichen wurden - erhöht wird. Laut der APEC Policy Support Unit sanken die Transaktionskosten für ABTC-Inhaber dadurch zwischen 2010 und 2011 um 38\%, was Gesamteinsparungen in Höhe von USD 3,7 Millionen entspricht. Die gesamte Zeitersparnis bei der Einreisekontrolle der ABTC-Karteninhaber an der Grenze lag im 
gleichen Zeitraum bei 62'413 Stunden, was einem finanziellen Wert von USD 1,9 Millionen entspricht.

\section{Kritische Unsicherheiten}

Im Folgenden werden kritische Unsicherheiten genannt, die die zu erwartende Entwicklung der Reisemobilität bis zum Jahr 2040 verändern könnten:

- Bei wirkungsvoller Steuerung können Synergien von Verkehr und Tourismus die Mobilität der Reisenden zu und in den Destinationen verbessern, das Besuchererlebnis aufwerten und dazu beitragen, die wirtschaftliche Tragfähigkeit der lokalen Verkehrssysteme und -dienstleistungen zu sichern und sowohl den Einheimischen als auch den Touristen zugute kommen. Eine mangelhafte Steuerung kann hingegen zu erheblichen Belastungen der Infrastruktur der betreffenden Reiseziele führen.

- Das künftige Wachstum des Tourismus und das Wachstum des Luftverkehrs sind miteinander verknüpft. Die Wachstumsraten werden stark vom anhaltenden Wachstum von Weltwirtschaft und Welthandel, der wachsenden Mittelschicht in den Entwicklungsländern sowie sinkenden Ticketpreisen und Betriebskosten in der Luftfahrt abhängen. Letztere werden durch neue Flugzeugtechnologien, Verbesserungen im Ressourcenmanagement der Fluggesellschaften und die Kraftstoffkosten beeinflusst.

- Die Welt ist in eine Phase signifikanter Unsicherheit eingetreten, in der protektionistische Ansichten an Boden gewinnen und viele Länder sich auf sich selbst zurückziehen. Die Reisemobilität ist stark von diesem geopolitischen Wandel betroffen, der naturgemäss nicht vorhersagbar ist und auf den sich kein Sektor problemlos vorbereiten kann.

\section{Plausible Zukunftsszenarien}

\section{Weltbürger: Konnektivität, Zusammenarbeit und reibungslose Mobilität}

- Jahrelange internationale Zusammenarbeit hat einer Tourismuslandschaft den Weg bereitet, die durch freies und einfaches Reisen geprägt ist. Abgesehen von sehr wenigen Ländern mit restriktiven Anforderungen an Besucher gehören Einreisevisa zum Grossteil der Vergangenheit an. In den meisten Teilen der Welt fühlen sich Grenzen unbedeutend an. Neue Technologien haben fortschrittliche ScreeningVerfahren und innovative Abläufe ermöglicht und Zoll- und Sicherheitsmassnahmen schlanker und effizienter gestaltet als je zuvor.

- Der Abbau bürokratischer Hürden hat auch jene, die bisher vor den betreffenden Prozessen zurückgeschreckt sind, verstärkt zu Auslandsreisen angeregt. Der Tourismussektor ist aufgrund der steigenden Anzahl von Reisenden weltweit aufgeblüht. Wachsende Nachfrage hat den Markteintritt neuer Akteure ermöglicht, die den Wettbewerb anheizen, die Preise nach unten treiben und die Auswahl bei Reisedienstleistungen erhöhen. Dies gilt insbesondere für neue Billigfluglinien, die die Wahlmöglichkeiten sowohl im internationalen als auch im inländischen Tourismus verbessern.

- Auch innerhalb der Destinationen gibt es deutlich bessere Verkehrsverbindungen. Verbesserungen bei strategischer Planung, Politik, Regulierung, Finanzierung, 
Beschaffung und Verwaltung von Infrastrukturen haben $\mathrm{zu}$ verstärkter Abstimmung der Institutionen untereinander und zu entscheidenden Kooperationen mit der Privatwirtschaft geführt. Investitionen in multimodale Knotenpunkte haben dazu beigetragen, die Besucherströme in den Griff zu bekommen, und den Wechsel zu nachhaltig umweltfreundlichen Transportmitteln ermöglicht. Ausserdem haben bessere Verkehrsverbindungen zwischen den Stadtzentren und regionalen und ländlichen Räumen Überfüllung und Überlastung der Infrastrukturen an den beliebten Destinationen ein Ende gesetzt und das Reiseerlebnis mit einer Vielzahl von Optionen bereichert.

2. Blick nach innen: Protektionismus und eingeschränkte weltweite Mobilität

- Mobilität im Tourismus gehört der Vergangenheit an. Die internationale Zusammenarbeit ist im Einklang mit zunehmenden geopolitischen Spannungen seit 2017 zurückgegangen. Die meisten Länder richten den Blick nach innen und haben ihre Grenzen für Handel und Einwanderung, aber auch hinsichtlich der Einreisevorschriften für Besucher weniger durchlässig gemacht. Die schon bestehenden für jeweils mehrere Destinationen geltenden Visa wie jene für den Schengenraum in Europa oder die Vereinigung südostasiatischer Staaten (ASEAN) wurden zugunsten restriktiver und teurer landesspezifischer Visa aufgegeben. Komplizierte bürokratische Prozesse und lange Wartezeiten auf Visa sind nun der Normalfall. Nach immer mehr Terroranschlägen hat die nationale Sicherheit in allen Ländern Priorität.

- Die Medien haben den negativen Gesamteindruck hinsichtlich der persönlichen Sicherheit und der Betriebssicherheit weiter verschlimmert. Berichte über terroristische Bedrohungen, Pandemien und Naturkatastrophen werden sensationsheischend verbreitet und begünstigen eine Kultur der Angst. Ob die betreffenden Bedrohungen real oder eingebildet sind, ist schwer zu sagen, aber auch unwichtig. Sie halten viele Menschen davon ab, überhaupt noch zu verreisen.

- Diejenigen, die reisen möchten, haben nur eine begrenzte Auswahl. Der Protektionismus geht auch mit einer Vernachlässigung des Klimaschutzes und von Bemühungen um die Erreichung weltweiter Klimaziele einher. Die Folgen des Klimawandels haben sich spürbar verschlimmert: Extreme Wetterbedingungen und Hitzewellen haben begonnen, Flugzeuge auf den Boden zu zwingen, und die Fluggesellschaften haben viele bestehende Flugstrecken aufgegeben. Der gesamte Niedergang des Luftverkehrs und anderer Tourismusdienstleistungen hat die Preise exponentiell in die Höhe getrieben, und nur wenige nationale Regierungen betrachten dies als einen vorrangigen Aspekt, der Eingriffe rechtfertigen würde.

\section{Fragmentation vor Integration: uneinheitliche Mobilitätsansätze}

- Der inländische und internationale Tourismus wächst bis in die frühen 2030er Jahre exponentiell. Ab da beginnt sich das Wachstum abzuschwächen und das BIP- und Bevölkerungswachstum klingen weltweit ab. Während die Jahrzehnte des Wachstums im Strassen-, Schienen- und Luftverkehr den Tourismussektor insgesamt begünstigt haben, hat sich das grosse Verkehrsvolumen auch negativ auf die Reisemobilität ausgewirkt. Das Wachstum scheint weltweit zu einer Polarisierung der Offenheit an den Grenzen geführt zu haben: Manche nationalen Regierungen haben die Mobilität und ihre Sicherheitsmassnahmen deutlich verbessert, während andere mit dem Wachstum nicht Schritt gehalten haben. 
- Manche OECD-Mitgliedsländer konnten neue, innovative Technologien nutzen, um ihre Sicherheitsmassnahmen an der Grenze zu verschlanken, während andere zurückgefallen und noch langsamer und bürokratischer geworden sind. Ähnliches gilt für die verwaltungstechnischen Hürden bei Einreisevorschriften und Reisevisa. Angesichts des relativ konstanten Auftretens von Sicherheitsbedrohungen setzen manche Länder nach wie vor restriktive Visaprozesse durch und bleiben für Besucher schwer zugänglich. Andere Regionen arbeiten im Gegensatz dazu stärker zusammen und haben für mehrere Destinationen geltende Visaprogramme und Reiseerleichterungen zwischen den teilnehmenden Ländern eingeführt. Die Inkonsistenzen zwischen den einzelnen Ländern sind eine Quelle der Frustration für viele Reisende.

- Die Reiselogistik innerhalb der Destinationen hat sich weltweit vielerorts verbessert. Multimodale Verkehrsknotenpunkte sind nun häufiger anzutreffen. Es war jedoch schwieriger, mehr Interesse für Reisen in nahegelegene Regionen oder ländliche Gebiete zu wecken und die Besucherströme entsprechend zu steuern. Dies gilt insbesondere für Destinationen, in denen sich die bei Touristen beliebten Wahrzeichen und Sehenswürdigkeiten häufen (wie z. B. Paris). Der Druck auf die dortige Infrastruktur ist ein nach wie vor ungelöstes Problem.

\section{Analyse der Szenarien}

Einreisevisa sind hinsichtlich der Reisemobilität eine ernstzunehmende Herausforderung. Die Probleme aufgrund restriktiver Grenzen könnten sich in Zukunft noch erheblich verschärfen, insbesondere bei verstärkten geopolitischen Spannungen oder einer protektionistischen Politik, die den Handel sowie die Zuwanderung und Einreise behindert. Viele entscheidende Faktoren, die den Zustand der Grenzkontrollen beeinflussen, sind jedoch weitgehend exogener Natur und entziehen sich insbesondere in den Tourismusministerien der Kontrolle der politischen Entscheidungsträger. Entscheidungen rund um die nationale Sicherheit - ebenso wie der individuelle Appetit nach Auslandsreisen - werden oft stark von aktuellen Ereignissen wie Terroranschlägen und Naturkatastrophen bestimmt. Ein weiteres Problem ist, dass die Regierungen, Bürger und Unternehmen die Auswirkungen eines restriktiven Reiseumfelds auf Handel, Beschäftigung und BIP als ihre erste Priorität ansehen könnten, die Auswirkungen auf den Tourismus jedoch als sekundär oder tertiär betrachtet werden könnten. Allerdings gibt es Möglichkeiten, einigen dieser systemischen Herausforderungen, die in allen Zukunftsszenarien wahrscheinlich immer wichtiger werden und die Gesundheit des Tourismussektors indirekt beeinflussen, auf internationaler Ebene zu begegnen.

Eine Welt, in der die Reisemobilität stark eingeschränkt würde, wäre ausgesprochen schlecht für die Tourismusunternehmen und auch für die Gesamtwirtschaft. Die bestehenden Geschäftsinteressen würden wahrscheinlich zu intensiver Lobbyarbeit gegen restriktive Ein- und Ausreisebestimmungen führen. Der private Sektor kann auch erheblich dazu beitragen, im Ausland Vertrauen zu schaffen. Beispielsweise könnten die durch Technologieplattformen ermöglichte Erfassung von Big Data und der Einsatz von Bewertungssystemen potenziell dazu beitragen, die Vertrauenslücke zwischen verschiedenen Ländern hinsichtlich Reisenden, die als höheres Risiko eingestuft werden, zu schliessen. Auch andere technologiebasierte Möglichkeiten sind denkbar, wie der Einsatz biometrischer Methoden und implantierbarer Technologie, die die Sicherheit verbessern könnten. 
Auch auf Seite der Abläufe könnte die Visavergabe vereinfacht werden. Sollte eine grössere weltweite Stabilität dies in Zukunft erlauben, könnten Möglichkeiten, in deren Rahmen Reisende nach entsprechender Vorabprüfung strengere Sicherheitskontrollen an Flughäfen oder anderen Grenzkontrollpunkten umgehen könnten, allgegenwärtig werden. Mit der Nexus Card wird beispielsweise ein freiwilliges Programm angeboten, mit dem Reisende mit niedrigem Risikoprofil die Grenze zwischen Kanada und den Vereinigten Staaten leichter überqueren können. Allerdings sind Ansätze dieser Art in der Regel gebührenpflichtig, was die Probleme rund um die Ungleichheit in einer Welt, in der das Reisen wahrscheinlich teurer werden wird, weiter verschärfen könnte.

Das Unerschwinglichkeitsproblem betrifft insbesondere die Zukunft der Luftfahrtbranche, auf die in nahezu allen Szenarien, in denen der Klimawandel für viele Länder vorrangig ist, wahrscheinlich Einschränkungen zukommen werden. Viele klimapolitische Entscheidungen wie die Bepreisung des Kohlendioxidausstosses, Regulierungen oder andere Strategien zur Emissionsminderung werden Flugreisen sehr wahrscheinlich verteuern. Sollten die Touristenströme und Umsätze in der Folge in bestimmten Bereichen zurückgehen, müsste der Tourismus an den betroffenen Destinationen innovativer gefördert werden und es müsste ein Wechsel hin zu Inlandsreisen und zu nachhaltigeren Transportmitteln (z. B. Elektrofahrzeuge, Velos) erfolgen. Die betreffenden Verschiebungen könnten für manche Länder grosse wirtschaftliche Chancen bieten und andere vor Probleme stellen. Dies könnte beispielsweise isolierte Destinationen oder Fernreiseziele, bei denen die Anreise der Touristen vom Flugverkehr abhängt, stark schädigen. An belebteren Destinationen, die auf derartige Nachfrageveränderungen nicht eingestellt sind, könnte es sogar zu Überfüllungsproblemen kommen.

Eine entscheidende Voraussetzung für den Tourismus ist in allen Zukunftsszenarien eine effizientere und barrierefreiere Infrastruktur - ein Gebiet, auf dem sich solide Politik und Planung massgeblich auswirken können. Die gut entwickelten Eisenbahnsysteme, die heute in vielen Teilen Europas anzutreffen sind, sind ein gutes Beispiel dafür, wie durch Infrastruktur reibungslose Transportmöglichkeiten über Grenzen hinweg geboten werden.

Dies könnte sehr gut auch in anderen Regionen der Welt umgesetzt werden. Auch multimodaler Verkehr und integrierte Ticket-/Fahrscheinverkäufe leisten einen wichtigen Beitrag zu besserer Reisemobilität. Tourismusanbieter, die diese Möglichkeiten umsetzen möchten, können viel von der Luftfahrtbranche lernen, deren heutige Backend-Systeme beim Kauf mehrere Flüge mit unterschiedlichen Fluggesellschaften nahtlos auf einem Ticket zusammenführen. Wichtig ist aber die Erkenntnis, dass internationale und länderübergreifende Zusammenarbeit ein entscheidender Aspekt für die Verstärkung der Bemühungen um reibungsloses Reisen ist.

Schliesslich haben sich auch technologische Innovationen über ein Jahrhundert lang grundlegend auf den Personen- und Güterverkehr ausgewirkt. Neu aufkommende Technologien werden auch weiterhin eine wichtige Rolle für grössere Reisemobilität spielen. Sie können beispielsweise für die Verschlankung von Sicherheitskontrollen und Abfertigungsmechanismen an Flughäfen eingesetzt werden oder bei anderen grenzüberschreitenden Verkehrsformen wie dem Bus- oder Bahnverkehr Vorabüberprüfungen ermöglichen. Während sich die weitere Entwicklung von Hochgeschwindigkeits-Bahnstrecken in vielen Ländern ausgesprochen positiv auf die Reisemobilität auswirken und insbesondere auf Kurz- und Mittelstrecken den Fluglinien Konkurrenz machen kann, unterliegen umwälzende Innovationen im Ultrahochgeschwindigkeitsverkehr (z. B. Magnetschwebebahnen und Hyperloop-Systeme, preiswerte Überschall-Passagierflugzeuge, Weltraumtourismus) oftmals Einschränkungen 
durch hohe Entwicklungs- und Baukosten, Sicherheitsbedenken und logistische Beschränkungen (z. B. der Notwendigkeit, sie in schwach bevölkerten Regionen einzusetzen) und sind deswegen die grosse Ausnahme.

\section{Mögliche politische Massnahmen}

1. Es sollte sichergestellt werden, dass die mittel- bis langfristigen Bedürfnisse der Tourismusbranche als Teil des Planungsprozesses für den Zugang zu Verkehr und Infrastruktur verstanden werden. Entscheidend ist, dass politische Entscheidungsträger in den Bereichen Tourismus und Verkehr eng zusammenarbeiten und gemeinsam mit der Branche Verkehrsdienstleistungen und Infrastrukturen entwickeln, die den Bedürfnissen sowohl der Einheimischen als auch der Touristen entsprechen.

2. Die Regierungen sollten zur Unterstïtzung der Reisemobilität strategisch in die Verkehrsinfrastruktur investieren, beispielsweise in multimodale Transitknotenpunkte, und mit privaten Beförderungsanbietern zusammenarbeiten, um den Verkehr effizienter und kostengünstiger zu gestalten ${ }^{8}$. Sie sollten integriertes Ticketing/Smartcards für Destinationen fördern, um für ein angenehmes Reiseerlebnis in den Städten zu sorgen und die Erreichbarkeit regionaler Destinationen und Attraktionen zu verbessern.

3. Politische Entscheidungsträger müssen auch weiterhin Möglichkeiten finden, die derzeitigen und neu entstehenden Technologien zu nutzen, um die Visaerteilung und den grenzüberschreitenden Verkehr für Reisende ohne erhöhtes Risiko zu vereinfachen (im Rahmen von Vorerfassungs- und VorabgenehmigungsProgrammen $)^{9}$. Neben der höheren Effizienz und den geringeren Kosten werden derartige Programme auch für ein deutlich angenehmeres Reiseerlebnis sorgen, wenn sie erfolgreich in grösserem Umfang eingesetzt werden und regional und/oder länderübergreifend die Mobilität verbessern.

4. Ausserdem sollten die politischen Entscheidungsträger Möglichkeiten überdenken, wie sie alternative und nachhaltige Mobilität im Tourismus unterstützen könnten - insbesondere angesichts der Folgen eines unveränderten weiteren Wachstums des Flugverkehrs für die Treibhausgasemissionen. Dies könnte die Förderung nachhaltigerer Transportmittel in und zwischen den Destinationen ebenso beinhalten wie eine Zusammenarbeit mit der Branche, um unterstützende Infrastruktur für Ausflüge mit Elektrofahrzeugen (z. B. Ladestationen) oder durch Muskelkraft angetriebene Mobilitätsoptionen anzubieten ${ }^{10}$.

\footnotetext{
${ }^{8}$ King's Cross St. Pancras in London ist sowohl für Pendler als auch für Reisende ein effektiver Verkehrsknotenpunkt. Er verbindet inländische und internationale HochgeschwindigkeitsBahnstrecken mit der Londoner U-Bahn, Taxis und Mietwagenanbietern, dem Veloverkehr und den fünf internationalen Flughäfen der Stadt (OECD, 2016).

${ }^{9}$ Das Programm «Nexus Card», an dem derzeit berechtigte Reisende zwischen Kanada und den Vereinigten Staaten teilnehmen, ist ein gutes Beispiel für ein derartiges Arrangement.

${ }^{10}$ Der «New Zealand Cycle Trail», ein Radwegenetz in Neuseeland besteht beispielsweise aus $2500 \mathrm{~km}$ Radwegen durch das gesamte Land, die als Möglichkeit für Abenteuer- und Entspannungsurlaub angeboten werden und die der Wirtschaft, der Gesellschaft und dem Umweltschutz in den jeweiligen Gemeinden zugute kommen.
} 
5. Wichtig ist, dass die politischen Entscheidungsträger Strategien für das Krisenmanagement entwickeln, um besser auf im Wesentlichen unvorhersehbare Ereignisse wie Sicherheitsvorfälle, politische Instabilitäten, Pandemien und Naturkatastrophen vorbereitet zu sein und entsprechend reagieren zu können. Dies umfasst Strategien sowohl für spezifische Destinationen als auch für den Tourismussektor ganz allgemein, der für derartige externe Schocks in besonderer Weise anfällig ist.

\section{Vorbereitung auf Megatrends}

Wie sollten sich politische Entscheidungsträger auf die Herausforderungen und Chancen vorbereiten, die sich im Zuge der im kommenden Vierteljahrhundert entstehenden Megatrends ergeben werden? Die Vorhersage des spezifischen Verlaufs bestimmter Megatrends, beispielsweise der Auswirkungen spezifischer Technologien, unterliegt erheblichen inhärenten Unsicherheiten. Andere Entwicklungen, wie die Bevölkerungsalterung, verlaufen dagegen in gesicherteren Bahnen. Auch hier bleiben jedoch Fragen hinsichtlich der wahrscheinlichen Auswirkungen und der wirkungsvollsten Reaktionen. Der beste Ansatz für politische Entscheidungsträger wäre demnach, zu überdenken, welche systemischen und strategischen Ansätze am geeignetsten wären, um sich an ein immer schneller änderndes, stark vernetztes und dynamisches Umfeld anpassen zu können.

Neben einem integrierten gesetzgeberischen Ansatz sind drei Schlüsselbereiche der Betrachtung wert: i) die Modernisierung der regulatorischen und rechtlichen Rahmenbedingungen, ii) das Kultivieren von Partnerschaften mit den wichtigsten Interessengruppen und iii) die Erkundung von Möglichkeiten einer zukunftssicheren Politik.

\section{Modernisieren der regulatorischen und rechtlichen Rahmenbedingungen}

Das Entstehen neuer Geschäftsmodelle und technologischer Innovationen in den vergangenen Jahren, wie Mitfahr- und Mitwohnplattformen, haben gezeigt, dass die Regierungen dringend flexiblere und anpassungsfähigere regulatorische und rechtliche Rahmenbedingungen schaffen müssen. Angesichts der Wahrscheinlichkeit anhaltender rascher technologischer Entwicklungen in der Sharing Economy sowie der wachsenden Bedeutung künstlicher Intelligenz werden die bestehenden Rahmenbedingungen weiter unter Druck geraten. Die betreffenden Reformen werden damit umso dringlicher.

Die regelmässige Überprüfung der regulatorischen Rahmenbedingungen, um veraltete Anforderungen abzuschaffen und das Entstehen innovativer Ansätze für die Bereitstellung von Gütern und Dienstleistungen zu fördern, wäre eine der betreffenden Strategien. Auch die breit angelegte Einbindung aller Interessengruppen in die Entwicklung neue regulatorischer Rahmenbedingungen, um sicherzustellen, dass die Sichtweisen neuer und neu hinzukommender Marktteilnehmer berücksichtigt werden, ist sehr wichtig.

Die verstärkte Einbeziehung und Unterstützung prädiktiver Mechanismen in den politischen und regulatorischen Prozess ist ebenfalls ein wichtiges Mittel, um zu gewährleisten, dass heute entwickelte politische Konzepte nicht schon veraltet sind, bevor sie in Kraft treten. Sowohl neue als auch bestehende Rahmenbedingungen sollten vor dem Hintergrund der mittel- und langfristigen Trends bewertet werden.

Regierungen bewegen sich im Allgemeinen langsamer, als sich die Herausforderungen entwickeln. Dem abzuhelfen, wird ein wichtiges Element der strategischen Planung für die 
Zukunft des Tourismus sein. In der jetzigen Situation wird tendenziell eher reagiert. Dies sollte sich hin zu einer proaktiven Vorgehensweise ändern. Auch wenn dies Frühaufklärung und Planung erfordert, ist klar, dass es nicht ausreichen wird, eine feste Zehnjahresstrategie zu entwickeln. Die Ansätze müssen flexibel und anpassungsfähig sein und regelmässige Rückmeldungsmechanismen zwischen Regierung, lokalen Gemeinden und der Branche beinhalten. Rückmeldungsmechanismen können kontinuierliche Diskussionen ermöglichen und gegebenenfalls Anpassungsmöglichkeiten offenbaren.

\section{Kultivieren von Partnerschaften mit wichtigen Interessengruppen}

Die Auswirkungen von Megatrends und der politische Prozess im Allgemeinen sind heute sektoren- und länderübergreifender als je zuvor. Die Probleme der Reisemobilität, zu denen Visa und die zwischenstaatliche Koordination von Sicherheitsmassnahmen gehören, nachhaltige Tourismusansätze, bei denen Ressourcen zwischen verschiedenen Ländern geteilt werden, sowie die regulatorischen Herausforderungen im Rahmen weltweit agierender digitaler Plattformen, zeigen ausnahmslos, dass es immer notwendiger wird, über lokale und nationale Aspekte hinaus zu denken, um wirkungsvolle Lösungen zu finden.

Ein neuer Fokus und Investitionen in internationale und regionale Foren, die horizontale Zusammenhänge wirkungsvoll analysieren und gemeinsame Governance- und Politiklösungen entwickeln können, sind ein möglicher Weg, um sicherzustellen, dass ausgewogene und effektive Antworten gefunden werden. Auch die verstärkte Einbeziehung wichtiger Interessengruppen (Industrie und Zivilgesellschaft) im Tourismussektor und in damit zusammenhängenden Sektoren sollte vorrangig betrieben werden. Beispielsweise brachte das türkische Kultur- und Tourismusministerium kürzlich über 300 Interessenvertreter im Tourismusbereich zu einem Treffen des Tourismusrates zusammen, darunter Minister, Führungspersönlichkeiten aus dem Tourismus, Kommunalbehörden und NGOs, um die wichtigsten Entwicklungen im Tourismus besser zu verstehen und Informationen für die Entwicklung eines langfristigen Strategie- und Massnahmenplans für den Tourismus zu sammeln. Um zu verstehen, wie die Anpassung an die Infrastrukturbedürfnisse einer alternden Bevölkerung am besten zu bewerkstelligen wäre, sind Gespräche mit Beamten und Vertretern aus den Bereichen Finanzen, Infrastruktur, Wohnungsbau, Planung, Sozialwesen und vielen anderen Ministerien erforderlich. Die Entscheidungsträger in der Tourismuspolitik werden eine wichtige Rolle bei der Formulierung der entsprechenden Herausforderungen spielen, für die politischen Lösungen werden jedoch oft andere zuständig sein.

Angesichts des sich ändernden Charakters des Sektors in den kommenden Jahren und Jahrzehnten ist es unbedingt nötig, enger mit der Branche zusammenzuarbeiten und sicherzustellen, dass die Sichtweisen von KMU, neu entstehenden Unternehmen und traditionellen Betreibern ausnahmslos verstanden werden. Die politischen Entscheidungsträger müssen sicherstellen, dass die Perspektiven der Unternehmen an vorderster Front neuer und innovativer Ansätze für das Erbringen von Dienstleistungen zu einem erheblichen Mass in die Entscheidungen einfliessen, die sie im vorrangigen öffentlichen Interesse treffen. Runde Tische, an denen Branche und Regierungen beteiligt sind, um über vorrangig zu behandelnde mittel- und langfristige Aspekte zu beraten, sind eine Möglichkeit, regelmässige und enge Zusammenarbeit aufzubauen und sicherzustellen.

Partnerschaft und Kooperation sind entscheidend. Innerhalb der Destinationen muss ein kontinuierlicher Dialog geführt werden, an dem nicht nur Regierungs- und Branchenvertreter, sondern auch die Gemeinschaft teilnehmen. Innerhalb der einzelnen 
Länder sollten die verschiedenen Regierungsebenen sowie die einzelnen Ministerien so miteinander koordiniert werden, dass die komplexen Themenfelder, die sich auf den Sektor auswirken können, angemessen berücksichtigt werden können. Der Tourismus ist ein Sektor, der sich weit über das Aufgabengebiet des Tourismusministeriums hinaus erstreckt. Er betrifft die verschiedensten Politikfelder, von der wirtschaftlichen Entwicklung, über Bildung und Verkehr bis hin zur Infrastruktur. Schliesslich ist auch internationale Zusammenarbeit notwendig, um Fortschritte erzielen zu können. Der Umgang mit weltweit relevanten Themenfeldern wird internationale Vereinbarungen erfordern, die in nationale politische Massnahmen münden (z. B. die Agenda 2030 für nachhaltige Entwicklung und die Ziele für nachhaltige Entwicklung) - auch wenn derartige Prozesse mühsam sein können und der Weg bis zur realen Umsetzung viele Jahre dauern kann.

\section{Schritte in Richtung einer zukunftssicheren Tourismuspolitik}

Für Regierungen ist es oftmals eine Herausforderung, schnellen Änderungen und Verschiebungen des Status quo gerecht zu werden. Es wird entscheidend darauf ankommen, eine Kultur der Innovationen und des Veränderungsmanagements innerhalb der Regierung zu fördern, um sicherzustellen, dass langfristige Megatrends innerhalb des Entscheidungsprozesses angemessen berücksichtigt werden. Ein mögliches Mittel, um eine Kultur der kontinuierlichen Verbesserung und des zukunftsorientierten Denkens zu fördern, sind Innovations- und Designlabore, die sich mit Zukunftsthemen beschäftigen und in denen sich eine Vielzahl interner und externer Interessenvertreter kreativ engagieren.

Eine weitere Möglichkeit, um in Gespräche über sich abzeichnende potenziell transformative Veränderungen einzutreten, sind langfristige Szenarioplanungen. Ein Beispiel für einen landesspezifischen Ansatz ist das finnische nationale Vorhersagenetzwerk, das Daten als Grundlage für Entscheidungen und die Vorbereitung auf die Zukunft bereitstellen und auswerten soll. Das Netzwerk ist ein mögliches Modell für die Vorhersage von und Vorbereitung auf Änderungen (Hartikainen, 2015). Ein weiteres Beispiel, wie speziell den Tourismussektor beeinflussenden Trends Rechnung getragen werden kann, ist die umfassende Studie und Szenarioplanung des für Tourismus zuständigen Ministeriums in Österreich (Kasten 6). Auch die Schweiz arbeitet mit Trendanalysen und Szenarioplanungen, um politische Konzepte zu entwickeln und umzusetzen, die der Tatsache gerecht werden, dass der Tourismussektor durch eine Vielzahl externer Faktoren beeinflusst wird (Kasten 7).

Die mit dem Tourismus befassten politischen Entscheidungsträger werden auch eng mit ihren Kolleginnen und Kollegen in anderen Ministerien zusammenarbeiten müssen, um Systeme zu entwickeln, die Megatrends wie den demografischen Wandel messen und überwachen können. Nur so wird es möglich sein, sich besser auf die betreffenden Auswirkungen vorzubereiten. Soweit diese Systeme bereits existieren, müssen sie genutzt werden, um sich auf gegebenenfalls erforderliche Änderungen der Politik und der Dienstleistungserbringung einzustellen. Die betreffenden Systeme benötigen darüber hinaus eine robuste Datengrundlage, um wichtige Megatrends analysieren und ihnen voraus sein zu können, um zu verstehen, wie sie sich entwickeln und ob Kurskorrekturen oder Anpassungen stattfinden oder Massnahmen getroffen werden müssen. 


\section{Kasten 6. Strategische Tourismusplanung in Österreich}

\section{Plan T-Masterplan für den österreichischen Tourismus}

Im Jahr 2018 leitete Österreich als ersten Schritt im Rahmen der Entwicklung eines neuen Masterplans für das fortgesetzte Wachstum eines nachhaltigen und wettbewerbsfähigen Tourismus einen Konsultationsprozess ein. An diesem Prozess nehmen Experten und Interessenvertreter teil, die nicht nur aus dem Tourismus, sondern auch aus anderen Bereichen kommen. Die Diskussionen sind in eine Reihe Themenfelder untergliedert, wie i) die engere Zusammenarbeit zwischen Tourismus, Landwirtschaft und dem kulinarischen Sektor, ii) neue Wege der Förderung und Finanzierung des Tourismus, iii) nachhaltiger Tourismus - Umwelt, Mobilität, Klima/Energie, iv) die Entwicklung eines zukunftsgerichteten Systems von Indikatoren für die Messung des Tourismus, v) Marketing, Verkaufsförderung und Kommunikation, vi) die Schaffung günstiger Rahmenbedingungen für die künftige Entwicklung des Tourismus (einschliesslich des Umgangs mit neuen Geschäftsmodellen), vii) der Arbeitsmarkt und die Aus- und Weiterbildung im Tourismus sowie viii) die Digitalisierung im Tourismus. Der Masterplan wird in der ersten Jahreshälfte 2019 vorgestellt werden.

Quelle: www.bmnt.gv.at/tourismus/masterplan_tourismus.html

\section{Europäisches Tourismusforum 2018}

Angesichts des sich rasch wandelnden, vernetzten und dynamischen Umfelds, mit dem sich die Entscheidungsträger im Tourismus konfrontiert sehen, widmete Österreich das Europäische Tourismusforum 2018 (unter österreichischer EU-Ratspräsidentschaft in der zweiten Jahreshälfte 2018) der strategischen Planung des Tourismus. Der Schwerpunkt lag auf einer zentralen Frage: Wie kann der Tourismus nachhaltig gestaltet werden, um langfristig Lebensqualität und Wertschöpfung sicherzustellen? Experten lieferten Einblicke, wie Megatrends wie der digitale und technologische Fortschritt, demografische Entwicklungen und die sich wandelnde weltweite Besuchernachfrage und die Reisemuster sowie der Übergang zu einer kohlenstoffarmen Wirtschaft und mehr Ressourceneffizienz die Zukunft des Tourismus bestimmen werden. Dem folgten Diskussionen über mögliche Antworten auf aktuelle und künftige Herausforderungen für die strategische Tourismusplanung.

Quelle: $\underline{\text { www.eu2018.at/calendar-events/political-events/BMNT-2018-10-01-Tourism-Forum.html }}$

\section{Studie zu Megatrends}

Das für Tourismus zuständige Ministerium führte in den Jahren 2016/2017 gemeinsam mit dem Interfakultären Forschungszentrum Tourismus und Freizeit der Universität Innsbruck eine Studie durch, die die Auswirkungen von Megatrends auf den österreichischen Tourismus untersuchte. Die Studie «Bleibt alles anders? Tourismus 2025» lieferte eine umfassende Analyse der Trends und Treiber, die sich auf den Tourismussektor des Landes auswirken. Sie entwickelte sowohl positive als auch negative Szenarien bis 2025 und unterbreitete entsprechende Empfehlungen für die Politikgestaltung. Um ein vollständiges Bild der Angebots- und Nachfragesituation des Sektors zeichnen zu können, nutzte die Studie einen dreifach explorativen Ansatz für die Datenerhebung. Dieser beinhaltete eine systematische Medienanalyse, qualitative Interviews mit wichtigen Experten sowie einen Workshop, in dem die empirischen Ergebnisse ausgewertet wurden. Die Studie nennt wichtige Treiber - darunter Geopolitik, Klimawandel, Ökologie, Demografie, wirtschaftliche Entwicklungen und Technologien - die zusammengenommen für sechs Trendbereiche massgeblich sind. Für jeden dieser Trends wird eine Reihe von Herausforderungen hervorgehoben und entsprechende Empfehlungen formuliert, wie diesen begegnet werden könnte.

Quelle: www.bmnt.gv.at/service/publikationen/tourismus/studie-tourismus-2025.html 


\section{Kasten 7. Tourismusstrategie der Schweiz}

Die Schweiz verabschiedete im Jahr 2017 eine neue, durch das Staatssekretariat für Wirtschaft (SECO) im Auftrag des Eidgenössischen Departements für Wirtschaft, Bildung und Forschung (WBF) entwickelte Tourismusstrategie. Die neue Tourismusstrategie verfolgt vier Hauptziele: Verbesserung der Rahmenbedingungen für bessere politische Koordination und die Förderung von Synergien; Förderung des Unternehmertums; Nutzung der sich durch die digitale Wirtschaft eröffnenden Chancen sowie Verbesserung der Attraktivität der touristischen Angebote und Marktpräsenz.

Die Vision des Bundesrates ist es, die internationale Wettbewerbsfähigkeit der Schweizer Tourismusbranche und die Attraktivität des Landes als Tourismusstandort zu sichern. Bei der Entwicklung ihrer Tourismusstrategie arbeitet die Schweiz mit Trendanalysen und Szenarioplanungen, um politische Konzepte zu entwickeln und umzusetzen, die der Tatsache gerecht werden, dass der Tourismussektor durch eine Vielzahl externer Faktoren beeinflusst wird. $\mathrm{Zu}$ den identifizierten Megatrends gehören die Globalisierung und zunehmende Mobilität, der wachsende weltweite Wohlstand, technologische Fortschritte, Sicherheitsbedenken, Verstädterung, demografischer Wandel und zunehmendes Umweltbewusstsein. Die Stärken und Schwächen der Schweizer Tourismuswirtschaft, ebenso wie die Chancen und Risiken wurden mittels einer SWOTAnalyse herausgearbeitet. Basierend auf dieser Analyse identifizierte die Schweiz acht Handlungsfelder und die sie jeweils begleitenden Massnahmen sowie zwei Leitprinzipien, an denen alle Massnahmen auszurichten sind - Nachhaltigkeit und Subsidiarität (Tourismusstrategie des Bundes, November 2017).

\section{Abbildung 5. Überblick über die wichtigen Elemente der Schweizer Tourismuspolitik}

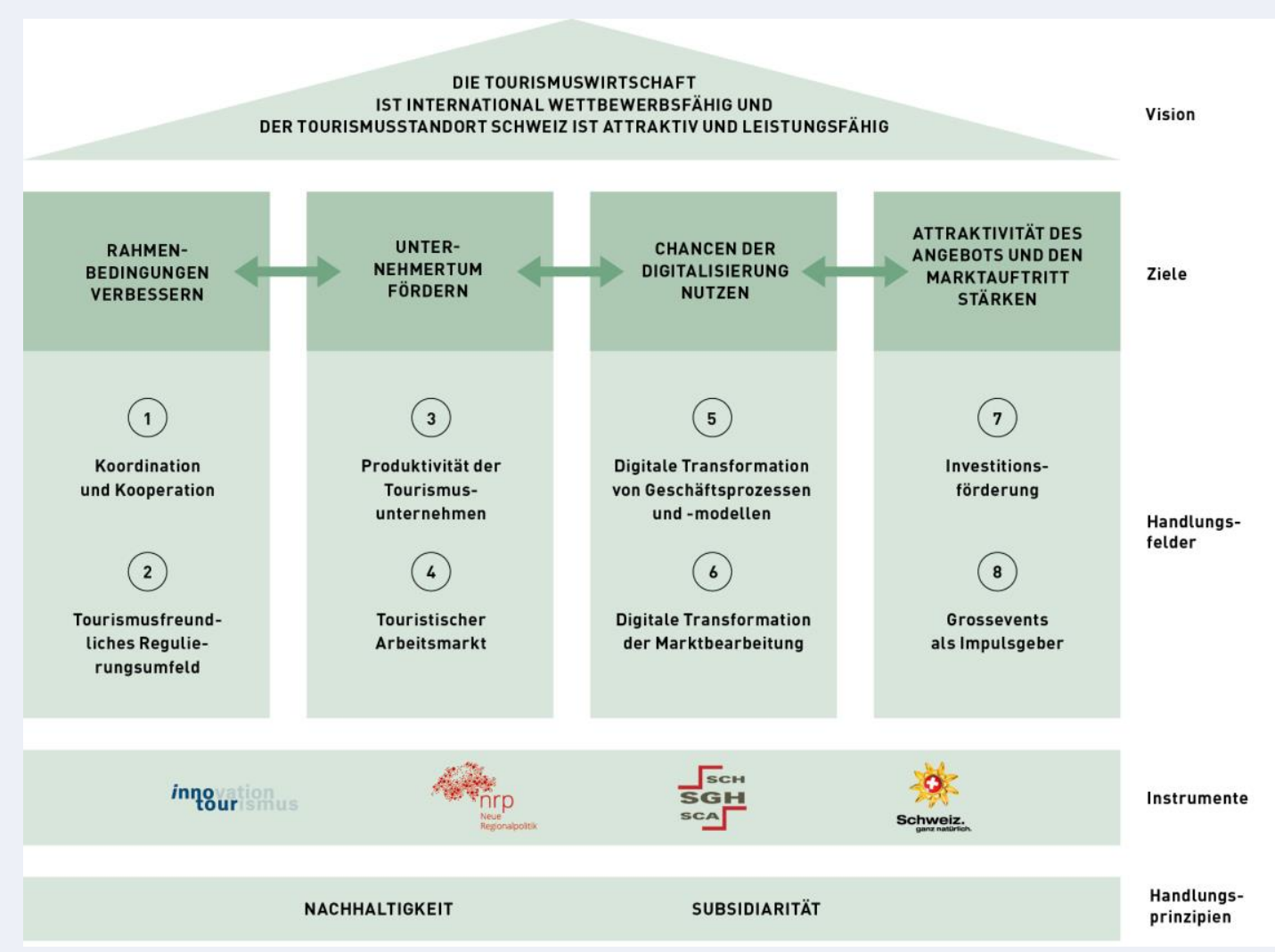

Quelle: https://www.seco.admin.ch/seco/de/home/Standortfoerderung/Tourismuspolitik/Tourismusstrategie_des_Bundes.html 
Im Umfeld eines öffentlichen Sektors, in dem Entscheidungen zunehmend datengestützt erfolgen, wird es umso wichtiger, Daten richtig einzusetzen und zu verstehen. Tourismuspolitische Entscheidungsträger müssen dafür sorgen, dass sie entweder ausreichend kompetent sind, um datengestützte Entscheidungen zu treffen, oder dass andere Abteilungen, die diese Kompetenz besitzen, umfassend über die wichtigen Trends und Probleme im Tourismus informiert sind, um unterstützend wirken zu können.

Ein sinnvoller Ansatz wäre ein Prozess der langfristigen Zukunftsbeobachtung, der schwache Signale für Veränderungen erkennt, die näher untersucht werden müssen. Die betreffenden langfristigen Planungsansätze sollten Experten aus anderen, mit dem Tourismus in Zusammenhang stehenden Bereichen in die Gespräche miteinbeziehen beispielsweise Fachleute aus dem Verkehrswesen, dem Steuerrecht, der Raumplanung und der Statistik. Alle Strategien und Entscheidungsprozesse müssen faktenbasiert sein, dürfen jedoch nicht ausschliesslich von oben nach unten ablaufen. In Visionen, die auf höheren Führungsebenen ausgearbeitet werden und die für diejenigen, die die betreffenden Pläne ausführen oder durch sie betroffen sind, nicht einfach verständlich sind, sollten Informationen aus Diskussionen mit der «Basis» einfliessen.

\section{Grundsätze für wirksame strategische Frühaufklärung im Tourismus}

Entsprechende strategische Frühaufklärung kann dazu beitragen, dass politische Entscheidungsträger mögliche zukünftige Entwicklungen vorhersehen und zukunftsweisende politische Konzepte entwickeln können. Verschiedene Methoden der strategischen Frühaufklärung gestatten es, Trends zu analysieren, eine Vorstellung von verschiedenen plausiblen Zukunftsszenarien zu entwickeln und sich wirksam auf die Herausforderungen und Chancen vorzubereiten, die die Zukunft mit sich bringt. Die folgenden breit gefassten Grundsätze sollen tourismuspolitischen Entscheidungsträgern dabei helfen, strategische Frühaufklärungsmassnahmen als politisches Hilfsmittel optimal einzusetzen:

\section{Abbildung 6. Leitprinzipien für wirksame strategische Frühaufklärung}
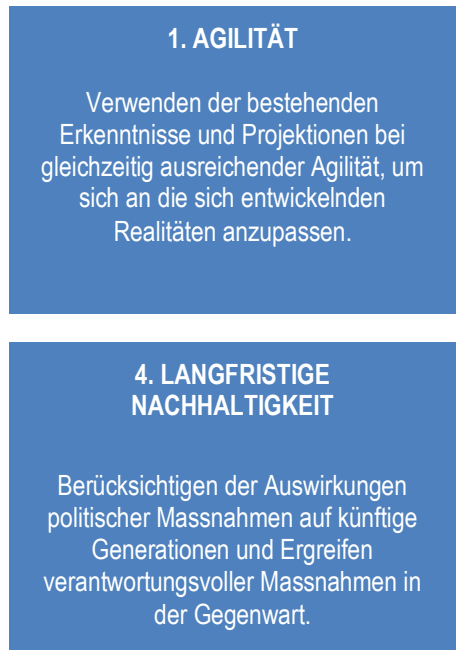
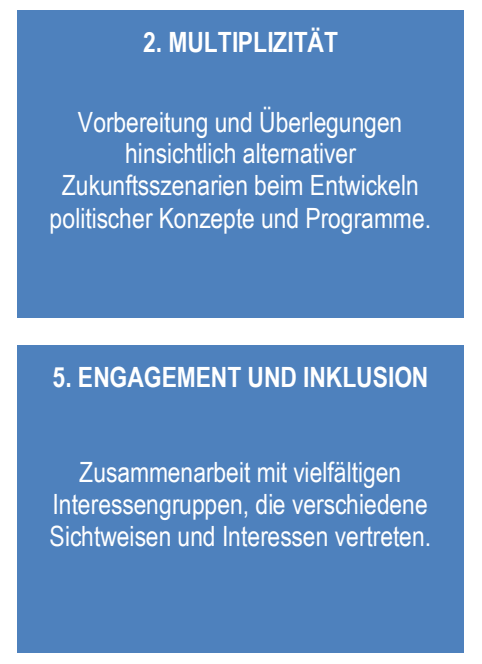
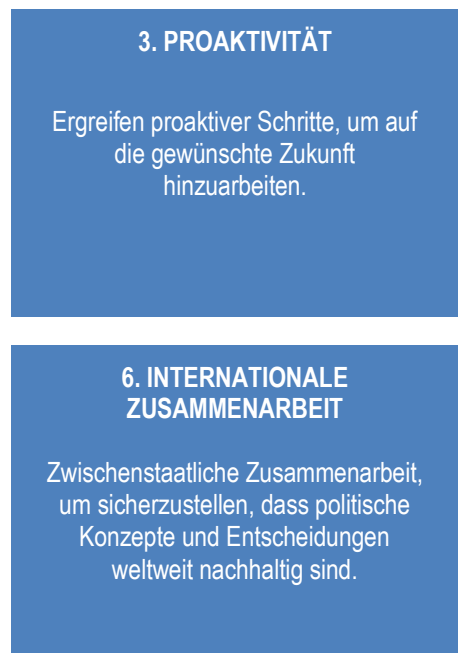

1. Agilität

- Obwohl politische Entscheidungsträger mit vorhandenen Belegen und Projektionen zur Unterstützung ihrer strategischen Planung arbeiten sollten, müssen sie dennoch 
anerkennen, dass sie wohl auch vor unerwartete Chancen und Herausforderungen gestellt werden (UNDP, 2018). Alle politischen Konzepte und Programme sollten daher die Gewissheit bieten, die Unternehmen benötigen, aber auch agil genug sein, um sich an sich entwickelnde Realitäten anzupassen.

\section{Multiplizität}

- Im Zusammenhang mit strategischer Frühaufklärung ist unbestreitbar, dass die Zukunft nicht mit Sicherheit vorhergesagt werden kann und dass es demzufolge viele mögliche Zukünfte gibt. Politische Entscheidungsträger sollten sich daher bei der Entwicklung politischer Konzepte und Programme entsprechend vorbereiten und auch alternative Zukunftsszenarien in Betracht ziehen. Zukunftsforscher schlagen vor, bei der Planung vier verschiedene, aber miteinander in Bezug stehende Zukunftsszenarien $\mathrm{zu}$ berücksichtigen. Dies sind die möglichen, plausiblen, wahrscheinlichen und wünschenswerten Zukunftsszenarien (Bengston, 2018). Die Ausarbeitung von Szenarien, wie im vorliegenden Bericht durchgeführt, kann ein nützliches Hilfsmittel zur Berücksichtigung dieser verschiedenen plausiblen Zukünfte sein.

\section{Proaktivität}

- Sowohl heute ergriffene als auch unterlassene Massnahmen wirken sich auf die Zukunft aus. Daher ist es ausgesprochen wichtig, mit proaktiven Schritten auf die wünschenswerte Zukunft hinzuarbeiten. Einer der Ansätze hierfür ist das «Backcasting», bei dem eine Vision der wünschenswerten Zukunft geschaffen und von dort aus in die Vergangenheit geblickt wird, um herauszufinden, auf welchem Pfad sich diese Zukunft erreichen lässt (Wilkinson, 2017). Mit dieser Technik können politische Entscheidungsträger die Zukunft eher als einen Prozess denn als ein Ziel begreifen und in der Gegenwart proaktive politische Massnahmen ergreifen, die zu den gewünschten Ergebnissen führen sollen. Die politischen Entscheidungsträger können auf diese Weise auch erkennen, dass sie in der Lage sind, die Zukunft in eine positive Richtung zu lenken (Bengston, 2018).

\section{Langfristige Perspektive}

- Politische Entscheidungen sollten nicht nur auf kurz- oder mittelfristige Ziele ausgerichtet sein, sondern vielmehr auch die Auswirkungen des Tourismus und damit zusammenhängender politischer Konzepte auf künftige Generationen berücksichtigen. Die politischen Entscheidungsträger müssen heute verantwortungsbewusst handeln. Nur wenn sie neben der kurz- und mittelfristigen auch die langfristige Zukunft im Blick behalten, bleiben Themen wie Umweltschutz, gesellschaftliche Entwicklung und wirtschaftliche Nachhaltigkeit zentrale Punkte der Politik. In ähnlicher Weise hilft ein Prozess der langfristigen Zukunftsbeobachtung beim Erkennen schwacher Signale für Veränderungen, die näher untersucht werden müssen und sich potenziell auf bestehende oder künftige politische Konzepte auswirken könnten.

\section{Engagement und Inklusion}

- Um zu eng gefasste Zukunftsvisionen zu vermeiden, müssen sich politische Entscheidungsträger unbedingt mit unterschiedlichen Interessengruppen auseinandersetzen, die für vielfältige Perspektiven und Interessen stehen. Die 
Einbeziehung und Beteiligung verschiedenartiger Akteure, insbesondere marginalisierter Stimmen, sind auch entscheidend, um unterschiedliche Bedürfnisse, Erwartungen und Sorgen zu verstehen und zu berücksichtigen, die verschiedene Gruppen mit der Zukunft verbinden. Dieses Engagement ist auch wichtig, damit diese Gruppen eher hinter den betreffenden politischen Massnahmen und Programmen stehen können (UNDP, 2018). Im Fall der Tourismuspolitik muss die strategische Frühaufklärung die Sichtweisen zweier entscheidender Interessengruppen - der Einheimischen und der Touristen - berücksichtigen und deren Wohlergehen in den Mittelpunkt aller Überlegungen stellen. Ein fortgesetzter Dialog zwischen Regierung, lokalen Gemeinden und der Branche, bei dem auch Mechanismen der regelmässigen Rückmeldung zum Tragen kommen, kann eine wichtige Rolle dabei spielen, im Entstehen begriffene Chancen und Herausforderungen zu erkennen und die zur Anpassung erforderlichen politischen Antworten zu entwickeln.

\section{Internationale Zusammenarbeit}

- Die Welt wird immer globalisierter und Basistechnologien vereinfachen Verknüpfungen rapide. In einer solchen Welt können sich politische Entscheidungsträger nicht auf Silodenken zurückziehen, sondern müssen international zusammenarbeiten, um sicherzustellen, dass die Vorteile des Tourismus inklusiv und gerecht verteilt werden und dass politische Konzepte und Entscheidungen weltweit nachhaltig sind. $\mathrm{Zu}$ den Bereichen, in denen internationale Zusammenarbeit dazu beitragen kann, dass die Regierungen komplexe Herausforderungen bewältigen, zählen die persönliche Sicherheit und Betriebssicherheit, die Verbesserung der Reisemobilität sowie das Erreichen von Nachhaltigkeitszielen im Tourismus.

\section{Literaturverweise}

ACI und IATA, Smart Security (abgerufen am 25. Oktober 2017) https://www.iata.org/whatwedo/security/Documents/smart-security-brochure.pdf.

Age Wave und Merrill Lynch (2016), Leisure in Retirement: Beyond the Bucket List, Merrill Lynch Bank of America Corporation, https://agewave.com/wp-content/uploads/2016/05/2016-Leisure-inRetirement_Beyond-the-Bucket-List.pdf.

Airbnb (2016), Airbnb and The Rise of Millennial Travel, Airbnb, https://www.airbnbcitizen.com/wpcontent/uploads/2016/08/MillennialReport.pdf.

Aitken, G. (2016) «Blockchain start-up TamTam eyes trillion dollar travel industry offering 〈crypto»» Forbes, https://www.forbes.com/sites/rogeraitken/2016/11/01/blockchain-start-up-tamtam-eyestrillion-dollar-travel-industry-offering-crypto/\#4986cb5f2b76.

Alén, E., Losada, N. und Domínguez, T. (2015), «The Impact of Ageing on the Tourism Industry: An Approach to the Senior Tourist Profile», Social Indicators Research, Band 127, Nr. 1, Seiten 303322.

Assis, C. (2017), «Tesla, Google, others accelerate driverless-car tests in California», MarketWatch http://www.marketwatch.com/story/tesla-google-others-accelerate-driverless-car-tests-in-california2017-02-01.

ATAG (Air Transport Action Group) (2016), Facts \& Figures, ATAG, http://www.atag.org/facts-andfigures.html. 
Bengston, David. (2018). Principles for Thinking about the Future and Foresight Education. World Futures Review. 194675671877725. 10.1177/1946756718777252.

Boztas, S. (2017) «Automated holidays: how AI is affecting the travel industry». The Guardian, Sustainable Business. https://www.theguardian.com/sustainable-business/2017/feb/17/holidays-travelautomated-lastminute-expedia-skyscanner.

Bremmer, I. (2016), These 5 Facts Explain the Unstable Global Middle Class, TIME, http://time.com/4198164/these-5-facts-explain-the-unstable-global-middle-class/.

Bussolo, M. Maliszewska, M. und Murard, E. (2014), The long-awaited rise of the middle class in Latin America is finally happening, Policy Research working paper; Nr. WPS 6912. Washington, DC: Weltbankgruppe. http://documents.worldbank.org/curated/en/823431468270865962/The-longawaited-rise-of-the-middle-class-in-Latin-America-is-finally-happening

Coffel, E.D., Thompson, T. R. und Horton, R. M. (2017), «The impacts of rising temperatures on aircraft takeoff performance», Climatic Change, Band 144, Seiten 381-388, https://doi.org/10.1007/s10584017-2018-9.

CREST (Center for Research in Economics and Statistics) (2016), The Case for Responsible Travel: Trends \& Statistics 2016, Center for Responsible Travel, Washington, DC, http://www.responsibletravel.org/whatWeDo/The Case for Responsible Travel 2016 Final.pdf.

Croatia National Tourist Board (2018). eVisitor-Programm. https://www.evisitor.hr/info/

Cruise Lines International Association (2015), State of the Cruise Industry Report, Washington DC: CLIA Europe.

Dobbs, R., Manyika, J., Woetzel, J., Remes, J., Perrey, J., Kelly, G., Pattabiraman, K. und Sharma H., (2016), Urban World: The Global Consumers to Watch, McKinsey Global Institute.

Duryee, T. (2012), Airbnb's Skyrocketing Growth Includes Four million Nights Booked in 2011, All Things Digital, http://allthingsd.com/20120126/airbnbs-skyrocketing-growth-includes-four-millionnights-booked-in-2011/.

ESPAS (European Strategy and Policy Analysis System) (2015), Global Trends to 2030: Can the EU meet the challenges ahead?, ESPAS, http://ec.europa.eu/epsc/sites/epsc/files/espas-report-2015.pdf.

Europäische Kommission (2018). «Reform der EU-Datenschutzvorschriften 2018» https://ec.europa.eu/commission/priorities/justice-and-fundamental-rights/data-protection/2018reform-eu-data-protection-rules_de

Expedia und The Centre for Generational Kinetics (2018). Generations of the Move. https://www.veilleinfotourisme.fr/files/2018-01/Expedia-Generations-on-the-Move.pdf

Frey, C. B. und Osborne, M. A. (2013), The Future of Employment: How Susceptible are Jobs to Computerisation?, University of Oxford, Oxford, http://www.oxfordmartin.ox.ac.uk/downloads/academic/The Future of Employment.pdf.

Future Foundation (2016), Millennial Traveller Report: Why Millennials Will Shape the Next 20 Years of Travel, Expedia, https://blog.expedia.co.uk/wp-content/uploads/2016/10/Expedia-MillennialTraveller-Report.pdf.

Future Travel Experience (2016) Smart Security boosting passenger satisfaction levels as 〈second wave〉 begins http://www.futuretravelexperience.com/2016/10/smart-security-boosting-passengersatisfaction-levels-as-wave-two-begins.

Deutsche Zentrale für Tourismus. «Discover Germany - BarrierFree» http://www.germany.travel/en/ms/barrier-free-germany/start/barrier-free-germany.html 
Gjerding, K. (2017), How Blockchain technology will dominate the travel sector, Forbes. https://www.forbes.com/sites/forbesfinancecouncil/2017/03/28/how-blockchain-technology-willdominate-the-travel-sector/\#4f16b4d99de5.

Globetrender (2017), From Boomers to Gen Z: Travel Trends Across the Generations, Globetrender, http://globetrendermagazine.com/2017/05/19/travel-trends-across-generations/.

Gössling, S., Garrod, B., Aall, C., Hille, J. und Peeters, P. (2011), Food management in tourism. Reducing tourism's carbon 〈foodprint〉. Tourism Management 32(3): 534-543.

Hartikainen, E. (2015) Strategic Government Programme calls for foresight information, Sitra, https://www.sitra.fi/en/news/strategic-government-programme-calls-foresight-information/.

Hathaway, I. und Muro M. (2017), «Ridesharing hits hyper-growth», in The Avenue, The Brookings Institution, https://www.brookings.edu/blog/the-avenue/2017/06/01/ridesharing-hits-hyper-growth/.

Hetter, K. und Pearson M. (2016) «TSA Security line waits inevitable, DHS secretary says», CNN Travel, http://www.cnn.com/travel/article/tsa-long-lines-us-airports/index.html

IATA (International Air Transport Association) (2016), IATA Passenger Forecast - Global Report, IATA, https://www.researchandmarkets.com/reports/3973478/iata-passenger-forecast-global-report.

IATA (2013) Joint Press Release: ICI and IATA collaborate to deliver Smart Security, Pressemitteilung Nr. 70, http://www.iata.org/pressroom/pr/Pages/2013-12-12-02.aspx

ICAO (International Civil Aviation Organization) (2013), Global Air Transport Outlook to 2030 and trends to 2040. Montréal, Kanada.

IHS Markit (2016) «Autonomous vehicle sales forecast to reach 21 mil. Globally in 2035, according to IHS Automotive» https://www.ihs.com/country-industry-forecasting.html?ID=10659115737.

ITP (International Tourism Partnership) (2013), Water Risk Assessment. Stockholmer Internationales Wasserinstitut (SIWI).

Keating, D. (2017) «EU Commission drives home merits of autonomous vehicles», Euractiv. https://www.euractiv.com/section/automated-vehicles/news/eu-commission-drives-home-merits-ofautonomous-vehicles/.

Kharas, H. (2017), The Unprecedented Expansion of the Global Middle Class: An Update, Global Economy and Development at Brookings, Washington, DC, https://www.brookings.edu/wpcontent/uploads/2017/02/global_20170228_global-middle-class.pdf.

Kikuchi, D. (2017), ‘Strange> hotel, run by robots, opens near Tokyo; more to come, The Japan Times, https://www.japantimes.co.jp/news/2017/03/15/business/strange-hotel-run-by-robots-opens-neartokyo-more-to-come/\#.WfDfIGhSyUl.

Kim, K., Uysal, M. und Sirgy, M. J. (2013), «How Does Tourism in a Community Impact the Quality of Life of Community Residents?», Tourism Management, Band 36, Seiten 527-540, https://doi.org/10.1016/j.tourman.2012.09.005.

Kim, J. Y. (2016), Rede des Präsidenten der Weltbank, Jim Yong Kim: The World Bank Group's Mission: To End Extreme Poverty, Weltbank, Washington, DC,

http://www.worldbank.org/en/news/speech/2016/10/03/speech-by-world-bank-president-jim-yongkim-the-world-bank-groups-mission-to-end-extreme-poverty.

Kingman, D. (2012), Spending Power Across the Generations, Intergenerational Foundation, London, http://www.if.org.uk/wp-content/uploads/2013/01/Spending-Power-Across-the-Generations$\underline{\text { Report.pdf. }}$ 
Kowalewski, D., McLaughlin, J. und Hill, A. (2017) «Blockchain will transform customer loyalty programs», Harvard Business Review https://hbr.org/2017/03/blockchain-will-transform-customerloyalty-programs.

Kyyrä, S. und Rantala, O. (2016). Disoriented travellers or disoriented destinations? An analysis of future travel trend studies for Visit Arctic Europe project. Unveröffentlichtes Manuskript.

KPMG und Mowat Centre (2013), Future State 2030: The global megatrends shaping governments, Mowat Centre, Toronto, https://mowatcentre.ca/wpcontent/uploads/publications/75_future_state_2030.pdf.

Levere, J. L. (2016) «When a robot books your airline ticket», The New York Times, https://www.nytimes.com/2016/05/31/business/ai-may-book-your-next-trip-with-a-human-assist.html.

López-Sánchez, Y. und Pulido-Fernández, J. I. (2016), «Are Tourists Really Willing to Pay More for Sustainable Destinations?», Sustainability, Band 8, 1240, http://dx.doi.org/10.3390/su8121240.

Miah, S.J., Quan Vu, H., Gammack, J. und McGrath, M. (2017) «A big data analytics method for tourist behavior analysis», Information and Management, Band 54, Nr. 6, Seiten 771-785.

https://doi.org/10.1016/j.im.2016.11.011

Miller, G. (2014), Economic Impact and Travel Patterns of Accessible Tourism in Europe Service, Contract SI2.ACPROCE052481700, Europäische Kommission, Generaldirektion Unternehmen und Industrie; auf http://tinyurl.com/lzc6962.

Misrahi, T. (2015), MERS: 5 implications for the tourism industry, WEF, https://www.weforum.org/agenda/2015/06/mers-5-implications-for-the-tourism-industry/.

Nielsen (2015), Consumer-Goods' Brands That Demonstrate Commitment to Sustainability Outperform Those That Don't, Nielsen, New York, http://www.nielsen.com/ca/en/press-room/2015/consumergoods-brands-that-demonstrate-commitment-to-sustainability-outperform.html.

OECD (2018), OECD Tourism Trends and Policies 2018, OECD Publishing, Paris. http://dx.doi.org/10.1787/tour-2018-en.

OECD (2016a), OECD Science, Technology and Innovation Outlook 2016, OECD, https://www.oecd.org/sti/Megatrends\%20affecting\%20science,\%20technology\%20and\%20innovation .pdf.

OECD (2016b), OECD Tourism Trends and Policies 2016, OECD Publishing, Paris. http://dx.doi.org/10.1787/tour-2016-en.

OECD (2016c), Intermodal Connectivity for Destinations, OECD Centre for Entrepreneurship, SMEs and Local Development. https://www.oecd.org/industry/tourism/2016\%20-

\%20Policy\%20paper\%20on\%20Intermodal\%20Connectivity\%20for\%20Destinations.pdf

OECD (2015), «A Review of Effective Policies for Tourism Growth», OECD Tourism Papers, 2015/01, OECD Publishing. http://dx.doi.org/10.1787/5js4vmp5n5r8-en.

OECD (2014), «Megatrends: Policies for a Shifting World», Diskussionsnotizen, Global Strategy Group.

OECD (2013), «Green Innovation in Tourism Services», OECD Tourism Papers, 2013/01, OECD

Publishing. http://dx.doi.org/10.1787/5k4bxkt1cjd2-en.

OECD/ITF (International Transport Forum), (2017), ITF Transport Outlook 2017, OECD Publishing, Paris. http://dx.doi.org/10.1787/9789282108000-en.

OECD/ITF (2015), ITF Transport Outlook 2015, OECD Publishing/ITF. http://dx.doi.org/10.1787/9789282107782-en. 
OECD/UNEP (Umweltprogramm der Vereinten Nationen) (2011), Climate Change and Tourism Policy in OECD Countries, OECD Studies on Tourism, OECD Publishing.

http://dx.doi.org/10.1787/9789264119598-en.

PwC (2015), «The Sharing Economy», in Consumer Intelligence Series, PwC, https://www.pwc.com/us/en/technology/publications/assets/pwc-consumer-intelligence-series-thesharing-economy.pdf.

Quinby, D. (2016), The End of Alternative Accommodation: Airbnb is Now the Third-Largest Online Accommodation Seller Worldwide, Phocuswright, http://www.phocuswright.com/TravelResearch/Research-Updates/2016/The-End-of-Alternative-Accommodation.

Sawers, P. (2016), Uber's quest to catch the tourist buck, VentureBeat, https://venturebeat.com/2016/03/19/ubers-quest-to-catch-the-tourist-buck/.

Somerville, H. (2015), Exclusive: Airbnb to double bookings to 80 million this year-investors, Thomson Reuters, http://www.reuters.com/article/us-airbnb-growth/exclusive-airbnb-to-doublebookings-to-80-million-this-year-investors-idUSKCNORS2QK20150928.

Song, H. und Liu, H. (2017) «Predicting tourist demand using big data», Kapitel in Analytics in Smart Tourism Design, Seiten 13-29. Schweiz: Springer International Publishing.

UN (United Nations) (2017), World Population Prospects: The 2017 Revision, Key Findings and Advance Tables, Department of Economic and Social Affairs, Population Division, United Nations, New York, https://esa.un.org/unpd/wpp/Publications/Files/WPP2017_KeyFindings.pdf.

UN Environment. «Sustainable Tourism Growth», Präsentation für die OECD von Arab Hoballah, Executive Director, SEED, Projekt zur Förderung des nachhaltigen Unternehmertums. 21. Juni 2017, Paris, Frankreich.

UNEP (2017), The Emissions Gap Report 2017. Umweltprogramm der Vereinten Nationen (UNEP), Nairobi, www.unenvironment.org/resources/emissions-gap-report

UNEP (2011), Towards a Green Economy: Pathways to Sustainable Development and Poverty Eradication - A Synthesis for Policy Makers, www.unep.org/greeneconomy.

UNDP (2018) «Foresight Manual Empowered Futures for the 2030 Agenda». UNDP Global Centre for Public Service Excellence. https://www.undp.org/content/dam/undp/library/capacitydevelopment/English/Singapore\%20Centre/UNDP ForesightManual 2018.pdf

UNWTO (UN Welttourismusorganisation) (2017a), UNWTO World Tourism Barometer, Band 15, Juni 2017, http://mkt.unwto.org/barometer.

UNWTO (2017b), «FAQ - Climate Change and Tourism», in Sustainable Development of Tourism, UNWTO, http://sdt.unwto.org/content/faq-climate-change-and-tourism (abgerufen am 25. Oktober 2017).

UNWTO (2016a), UNWTO Tourism Highlights, Ausgabe 2016. Madrid, Spanien.

UNWTO (2016b), Visa Openness Report 2015, Welttourismusorganisation, Madrid, http://cf.cdn.unwto.org/sites/all/files/docpdf/2015visaopennessreportonline.pdf.

UNWTO-UNEP (2008), Climate Change and Tourism - Responding to Global Challenges, UNWTO, Madrid.

UNWTO und WTTC (2012), The Impact of Visa Facilitation on Job Creation in the G20 Economies, UNWTO und WTTC, https://www.wttc.org/Imedia/files/reports/policy\%20research/visa facilitation\%20g20.pdf. 
WEF (World Economic Forum) (2017) Digital Transformation Initiative: Aviation, Travel and Tourism Industry. Weissbuch, in Zusammenarbeit mit Accenture. https://www.accenture.com/t20170116T084449_w_/us-en/_acnmedia/Accenture/ConversionAssets/WEF/PDF/Accenture-DTI-Aviation-Travel-and-Tourism-Industry-White-Paper.pdf.

WEF (2016), Security in Travel Promoting Seamless and Secure Travel through Cross-Border Data Sharing and Collaboration, Weltwirtschaftsforum, Genf, http://www3.weforum.org/docs/IP/2016/MO/WEF_AT_SecurityinTravel.pdf.

Weinswig, D. (2016), Gen Z: Get Ready for the Most Self-Conscious, Demanding Consumer Segment, Fung Global Retail \& Technology, https://www.fbicgroup.com/sites/default/files/Gen\%20Z\%20Report\%202016\%20by\%20Fung\%20G1 obal\%20Retail\%20Tech\%20August\%2029,\%202016.pdf.

Williams, P.D. (2017), «Increased light, moderate, and severe clear-air turbulence in response to climate change», Advances in Atmospheric Sciences, Band 34, Seiten 576-586, https://doi.org/10.1007/s00376-017-6268-2.

Wilkinson, A. (2017). «Strategic Forecast Primer», European Political Strategy Centre. https://ec.europa.eu/epsc/sites/epsc/files/epsc - strategic foresight primer.pdf

WTTC (World Travel and Tourism Council) (2016), Sustainable Tourism: The Past, Present and Future, World Travel and Tourism Council, https://www.wttc.org/-/media/files/reports/special-and-periodicreports/sustainable-tourism_past-present-future.pdf?la=en. 